WSRC-TR-2002-00322

Revision 0

Keywords: DWPF, CPC, sludge, SRAT, Sludge Batch 3, Plutonium

Retention: Permanent

\title{
SRAT Processing of Sludge Batch 3 Simulant to Evaluate Impacts of H-Canyon Slurry Containing Precipitated Pu and Gd
}

\author{
C.C. Herman \\ D.C. Koopman \\ N.E. Bibler \\ D.R. Best \\ M.F. Williams
}

Publication Date: July 25, 2002

Westinghouse Savannah River Company

Savannah River Technology Center Aiken, SC 29808

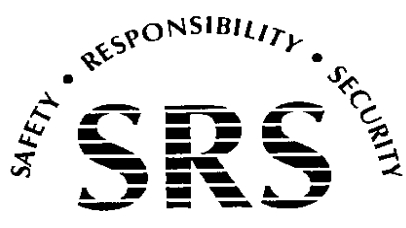

SAVANNAH RIVER SITE

PREPARED FOR THE U.S. DEPARTMENT OF ENERGY UNDER CONTRACT NO. DE-AC09-96SR18500 
This document was prepared in conjunction with work accomplished under Contract No. DE-AC09-96SR18500 with the U. S. Department of Energy.

\section{DISCLAIMER}

This report was prepared as an account of work sponsored by an agency of the United States Government. Neither the United States Government nor any agency thereof, nor any of their employees, makes any warranty, express or implied, or assumes any legal liability or responsibility for the accuracy, completeness, or usefulness of any information, apparatus, product or process disclosed, or represents that its use would not infringe privately owned rights. Reference herein to any specific commercial product, process or service by trade name, trademark, manufacturer, or otherwise does not necessarily constitute or imply its endorsement, recommendation, or favoring by the United States Government or any agency thereof. The views and opinions of authors expressed herein do not necessarily state or reflect those of the United States Government or any agency thereof.

This report has been reproduced directly from the best available copy.

Available for sale to the public, in paper, from: U.S. Department of Commerce, National Technical Information Service, 5285 Port Royal Road, Springfield, VA 22161, phone: (800) 553-6847, fax: (703) 605-6900

email: orders@ntis.fedworld.gov

online ordering: http://www.ntis.gov/help/index.asp

Available electronically at http://www.osti.gov/bridge

Available for a processing fee to U.S. Department of Energy and its contractors, in paper, from: U.S. Department of Energy, Office of Scientific and Technical Information, P.O. Box 62, Oak Ridge, TN 37831-0062,

phone: (865)576-8401,

fax: (865)576-5728

email: $\underline{\text { reports@ adonis.osti.gov }}$ 
AUTHORS: ;

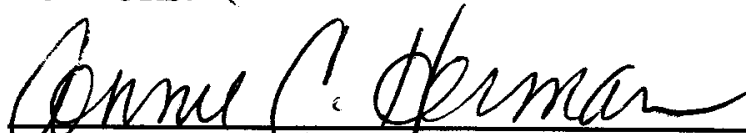

E.C. Herman, Immobilization Technology Section

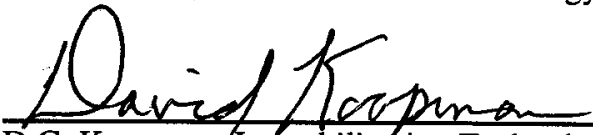

D.C. Koopman, Immobilization Technology Section

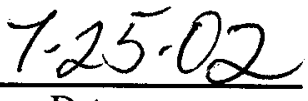

Date

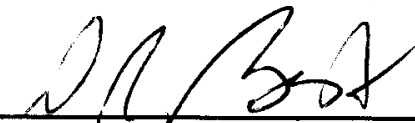

D.R. Best, Immobilization Technology Section
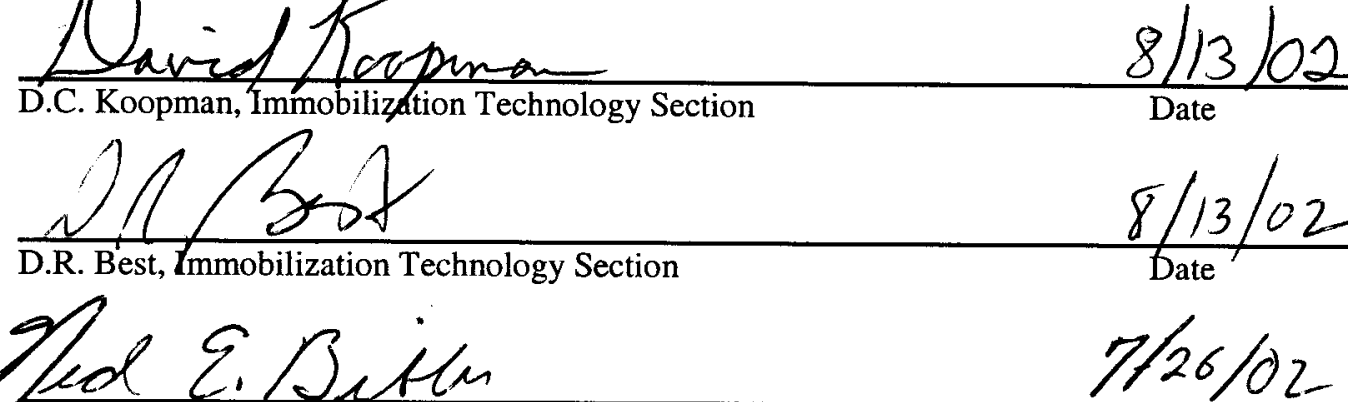

N.E. Bibler, Immobilization Technology Section

Date

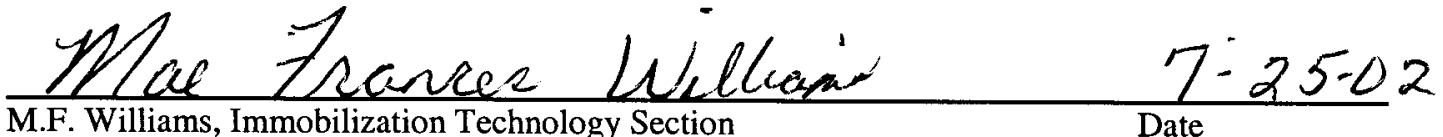

\section{TECHNICAL REVIEWERS:}

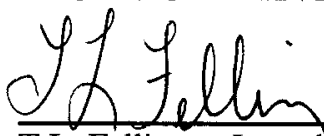

T.L. Fellinger, Immogylization Technology Section

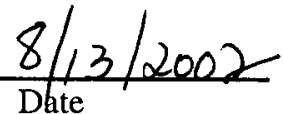

\section{APPROVERS:}

\section{Shaven R.Mana}

S.L. Marra, Manager, Immobilization Technology Section

$8 / 13 / 02$

Date

WaR gob w. Rey for B.L. Lewis $8 / 15 / 02$

B.L. Lewis, Processing Engineering Manager, WD Engineering per telecon Date

\begin{tabular}{ll}
\hline$R \varepsilon R d u-d s$ & $8 / 19 / 02$ \\
\hline R.E. Edwards, Jr., Manager, High Level Waste Process Engineering & Date
\end{tabular}




\section{TABLE OF CONTENTS}

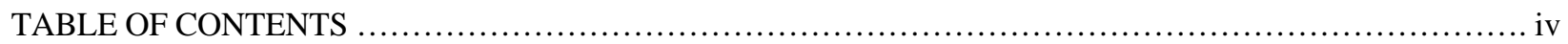

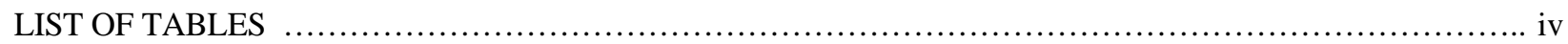

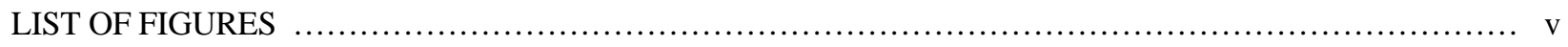

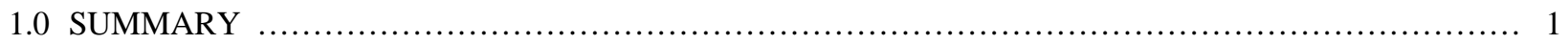

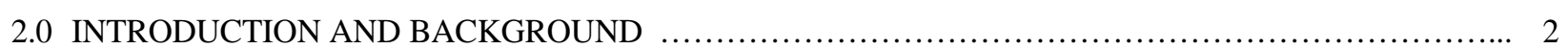

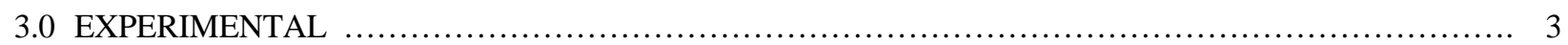

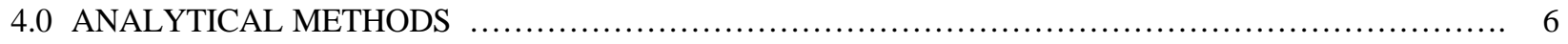

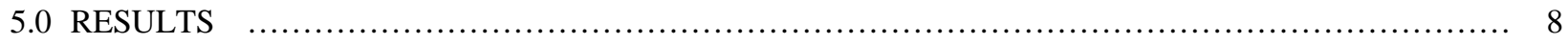

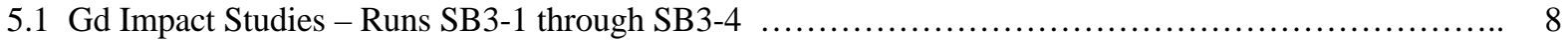

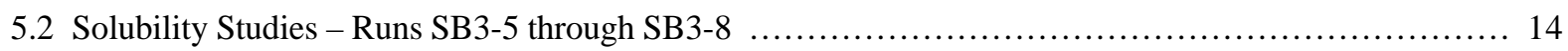

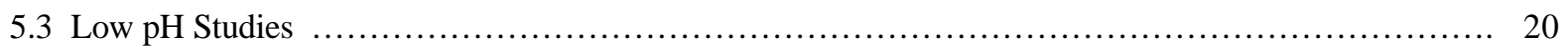

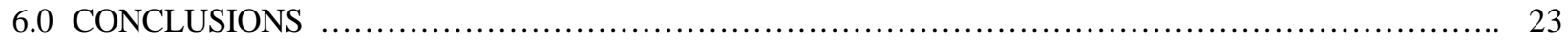

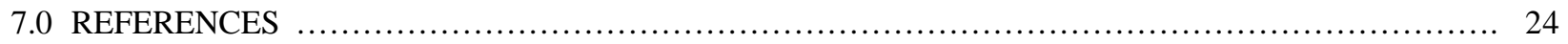

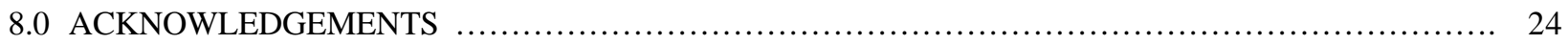

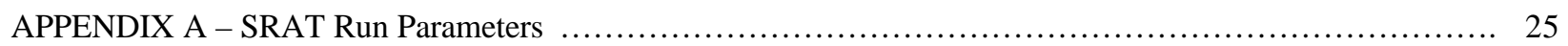

APPENDIX B - Rheology Measurements Performed on SRAT Products from Runs SB3-1 to SB3-4 .......... 27

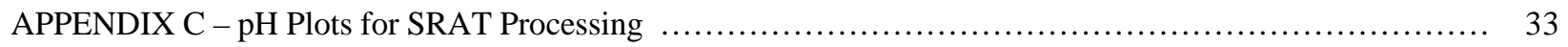

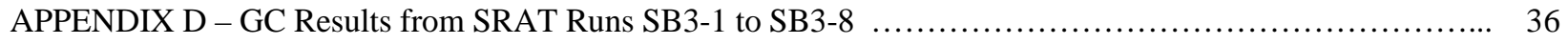

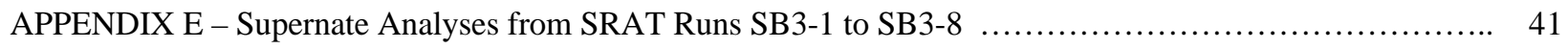

\section{LIST OF TABLES}

Table 1 - Sludge Compositions (Wt\% Calcined Basis with Calcine Factor of 0.80) $\ldots \ldots \ldots \ldots \ldots \ldots \ldots \ldots \ldots \ldots \ldots$

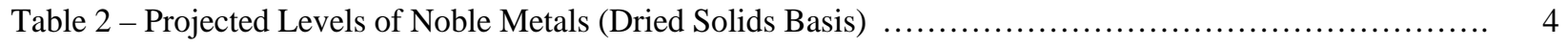

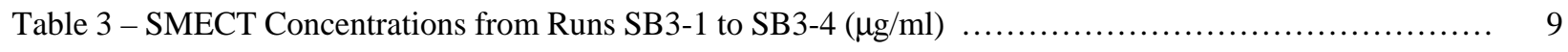

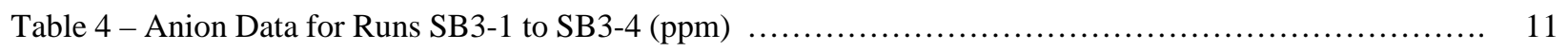

Table 5 - Bingham Plastic Model Fit Data for SB3-1 to SB3-4 ......................................... 12

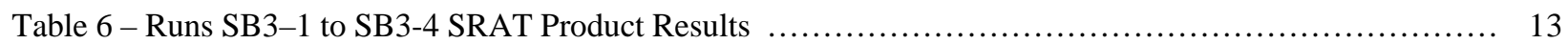

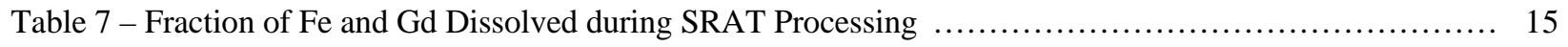

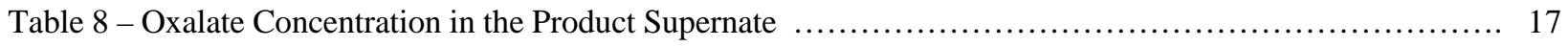

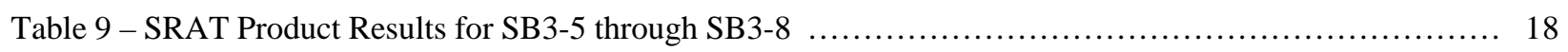

Table 10 - Anion Results for SB3-5 through SB3-8 during SRAT Processing (mg/L) . ....................... 19

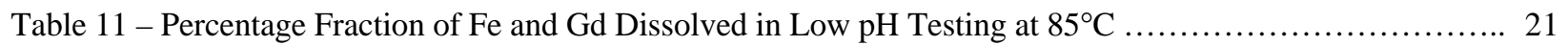

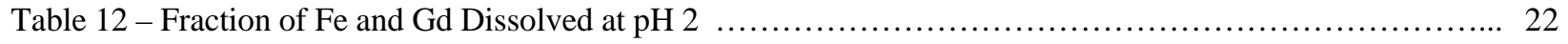

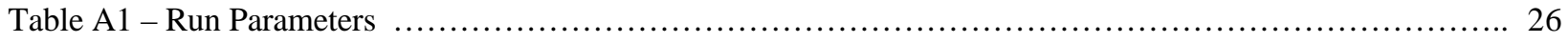




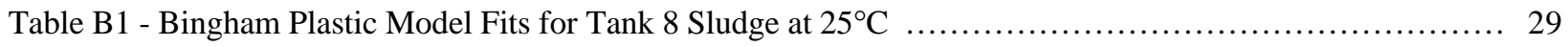

Table E1 - Supernate Results during Processing for Runs SB3-5 through SB3-8 (mg/L) .................... 42

Table E2 - Supernate Results for SRAT Product Samples (mg/L) ….................................. 43

Table E3 - Supernate Results for Low pH Test with Oxalate in SRAT Product Samples (mg/L) ............. 44

Table E4 - Supernate Results for Low pH Test without Oxalate in SRAT Product Samples (mg/L) ............ 45

Table E5 - Supernate Results for pH 2 Tests in SRAT Product Samples (mg/L) ........................... 46

\section{LIST OF FIGURES}

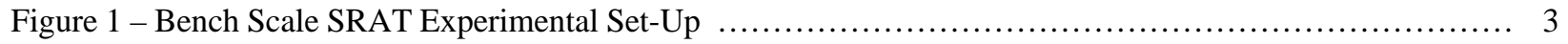

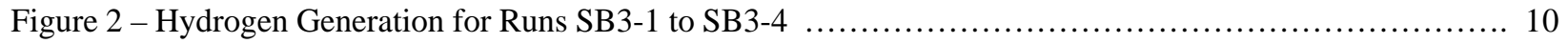

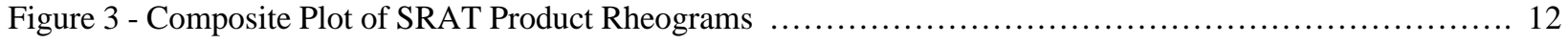

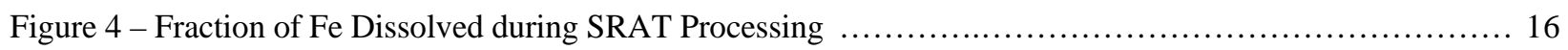

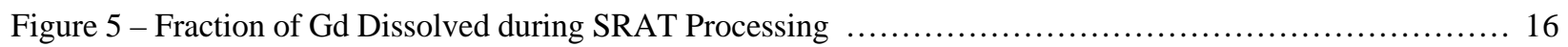

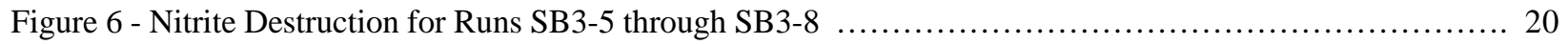

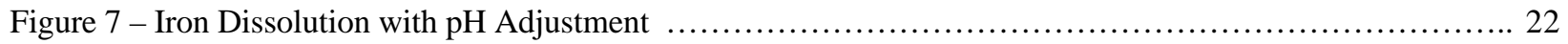

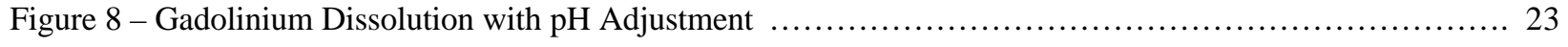

Figure B1 - SB3-1 SRAT Product Raw Rheogram Data (Noble Metals; No Sand, Carbon, or Gd) ............... 30

Figure B2 - SB3-2 SRAT Product Raw Rheogram Data (Noble Metals, Sand and Carbon; No Gd) .............. 30

Figure B3 - SB3-3 SRAT Product Raw Rheogram Data (Sand, Carbon, and Gd; No Noble Metals) ............. 31

Figure B4 - SB3-4 SRAT Product Raw Rheogram Data (Noble Metals, Sand, Carbon, and Gd) ................ 31

Figure B5 - SB3-1 SRAT Product and Tank 8 Sludge Simulant Data (No Sand, Carbon, or Gd) ................ 32

Figure B6 -Tank 8 Simulant Dewashed with Sodium Salts (Containing Sand and Carbon) ...................... 32

Figure C1 - pH During SRAT Processing for SB3-1 through SB3-4 .................................... 34

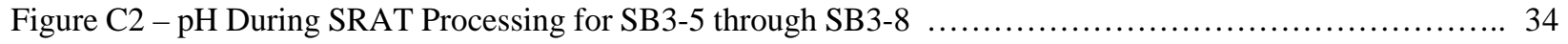

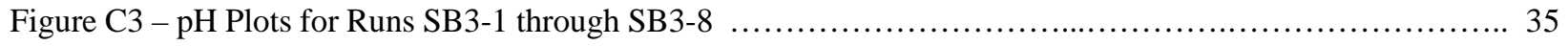

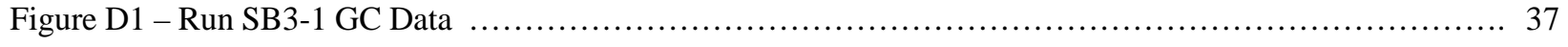

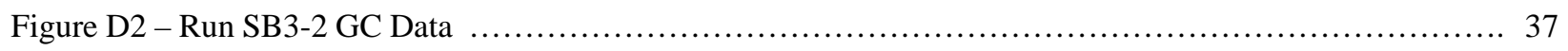

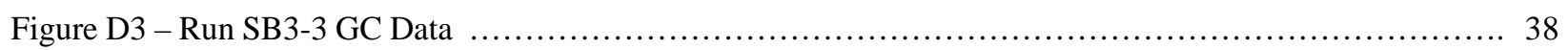

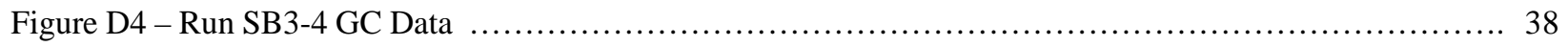

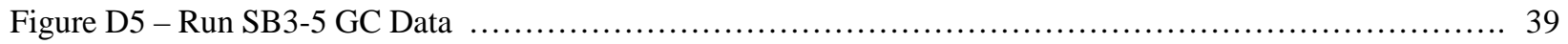

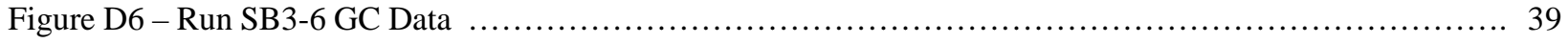

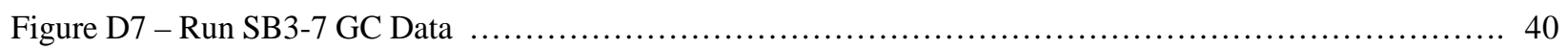

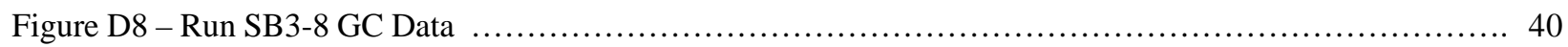




\subsection{SUMMARY}

The Savannah River Technology Center (SRTC) was requested to investigate the effects of the addition of Pu and Gd from H-Canyon to Sludge Batch 3 (SB3). This report addresses the effects of the Pu/Gd on Sludge Receipt and Adjustment Tank (SRAT) processing. Preliminary impacts of the non-traditional sludge components, which are contained in Tank 7, are also discussed.

Three programs were performed with non-radioactive simulated sludge to address the effects of the $\mathrm{Pu} / \mathrm{Gd}$ additions on the Defense Waste Processing Facility (DWPF) SRAT processing. The first looked at the impacts of Gd on SRAT processing and consisted of SRAT Runs SB3-1 through SB3-4. Gd was added at the anticipated level and was also added for the anticipated $\mathrm{Pu}$ amount. The second study addressed the impacts of sodium oxalate on iron solubility during SRAT processing and consisted of SRAT Runs SB3-5 through SB3-8. Finally, the third studied lower pH effects on iron solubility of the SRAT product with and without sodium oxalate present. In these studies, the rare earth element samarium was added to simulate the behavior of actinide elements in the plus three valance state. A surrogate was not added to simulate $\mathrm{Pu}$ in the plus four valance state, which is the most common for $\mathrm{Pu}$ in alkaline solutions.

Based on the results of this initial testing, the following conclusions were made with respect to processing of $\mathrm{Pu} / \mathrm{Gd}$ :

I. Gadolinium had no or minimal impact on SRAT processing with respect to the following:

- Sampling and analytical capability,

- Hydrogen generation,

- Foaming during processing,

- Redox of SRAT feed,

- Product rheology,

- Emitted offgas species (i.e., solids carry-over and Gd volatility), and

- SRAT product acceptability

- Mercury stripping efficiency and

- Nitrite destruction.

II. The impacts of sodium oxalate on solubility during SRAT processing were as follows:

- Negligible amounts of iron and gadolinium became soluble with sodium oxalate at 50\% ( 330,000 pounds) of the amount anticipated in Tank 7. The maximum fraction of iron dissolved was $5.84 \times 10^{-3}(0.58 \%$ of total Fe $)$ during Run SB3-8, while the maximum fraction of gadolinium dissolved was $3.36 \times 10^{-2}$ (3.36\% of total Gd) during SB3-5. Samarium remained in the sludge solids throughout SRAT processing.

- At sodium oxalate levels of $25 \%$ ( 165,000 pounds) of the anticipated amount in Tank $7,100 \%$ of the iron, gadolinium, and samarium remained in the sludge solids.

III. In the testing to support solubility determinations at $\mathrm{pH}$ levels below those expected in typical SRAT processing (i.e., $2<\mathrm{pH}<4$ ), the following was observed:

- Higher levels of the available iron and gadolinium were solubilized at $\mathrm{pH}$ levels less than those typical in SRAT processing (i.e., $\mathrm{pH}<4$ ). At a $\mathrm{pH}$ of $\sim 2, \sim 7 \%$ iron and $\sim 43 \%$ gadolinium were dissolved from the SRAT product without sodium oxalate, while $\sim 4 \%$ iron and $\sim 58 \%$ gadolinium were dissolved from the SRAT product containing sodium oxalate. Therefore, $\sim 93 \%$ of the iron and $\sim 57 \%$ of the gadolinium remained insoluble in testing without sodium oxalate, while $\sim 96 \%$ of the iron and $\sim 42 \%$ of the gadolinium remained insoluble for the testing with sodium oxalate.

- At $\mathrm{pH}>3$, the amounts of dissolved material were much smaller for both cases.

Preliminary results from testing with the non-typical components of Tank 7 identified the following issues for SB3 processing, which will be further investigated as part of qualification of SB3:

- The presence of sand and coal without oxalate present resulted in an increase in the hydrogen production during SRAT processing. Peak hydrogen rate was 2 to 3 times higher than in testing without sand and coal present. It is believed that coal may be acting as a catalyst or catalyst support for hydrogen production.

- The presence of sodium oxalate mitigated the release of hydrogen during SRAT processing even in the presence of sand and coal. No appreciable amounts of hydrogen were detected in the presence of sodium oxalate in any of the runs performed as part of this testing.

- The presence of sodium oxalate also decreased the nitrite destruction rate, thereby increasing the acid demand. With increased acid or with $25 \%$ of the sodium oxalate remaining, the nitrite was destroyed to below the DWPF limits. 


\subsection{INTRODUCTION AND BACKGROUND}

Currently, DWPF is operating using a sludge-only processing flowsheet. Since start-up, DWPF has modified its operating flowsheet to adjust for processing of the incoming or existing sludge batch. For each sludge batch, SRTC has performed non-radioactive and radioactive sludge runs to evaluate potential chemical processing issues, quantify the potential hydrogen generation rates that will be seen in DWPF, and to estimate the required acid stoichiometry. The next sludge batch, SB3, which is primarily Tank 7 sludge, is expected to contain several components that are considered non-typical to DWPF sludge and also higher levels of noble metals than previously processed sludge batches. In addition to the Tank 7 contents, it has been proposed to add $\mathrm{Am} / \mathrm{Cm}$ feed and an H-Canyon slurry containing precipitated $\mathrm{Pu}$ with $\mathrm{Gd}$ to SB3. The studies discussed in this report concentrate on the effects of the H-Canyon addition on SRAT processing with simulated sludge, $\mathrm{Gd}$, and a surrogate material for the actinides in the H-Canyon slurry. Preliminary information on SRAT processing of the other non-typical components of Tank 7 (sand, coal, and sodium oxalate) is also included as part of the $\mathrm{Pu}$ and $\mathrm{Gd}$ investigations.

Since the H-Canyon slurry will contain a large amount of Gd and this is not a material found in large quantities in typical DWPF streams, its effect on the High Level Waste (HLW) system had to be understood. SRTC has been and is performing scoping studies to evaluate the effects of the Gd. The impacts on SRAT processing with simulated sludge were performed under the guidance of SRT-GPD-2002-0044 [1], while the effect on SRAT processing with a precipitated Pu/Gd slurry and simulated sludge was performed under the guidance of WSRC-RP-2002-00178 [2]. These studies also used sand and coal at the levels anticipated for SB3 [3] so the interaction with the H-Canyon stream could be understood and to gain an initial understanding of the impacts on processing. Noble metals at the anticipated levels [3] were used in the runs without the Pu/Gd slurry.

The specific objectives for determining the impact of Gd on SRAT processing are described below. These objectives were identified by the HLW division and SRTC in an Impact Matrix for the addition of the H-Canyon stream [4] and were also identified by DWPF in an Issue Card for the Tank 7 Sludge Contents.

1) Determine if there are any sampling or analytical issues for SRAT analytical prep and if there is any interference with analyses from the non-typical sludge components (i.e., Gd, coal, and sand).

2) Determine if Gd volatility is an issue during the SRAT cycle.

3) Determine any change in solids carryover.

4) Determine the reaction of the non-typical sludge components with formic acid, nitric acid, the typical sludge components, and the noble metals.

5) Determine the hydrogen generation from each run.

6) Determine the ammonia generation from each run.

7) Determine the efficiency of mercury stripping and if there is interference from the non-typical sludge components.

8) Determine the impact of non-typical components on redox of SRAT feed.

9) Determine the impact of non-typical components on foam evolution during SRAT processing.

10) Determine Gd solubility.

11) Determine any change in rheology due to the non-traditional components.

12) Determine the acceptability of the SRAT products.

Historical information indicates that Tank 7 may contain sodium oxalate at levels up to 660,000 pounds [5]. This level is much higher than other tanks processed in the DWPF, therefore its impacts on processing have not been fully understood or researched. Issues related to criticality are of utmost concern with regards to the ability to process the $\mathrm{H}$ Canyon precipitated slurry since it is believed that the oxalate may solubilize iron contained in SB3 to the tris-oxalato ion, $\mathrm{Fe}\left(\mathrm{C}_{2} \mathrm{O}_{4}\right)_{3}{ }^{3-}$. Since iron is considered the primary neutron poison in the DWPF feed and is normally present in the sludge solids, any impacts on its behavior due to the presence of the sodium oxalate must be understood before SB3 can be processed in DWPF. Studies to address issues related to sodium oxalate and Pu were performed as part of Task Technical and Quality Assurance Plan WSRC-RP-2002-00320 [6]. Scoping tests were also performed as part of this task to determine Fe solubility at lower than prototypical $\mathrm{pH}$ levels.

While the main focus of the SRAT runs was to understand the issues with processing Pu and Gd, the potential hydrogen generation rate was also quantified, and insight into SRAT processing issues was obtained. Insight was provided on:

- Effect on the redox (i.e., formate and nitrate concentration) of the SRAT product, 
- Foam evolution and air entrainment,

- Potential rheology changes,

- Oxalate reaction with formic and nitric acid and the noble metals,

- Nitrite destruction rate during SRAT cycle,

- Maximum nitrous oxide $\left(\mathrm{N}_{2} \mathrm{O}\right)$ generation rate during SRAT processing, and

- Acceptability of the SRAT product (from a processing as opposed to glass product perspective).

The Slurry Mix Evaporator (SME) cycle and melting of the SME product were not performed as part of this study.

\subsection{EXPERIMENTAL}

The testing was performed at the Aiken County Technology Laboratory (ACTL) using a four-liter kettle with various glassware fabricated to functionally replicate the DWPF processing vessels. The kettle replicates both the SRAT and the SME, but only SRAT processing was performed in these studies. The SRAT Condenser, the Formic Acid Vent Condenser (FAVC), the Mercury Water Wash Tank (MWWT), and the Slurry Mix Evaporator Condensate Tank (SMECT) were also simulated. A sketch of the experimental setup is given as Figure 1:

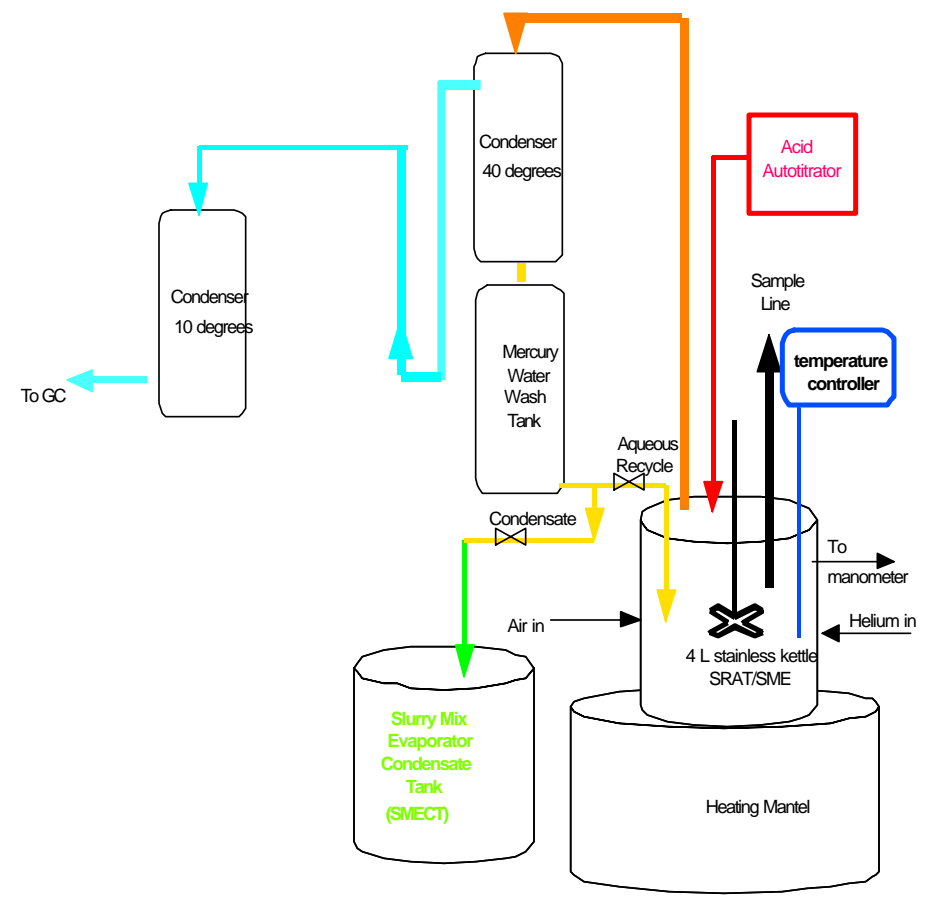

Figure 1 - Bench-Scale SRAT Experimental Set-up

The simulated sludge that was used in all of the testing was made for processing of Sludge Batch 2 (SB2) and is representative of Tank 8 material. The sludge simulant was prepared at the University of South Carolina in the FRED cross flow filter facility. The composition of the Tank 8 surrogate and the projected Tank 7 compositions [3] are given in Table 1. The composition of the Tank 8 simulant did not exactly match the composition of the projected Tank 7 sludge; however, the small deviations in composition were expected to have minimal impact on processing with regards to the $\mathrm{Pu} / \mathrm{Gd}$ precipitate.

For the first set of SRAT runs to determine the impact of Gd, $0.061 \mathrm{wt} \% \mathrm{Gd}$ was added to the sludge to represent both components of the $\mathrm{Pu} / \mathrm{Gd}$ precipitate contribution to SB3. For the SRAT runs to determine the solubility of sludge components with oxalate during SRAT processing, Gd was added to the sludge at $0.037 \mathrm{wt} \%$ and $\mathrm{Sm}$ was added at $0.024 \mathrm{wt} \%$. 
Table 1 - Sludge Compositions (Wt\% Calcined Basis with Calcine Factor of 0.80)

\begin{tabular}{|c|c|c|}
\hline $\begin{array}{c}\text { Element/ } \\
\text { Species }\end{array}$ & $\begin{array}{c}\text { Tank 8 } \\
\text { Simulant }\end{array}$ & $\begin{array}{c}\text { Projected } \\
\text { Tank 7 [3] }\end{array}$ \\
\hline $\mathrm{Al}$ & 11.8 & 11.02 \\
\hline $\mathrm{Ba}$ & 0.26 & 0.26 \\
\hline $\mathrm{Ca}$ & 2.82 & 2.96 \\
\hline $\mathrm{Ce}$ & $\mathrm{N} / \mathrm{A}$ & 0.34 \\
\hline $\mathrm{Cr}$ & 0.27 & 0.29 \\
\hline $\mathrm{Cu}$ & 0.17 & 0.18 \\
\hline $\mathrm{Fe}$ & 33.3 & 32.4 \\
\hline $\mathrm{K}$ & 0.01 & 0.41 \\
\hline $\mathrm{La}$ & $\mathrm{N} / \mathrm{A}^{*}$ & 0.20 \\
\hline $\mathrm{Mg}$ & 0.16 & 0.13 \\
\hline $\mathrm{Mn}$ & 3.24 & 6.40 \\
\hline $\mathrm{Na}$ & 7.58 & 9.08 \\
\hline $\mathrm{Ni}$ & 3.57 & 1.45 \\
\hline $\mathrm{Pb}$ & 0.12 & 0.32 \\
\hline $\mathrm{Si}$ & 1.12 & 1.13 \\
\hline $\mathrm{Zn}$ & 0.28 & 0.38 \\
\hline $\mathrm{Zr}$ & 0.47 & 0.66 \\
\hline * La was not added to the Tank 8 simulant.
\end{tabular}

Mercury was added in all of the testing at a level of $0.076 \mathrm{wt} \%$ (dried solids basis), which is the anticipated level for Tank 7 [3]. Sand and coal were also added to the SRAT feed in some of the testing, since these components are also anticipated to be in Tank 7. On a dried sludge solids basis (free of any sodium oxalate additions), these levels were 1.12 $\mathrm{wt} \%$ sand (nominal size range of 0.4 to $0.5 \mathrm{~mm}$ ) and $0.72 \mathrm{wt} \%$ coal (nominal range of 0.6 to $0.8 \mathrm{~mm}$ ) [3]. The coal source for these runs was activated carbon since anthracite coal was not readily available. Sodium oxalate was added to the sludge for the solubility studies using either a basis of $25 \%$ or $50 \%$ sodium oxalate remaining after washing. Therefore, the amount represented either 165,000 or 330,000 pounds of sodium oxalate remaining.

The levels of noble metals used throughout the SB3 testing are shown in Table 2 and are based on projections using the La-139 content of SB3 [3]. Table 2 also compares the noble metal amounts projected for SB3 to the HM levels of noble metals. The Rh projection is almost one and a half times greater than the corresponding HM level. The Rh concentration is noteworthy because it is the most catalytically active of the noble metals listed with respect to hydrogen production during the SRAT cycle.

Table 2 - Projected Levels of Noble Metals (Dried Solids Basis)

\begin{tabular}{|c|c|c|}
\hline Species & Target Amount [3] & HM Level \\
\hline $\mathrm{Ag}$ & $5.42 \mathrm{E}-04 \mathrm{wt} \%$ & $1.4 \mathrm{E}-02 \mathrm{wt} \%$ \\
\hline $\mathrm{Pd}$ & $2.76 \mathrm{E}-02 \mathrm{wt} \%$ & $7.9 \mathrm{E}-02 \mathrm{wt} \%$ \\
\hline $\mathrm{Rh}$ & $5.11 \mathrm{E}-02 \mathrm{wt} \%$ & $3.8 \mathrm{E}-02 \mathrm{wt} \%$ \\
\hline $\mathrm{Ru}$ & $1.83 \mathrm{E}-01 \mathrm{wt} \%$ & $2.17 \mathrm{E}-01 \mathrm{wt} \%$ \\
\hline
\end{tabular}

The target sludge solids content for each of the runs was nominally $18 \mathrm{wt} \%$ air-dried total solids. The solids content was slightly higher for the first two runs with sodium oxalate because of the contribution from the oxalate solids, but the total solids were adjusted using distilled water for the last two runs with sodium oxalate to match the nominal $18 \mathrm{wt} \%$ target. Acid additions were based on (1) total acid to achieve the acid stoichiometry and (2) acid mix to produce redox target $\left(0.2 \mathrm{Fe}^{2+} / \mathrm{O} F e\right.$ redox ratio $)$ by the F-3N correlation [7]. The possible effects of coal and oxalate were not accounted for in the redox correlation or in the acid calculation. Acid addition levels were changed in the last two SRAT runs evaluating solubility since the results of the first scoping test at $50 \%$ oxalate indicated that the acid addition amount was insufficient to destroy nitrite. Concentrated formic acid (90-wt $\%)$ and nitric acid (50-wt $\%)$ were used during processing. In addition, IIT 747 antifoam was added during heat-up (200 ppm) and after acid addition (500 ppm). After acid addition was completed, the temperatures of the slurries were ramped to boiling and remained at 
boiling for 10.5 to 12 hours depending on the run. Concentrating/dewatering required between 2 to 3 hours depending on the amount of acid and rinse water added during each run. The vessels were refluxed the remainder of the boiling cycle.

SRAT processing followed the run plans written for each SRAT test and were performed in accordance with Procedure 2.02 ("Laboratory Scale Chemical Process Cell Simulations") of Manual L27 [8]. The SRAT kettle was monitored to observe reactions that were occurring during each run to include foaming, air entrainment, rheology changes, and offgas carryover. Any observations were recorded in a laboratory notebook. Slurry $\mathrm{pH}$ and offgas hydrogen, $\mathrm{N}_{2} \mathrm{O}$, and $\mathrm{CO}_{2}$ concentrations were measured during the experiments using an in-line Gas Chromatograph (GC). Slurry samples were pulled at the start of boiling and every two hours thereafter to monitor nitrite, nitrate, and formate concentrations in the slurry. The cation solubility and oxalate concentrations were also monitored during the four solubility tests with oxalate.

The eight runs were divided into two subgroups of four, with the first four addressing the Gd Impact Studies and the last four addressing the Solubility Studies. The runs were characterized as follows:

SB3-1 Process operating parameters similar to the current DWPF sludge-only processing strategy. The acid target was $125 \%$ of the stoichiometric acid requirement. Noble metal levels and the mercury level were as predicted for SB3. No non-traditional sludge components were added.

SB3-2 Identical to SB3-1, but coal and sand were added at the anticipated levels and expected particle sizes. The acid addition volume was the same as used during SB3-1.

SB3-3 Gd was added at the levels anticipated for the incoming H-Canyon stream (Gd was also substituted for the $\mathrm{Pu}$ ) and no noble metals were added to the feed. Coal and sand were also added to the simulated sludge. The acid addition volume was the same as used during SB3-1.

SB3-4 The same as SB3-2 but the anticipated level of Gd was also added. The acid addition volume was the same as used during SB3-1. This test provided information on the interaction of the Gd with the noble metals.

SB3-5 The same as SB3-1, but 50\% of the historical sodium oxalate was added. The acid addition level was the same as used during SB3-1 to SB3-4. Gadolinium and Sm were added at the anticipated levels. Iron, gadolinium, samarium, and oxalate were monitored throughout the testing.

SB3-6 The same as SB3-5, but only $25 \%$ of the historical sodium oxalate was added. The acid addition target was also the same.

SB3-7 The same as SB3-5, but acid addition level was increased due to poor nitrite destruction seen in SB3-5. Addition was stopped when $\mathrm{pH}$ reached $\sim 4.5$ as measured by the $\mathrm{pH}$ probe, which was shown to have acceptable nitrite destruction during SB3-6.

SB3-8 The same as SB3-7, but sand and coal were added to determine the impacts on solubility and processing.

A matrix showing the parameters of each run is given as Appendix A.

SRAT products from runs SB3-4 and SB3-8 were selected for adjustment to low pH levels to simulate upset conditions in DWPF that could indeed lower the $\mathrm{pH}$. An example would be transfer of a portion of the SRAT contents to the SMECT. The specific issues were the effect of lowering the $\mathrm{pH}$ on the solubility of Fe and of Gd during such an upset. Moving a large fraction of $\mathrm{Fe}$ to the supernate phase has the potential to remove a key neutron poison for the $\mathrm{Pu}$ from the insoluble solids.

The apparatus was similar to that used for SRAT simulations, only smaller. The entire experiment was conducted at $85^{\circ} \mathrm{C}$, which was less than boiling in order to minimize evaporation losses. The apparatus contained a calibrated $\mathrm{pH}$ probe, which was set to adjust $\mathrm{pH}$ temperature measurements to $25^{\circ} \mathrm{C}$. Standard practice to this point for bench-scale SRAT runs was not to compensate the $\mathrm{pH}$ measurement for the temperature during processing since runs were 
compared on a relative basis. However, for the accident scenario being investigated, the $\mathrm{pH}$ to be encountered would be temperature dependent. In the initial experiments where temperature affect on $\mathrm{pH}$ was not considered, the $\mathrm{pH}$ of a weighed aliquot of the SRAT products for SB3-4 and SB3-8 were adjusted using 10M nitric acid. The nitric acid was metered in until the $25^{\circ} \mathrm{C}$ adjusted $\mathrm{pH}$ reached approximately $6,5,4,3.5,3,2.5,2$, and slightly lower. The $\mathrm{pH}$ readings were later corrected using the following formula:

$$
\begin{aligned}
& \mathrm{pH}_{\mathrm{c}}=7+[(273.13+25) /(273.13+\mathrm{T})] \mathrm{x}\left(\mathrm{pH}_{\mathrm{r}}-7\right) \\
& \text { where, } \quad \begin{array}{l}
\mathrm{T}=\text { test temperature, }{ }^{\circ} \mathrm{C} \\
\mathrm{pH}_{\mathrm{r}}=\text { raw } \mathrm{pH} \text { reading } \\
\mathrm{pH}_{\mathrm{c}}=\text { corrected pH reading }
\end{array}
\end{aligned}
$$

The corrected $\mathrm{pH}$ levels corresponded to approximately $6.17,5.34,4.50,4.09,3.67,3.25$, and 2.84, respectively, for the $85^{\circ} \mathrm{C}$ process temperature. The nitric acid addition was stopped when each $\mathrm{pH}$ level was reached. The process was held near that $\mathrm{pH}$ level for at least 30 minutes. In some cases, additional acid was added after 15 minutes to offset upward drift in the $\mathrm{pH}$ and to return the $\mathrm{pH}$ to the target value for that period.

Samples were taken upon reaching each $\mathrm{pH}$ level. These were centrifuged and decanted. Additional samples were taken at the lower $\mathrm{pH}$ 's just prior to dropping the $\mathrm{pH}$ to the next target. These were prepared the same way. A partial third set of samples was pulled upon reaching most $\mathrm{pH}$ targets. These were analyzed for weight percent total and dissolved solids, and weight percent soluble and insoluble fractions were determined based on this analysis. A combination of sample results and material balance data permitted determination of the masses of supernate and insoluble solid phases throughout the test. This, combined with the compositional analysis, permitted the determination of the dissolved mass of $\mathrm{Fe}$ and $\mathrm{Gd}$. The dissolved mass of $\mathrm{Fe}$ and $\mathrm{Gd}$ was divided by the total mass of $\mathrm{Fe}$ or $\mathrm{Gd}$ to determine the fraction of each element in the supernate phase.

To ensure that the SRAT products were adjusted to a $\mathrm{pH}$ of 2.0 at $25^{\circ} \mathrm{C}$, which would be more representative of the SMECT, $\sim 100 \mathrm{~g}$ of the $\mathrm{pH}$ adjusted SB3-4 and SB3-8 products were removed and the $\mathrm{pH}$ was adjusted to 2.0 at room temperature. Once the products were at 2.0 , the samples were heated to $85^{\circ} \mathrm{C}$ and the $\mathrm{pH}$ target of 2.0 was maintained for $3 \frac{1}{2}$ hours by slight acid addition adjustments as necessary. The acid used for this set of adjustments was also $10 \mathrm{M}$ nitric acid. Samples of the product were taken upon stabilization at the $2.0 \mathrm{pH}$ level and before additional acid was added to counteract the upward drift. The samples were centrifuged and decanted as performed in the other $\mathrm{pH}$ testing, and the supernate was analyzed to determine the amounts of dissolved metals. This combined set of tests was considered bounding for a transfer of the SRAT to the SMECT.

\subsection{ANALYTICAL METHODS}

A high-speed micro GC was used during the SRAT bench scale experiments to monitor the offgas for hydrogen, oxygen, nitrogen, carbon dioxide, and nitrous oxide. Hydrogen, nitrous oxide, and oxygen are monitored to demonstrate that a flammable mixture is not formed by maintaining the hydrogen concentration below approximately 4 volume \%, the Lower Explosive Level (LEL). The other monitored species provide insight into the reactions occurring during the SRAT processing. The GC is self-contained and is designed specifically for fast and accurate analysis. There are five main components of the GC. The first is the carrier gas (argon for this testing) to transport the sample through the molecular sieve and poraplot Q columns. The second is the injector, which introduces a measured amount of sample into the inlet of the analytical columns. The amount of sample injected depends on the length of time the injector is open. The injected sample flows to the analytical column where it is separated. The third component is the column, which is the separation system. The column is capillary tubing coated or packed with a chemical substance known as the stationary phase that preferentially attracts the sample components. As a result, components separate as they pass through the column based on their solubility. Since solubility is affected by temperature, column temperature must be controlled. The fourth component is a detector. The detector monitors the carrier and senses a change in its composition when a component in the sample elutes from the column. The fifth component is the data system, EZChrom. Its main purpose is to generate both qualitative and quantitative data. It provides a visual recording of the detector output and an area count of the detector response. The detector response is used to identify the sample composition and measure the amount of each component by comparing the area counts of the sample to the analysis of known calibration standards. The calibration standard used for the SRAT runs consisted of $0.5 \%$ helium, $1.0 \%$ 
hydrogen, $20.0 \%$ oxygen, $10.0 \%$ carbon dioxide, and $1.0 \%$ nitrous oxide. The calibration standard is balanced in argon because helium was used to detect leakage during the actual run.

The sludge surrogate was sampled and analyzed to obtain baseline data on the chemical composition of the soluble and insoluble fractions. Samples were generated throughout the runs and at the end of the runs for analyses to quantify the SRAT processing behavior. The SRAT samples were analyzed by the Savannah River Technology Center/Immobilization Technology Section Mobile Lab (SRTC-ML) and the Analytical Development Section (ADS) to determine the chemical composition of the soluble and insoluble fractions. The SRAT samples were prepared by calcining a portion of the samples at $900^{\circ} \mathrm{C}$ and then dissolving the calcined product using $\mathrm{Na}_{2} \mathrm{O}_{2} / \mathrm{NaOH}$ fusion, lithium metaborate fusion, and microwave acid dissolution. Cation analyses were performed using Inductively Coupled Plasma - Atomic Emission Spectroscopy (ICP-AES). Hg analyses were performed using cold vapor digestions and Atomic Adsorption (AA) spectroscopy. Anion analyses were performed using weighted dilutions and Ion Chromatography (IC). In-process samples for anion analyses were diluted with a $1 \mathrm{~N} \mathrm{NaOH}$ solution immediately after the sample was removed from the vessel. A weighted dilution was performed on these samples and they were then analyzed using IC. Supernate samples were obtained by centrifuging the slurry samples and removing the supernate. The SRAT product was also submitted for wt $\%$ calcined, total, insoluble, and soluble solids determinations. Total and dissolved solids were measured and insoluble and soluble solids were calculated based on the results. The dissolved cations and anions in the supernate were analyzed using ICP-AES and IC. Solids from the solubility studies and the low pH studies were also submitted to the ADS for X-ray Diffraction (XRD) analyses to determine the compounds present.

The SMECT, FAVC, and MWWT from some of the runs were also sampled and analyzed to determine offgas constituent differences and to complete mass balances. The SMECT was analyzed for total constituent content by ICPAES and IC. FAVC and MWWT samples were analyzed for Hg using AA spectroscopy and for Gd by ICP-AES.

All analyses for this task were governed by the Analytical Study Plan (ASP) [9]. A sample request form accompanied each sample. A unique lab identification number was assigned to each sample for tracking purposes. Analyses were performed using approved analytical and QA procedures.

The rheological properties of the SRAT products were measured by the Immobilization Technology Section (ITS). Rheological data was obtained in the concentric cylinder geometry on a ThermoHaake RS150 rheometer. Measurements in this geometry are less sensitive to issues such as solids settling and edge drying compared to the parallel plate geometry. Data analysis is also simplified by the nearly constant shear stress field that exists within the sample at a given shear rate. Data were taken for the starting Tank 8 simulant sludge free of sand, carbon, and gadolinium, as well as for the SRAT products from Runs SB3-1 to SB3-4. Two 125-ml SRAT product samples were pulled for rheological characterization from each of the four runs. A more detailed description of the rheometer configuration is provided in Appendix B. Two flow curves were obtained for each SRAT product. All samples were run using the same analysis method. A period of 30-60 seconds was allowed for the sample to reach thermal equilibrium depending on the temperature in the lab. The sample jacket temperature was $25^{\circ} \mathrm{C}$. This number has been independently checked in various ways to confirm its accuracy. Shear rate was then linearly ramped from $0 \mathrm{sec}^{-1}$ to 400 $\mathrm{sec}^{-1}$ over five minutes. The shear rate was held at $400 \mathrm{sec}^{-1}$ for one minute. Finally, the shear rate was ramped from $400 \mathrm{sec}^{-1}$ to $0 \mathrm{sec}^{-1}$ over five minutes. A 55-cP oil viscosity standard was run to confirm that the instrument was performing normally.

A portion of the uncorrected rheological data for each sample was fit to the Bingham plastic equation to give a yield stress and consistency (plastic viscosity). All samples showed evidence of the formation of secondary flows called Taylor vortices at shear rates near $200 \mathrm{sec}^{-1}$. The onset of Taylor vortices at lower than past shear rates is due to the larger gap width in the Z38/DZ43 configuration. Sample data at low shear rates suffer from inertial and other instrument effects. In addition, the fact that the samples are not true Bingham plastics shows up primarily at low shear rates. Rheological data was fit on the interval of $\sim 20 \mathrm{sec}^{-1}$ to $\sim 180 \mathrm{sec}^{-1}$. A segment of a down ramp that appeared to be most representative of the two flow curves was picked for the fit. A few pieces of data from tests on the same sample with two different gap widths indicate that the consistency is overestimated by a progressively larger amount as the gap width to cylinder width ratio increases. Making some correction(s) to the raw flow curve data could mitigate this problem. Such procedures are not standard at this time. The model parameters given are for the uncorrected flow curve data. 


\subsection{RESULTS}

\subsection{Gd Impact Studies - Runs SB3-1 through SB3-4}

The specific objectives of this set of SRAT runs (i.e., determining the impact of gadolinium on SRAT processing) were identified above. The path/methods that were used to meet the objectives and the results will be discussed in this section.

\section{Sampling or Analytical Issues for SRAT Analytical Prep}

The sludge simulant, SRAT process samples, and the SRAT products from each run were analyzed for Gd and other sludge components using standard methods. Gadolinium was analyzed using ICP-AES and no issues with analysis were encountered. The impacts of sand and coal on analyses are still being investigated as part of the SB3 task. However, preliminary slurry samples containing sand and coal were not problematic for chemical composition analyses. Issues with carbon analyses have been identified and are being investigated by the ADS as part of SB3 qualification efforts. Some issues may exist for sand analyses because of the size of the particles, but issues will be method dependent for sampling and analytical preparation. Some problems were experienced in sampling the SRAT slurry due to pluggage of the sample line by sand and coal.

\section{$\underline{\text { Gd Volatility }}$}

The SMECT and FAVC contents were analyzed for Gd and no Gd was detected. The SRAT product analyses also indicated that all of the Gd was retained during processing. Therefore, volatility of Gd does not appear to be an issue for SRAT processing.

\section{Change in solids carryover}

The SMECT contents from Runs SB3-1 through SB3-4 were analyzed to determine constituents that carried over to the offgas. Results are given in Table 3. No noble metals, chloride, or sulfate were detected in the SMECT samples. Concentrations of $\mathrm{Al}, \mathrm{Fe}, \mathrm{Mn}, \mathrm{Na}$, formate, and nitrate were slightly higher in the run with Gd (SB3-3) where noble metals were not added. When noble metals and sand and coal were present in the runs, the presence of Gd (Run SB3-4) resulted in lower $\mathrm{Ca}$ and higher $\mathrm{Cu}$ and $\mathrm{Na}$ concentrations in the SMECT compared to when Gd was not present (Run SB3-2). The data also suggested that the presence of sand and coal also had an impact on the SMECT composition, as evidenced by the higher concentrations of several species in the presence of sand and coal (Run SB3-1 vs Runs SB3-2 to -4). Of particular interest for the HLW system are the elevated levels of $\mathrm{Al}, \mathrm{Na}$, and $\mathrm{Si}$ in the presence of sand and coal. $\mathrm{Al}$ and $\mathrm{Si}$ were roughly $2 \mathrm{x}$ higher, while $\mathrm{Na}$ was up to $40 \mathrm{x}$ higher in the presence of sand and coal. However, the amounts of materials detected in the SMECT represent only a small fraction of the amounts of materials in the sludge. These differences should not present an issue for processing but will continue to be monitored during SB3 studies to ensure that it remains a non-issue. 
Table 3 - SMECT Concentrations from Runs SB3-1 to SB3-4 $(\mu \mathrm{g} / \mathrm{ml})$

\begin{tabular}{|l|c|c|c|c|}
\hline Analyte & SB3-1 & SB3-2 & SB3-3 & SB3-4 \\
\hline $\mathrm{Al}$ & 0.057 & 0.116 & 0.152 & 0.124 \\
\hline $\mathrm{Ba}$ & 0.037 & 0.045 & 0.040 & 0.039 \\
\hline $\mathrm{Ca}$ & 0.006 & 1.72 & 1.74 & 0.817 \\
\hline $\mathrm{Cu}$ & $<0.009$ & 0.025 & 0.054 & 0.052 \\
\hline $\mathrm{Fe}$ & 0.044 & 0.389 & 0.738 & 0.404 \\
\hline $\mathrm{Gd}$ & $<0.012$ & $<0.012$ & $<0.012$ & $<0.012$ \\
\hline $\mathrm{K}$ & 0.189 & 0.169 & 0.160 & 0.153 \\
\hline $\mathrm{La}$ & 0.071 & 0.079 & 0.072 & 0.074 \\
\hline $\mathrm{Mn}$ & $<0.001$ & 0.237 & 0.874 & 0.280 \\
\hline $\mathrm{Na}$ & $<0.100$ & 0.538 & 3.820 & 0.844 \\
\hline $\mathrm{Ni}$ & $<0.010$ & 0.034 & 0.025 & 0.042 \\
\hline $\mathrm{Si}$ & 51.2 & 108 & 116 & 107 \\
\hline $\mathrm{Zn}$ & 0.047 & 0.043 & 0.018 & 0.035 \\
\hline Formate & 84.4 & 72.8 & 363 & 83.7 \\
\hline Nitrate & 2190 & 2100 & 5400 & 1700 \\
\hline
\end{tabular}

Reaction of the Non-Typical Sludge Components during SRAT Processing

The SRAT cycle was visually monitored throughout testing to note any unusual observations. The SRAT process samples and products were also analyzed to monitor any changes. Gd did not impact the behavior of SRAT processing. A plot of $\mathrm{pH}$ versus SRAT processing time relative to the end of acid addition is given in Appendix C as Figure C1. The initiation of nitric acid addition is shown by the change in slope at the beginning of the run, whereas the low $\mathrm{pH}$ point on the plot indicates the end of acid addition. Very little difference was seen between the runs containing noble metals. During Run SB3-3, the pH measurements did not change much after the completion of acid addition. Towards the end of the run, it became obvious that the $\mathrm{pH}$ probe was malfunctioning. A pH measurement was made on the final product using a $\mathrm{pH}$ meter in another lab after the product cooled to room temperature. Although the final $\mathrm{pH}$ was much lower, it is expected that the second half of the $\mathrm{pH}$ curve would have followed trends similar to the other runs. The lower final $\mathrm{pH}$ is consistent with the runs performed with simulated SB3 and precipitated Pu/Gd slurry when no noble metals were added [10]. The data for the portion of the run where the operability of the $\mathrm{pH}$ probe is in question is not included in Figure C1. When Runs SB3-2 and SB3-4 were compared, no real difference in measured pH was seen. Therefore, the results did not indicate that any adverse reactions were occurring during SRAT processing due to the presence of Gd. Preliminary results also showed that the sand and coal did not impact the SRAT product pH during processing.

\section{Hydrogen Generation}

As mentioned above, the offgas from each run was monitored using a GC. Figure 2 shows the hydrogen generation for the runs scaled to DWPF parameters. The run with only Gd and no noble metals (SB3-3) did not have any appreciable hydrogen generated. Significant levels of hydrogen were generated during runs with sand and coal and the noble metals. The DWPF hydrogen limit was approached for Run SB3-4. Although a small difference in hydrogen peak level was seen between Runs SB3-2 and SB3-4 (no Gd vs Gd), it is believed to be not attributed to the presence of Gd, but rather to a reproducibility affect on the data since no hydrogen was generated when only $\mathrm{Gd}$ was present. During the runs, noble metals alone (SB3-1) had a much lower peak level of hydrogen generated and the timing of the peak was also shifted compared to runs containing sand and coal (SB3-2 \& SB3-4). It is believed that the coal was the species promoting the reaction, and the mechanisms for increased hydrogen generation are being investigated as part of SB3 investigations.

The GC data for the monitored gases are given in Appendix D as Figures D1 through D4. For Run SB3-1, problems with obtaining oxygen data occurred after the end of acid addition, so the data points were omitted from Figure D1. No problems were encountered with GC data from Runs SB3-2, SB3-3, and SB3-4. Similar trends were seen in all of the runs, with the data from Run SB3-3 being the least like the others due to the lack of noble metals. All plots showed a peak in carbon dioxide to complement a large drop in nitrogen concentration at the beginning of the runs. These peaks reflect the changeout from the nitric acid to the formic acid auto feeders. Two significant peaks of nitrous oxide 
occurred just after the end of acid addition in all of the runs with noble metals. For the run without noble metals, it was only a single peak. A peak in nitrous oxide was also seen just before the maximum hydrogen peak with another set of nitrous oxide double peaks after the hydrogen peak. For the run without sand and coal (SB3-1), the largest volume percent nitrous oxide was generated before the hydrogen peak, whereas it occurred after the hydrogen peak in the runs with sand and coal (SB3-2 and SB3-4). A small peak in carbon dioxide was also seen when the hydrogen peaked.

Figure 2 - Hydrogen Generation for Runs SB3-1 to SB3-4

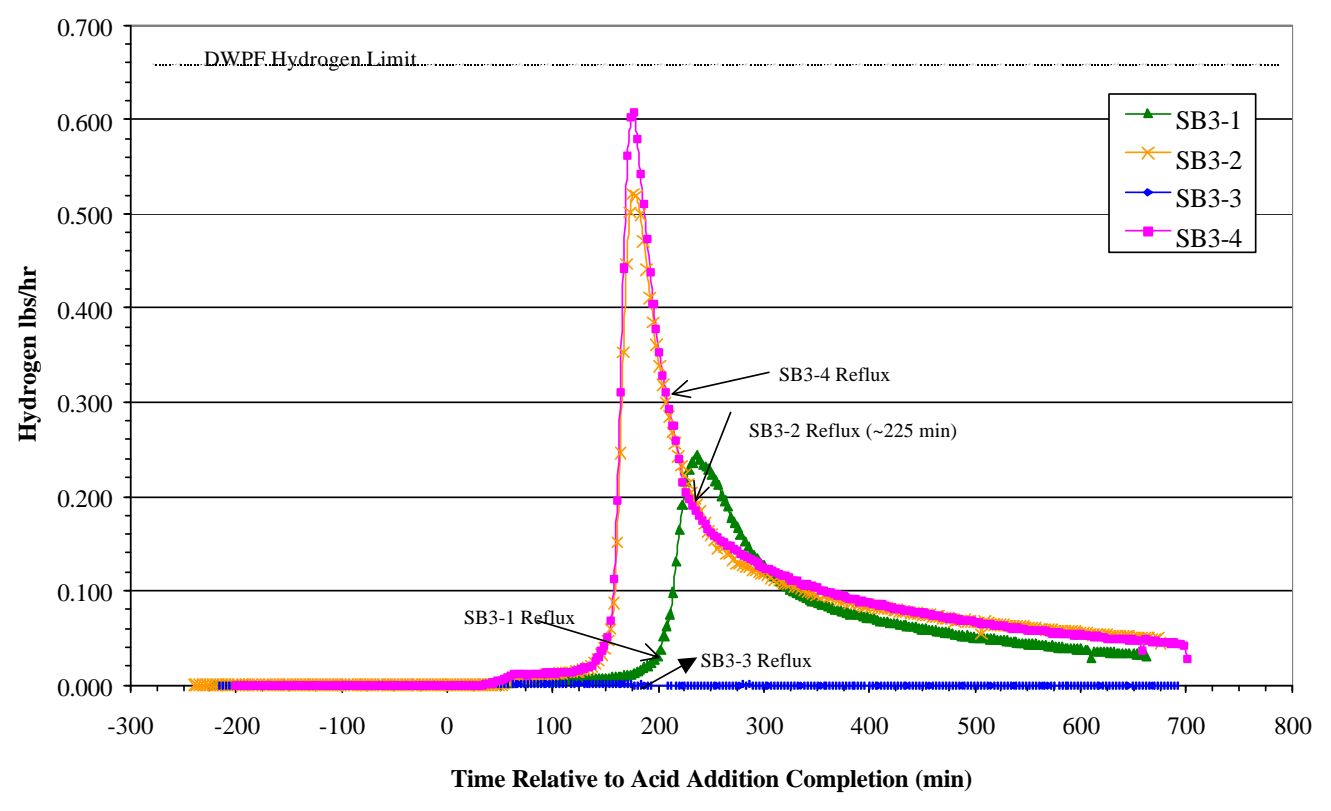

Ammonia Generation

Samples from the SMECT and MWWT were submitted for ammonium ion analyses. The ammonium ion was not detected in the SMECT samples. For the MWWT samples, small levels of ammonium were detected in samples from Runs SB3-1, SB3-2, and SB3-4. However, no appreciable difference was seen in the amounts found in Run SB3-4 containing Gd compared to Run SB3-2 without Gd. For Run SB3-3 containing Gd but no noble metals, no ammonium ion was detected. These results support the expectation of minimal impact on ammonia generation as documented in WSRC-TR-2002-00199 [11].

\section{Mercury Stripping Efficiency}

Samples of the SRAT product, the SMECT, the FAVC, and the MWWT were submitted for Hg analyses. SRAT product results for $\mathrm{Hg}$ were all less than the DWPF SRAT product limit of $0.45 \mathrm{wt} \%$. Mercury removal efficiency was not impacted by the presence of Gd. No differences were seen in the Hg content in the SMECT, FAVC, or MWWT that could be related to the presence of $\mathrm{Gd}$.

\section{SRAT Redox Impact}

The SRAT slurry process samples from throughout the runs and the SRAT product were analyzed for anion concentration to monitor the redox of the slurry. Table 4 presents the results of the anion analyses for nitrite, nitrate, and formate in the SRAT process samples and the SRAT product. The sample ID indicates the point in the process where the sample was taken relative to the end of acid addition. A column is also included in the table showing the time of sample collection relative to the end of acid addition. Nitrite was destroyed at the slowest rate when the run did not contain noble metals (Run SB3-3). In the presence of sand, coal, and the noble metals, Gd did not appear to impact nitrite destruction. Formate levels were generally higher for the run with Gd and no noble metals (Run SB3-3) than the runs containing noble metals. The formate level was also increasing during this run compared to the slight decrease in the formate levels seen for the runs containing noble metals and sand and coal (SB3-2 and SB3-4). No real difference was seen in nitrate concentrations for the four runs. Based on the available data, Gd did not impact redox. 
Table 4 - Anion Data for Runs SB3-1 to SB3-4 (ppm)

\begin{tabular}{|c|c|c|c|c|c|}
\hline \multirow{3}{*}{ Run ID } & Sample ID & $\begin{array}{c}\text { Time Relative } \\
\text { to End of Acid } \\
\text { Addition (min) }\end{array}$ & NO $_{2}$ & NO $_{\mathbf{3}}$ & $\mathbf{H C O}_{\mathbf{2}}$ \\
\hline \multirow{4}{*}{ SB3-1 } & IC-0 & 5 & 3386 & 10373 & 19348 \\
\cline { 2 - 6 } & IC-1 & 203 & $<100$ & 14746 & 19951 \\
\cline { 2 - 6 } & IC-2 & 325 & $<100$ & 14268 & 19132 \\
\cline { 2 - 6 } & IC-4 & 445 & $<100$ & 14322 & 20724 \\
\cline { 2 - 6 } & Product & N/A & $<100$ & 13600 & 20600 \\
\hline \multirow{4}{*}{ SB3-2 } & IC-0 & 5 & 2476 & 11294 & 20524 \\
\cline { 2 - 6 } & IC-1 & 260 & $<100$ & 14567 & 21850 \\
\cline { 2 - 6 } & IC-2 & 345 & $<100$ & 14495 & 20336 \\
\cline { 2 - 6 } & IC-4 & 465 & $<100$ & 14891 & 19926 \\
\cline { 2 - 6 } & Product & N/A & $<100$ & 14100 & 19700 \\
\hline & IC-0 & 9 & 3039 & 12372 & 23768 \\
\cline { 2 - 6 } & IC-1 & 193 & 327 & 14269 & 24398 \\
\cline { 2 - 6 } & IC-2 & 314 & 212 & 14557 & 23140 \\
\cline { 2 - 6 } & IC-4 & 434 & $<100$ & 13360 & 23135 \\
\cline { 2 - 6 } & Product & N/A & $<100$ & 14300 & 25600 \\
\hline \multirow{4}{*}{ SB3-4 } & IC-0 & 2 & 2829 & 11643 & 21980 \\
\cline { 2 - 6 } & IC-1 & 197 & $<100$ & 15313 & 22860 \\
\cline { 2 - 6 } & IC-2 & 317 & $<100$ & 15922 & 20333 \\
\cline { 2 - 6 } & IC-4 & 432 & $<100$ & 15064 & 21025 \\
\cline { 2 - 6 } & Product & N/A & $<100$ & 14500 & 19400 \\
\hline
\end{tabular}

Foam Evolution

SRAT runs were monitored throughout the process for evolution of foam or changes to slurry behavior during processing. Antifoam was added during heat-up and after acid addition per the run plan, but no additional antifoam was required. The behavior of the slurry material during SRAT processing was consistent, with no noticeable changes between runs and no significant foaming seen.

\section{Gd Solubility}

The SRAT product was analyzed to determine if Gd solubility would be an issue during processing or analyses. As mentioned above, no problems with Gd were seen during chemical composition analyses. Therefore, Gd solubility is not expected to be a problem. The SRAT product was analyzed for Gd concentration and $0.075 \mathrm{wt} \%$ was detected in the calcined product. The amount added was equivalent to $0.076 \mathrm{wt} \% \mathrm{Gd}$ in the calcined product. Therefore, retaining the Gd in the slurry did not appear to be a problem.

\section{Rheology Changes}

No processing issues were noted during testing that would presumably be linked to differences in rheological properties. Small amounts of bubbles were seen on the slurry surface after acid addition in all of the runs. However, the bubbles caused no significant disturbance or volume change. The rheological properties of the SRAT products were measured by ITS. The methods used were briefly described in section 4.0 and more details are given in Appendix B. The raw rheogram data for the products from Runs SB3-1 through SB3-4 are given as part of Appendix B. Appendix B also provides an in-depth discussion of testing with the baseline sludge material.

Figure 3 plots a portion of a down ramp flow curve from each of the four SRAT products in the region free of Taylor vortices. Results of a Bingham plastic model fit to the data from about $20 \mathrm{sec}^{-1}$ to the upper limits shown in Figure 3 are given in Table 5.

The differences between the components of SB3-2 and SB3-4 were insignificant rheologically (noble metals, sand, and coal without and with Gd). The two most apparent conclusions that can be made from Table 5 were: 
- Adding noble metals led to a more viscous SRAT product compared to the less viscous SRAT product when noble metals were not present. It is understood that noble metals promote formate destruction, leading to an altered SRAT product with a higher $\mathrm{pH}$, and that SRAT products become more viscous as the $\mathrm{pH}$ moves toward intermediate values. This helped to explain why SB3-3, with no noble metals, was the least viscous SRAT product.

- Addition of sand and coal correlated with less viscous SRAT products. It is less clear how the introduction of additional solids (sand and coal) led to a decrease in the viscous nature of the last three SRAT products relative to SB3-1 (no sand and coal).

Figure 3 - Composite Plot of SRAT Product Rheograms

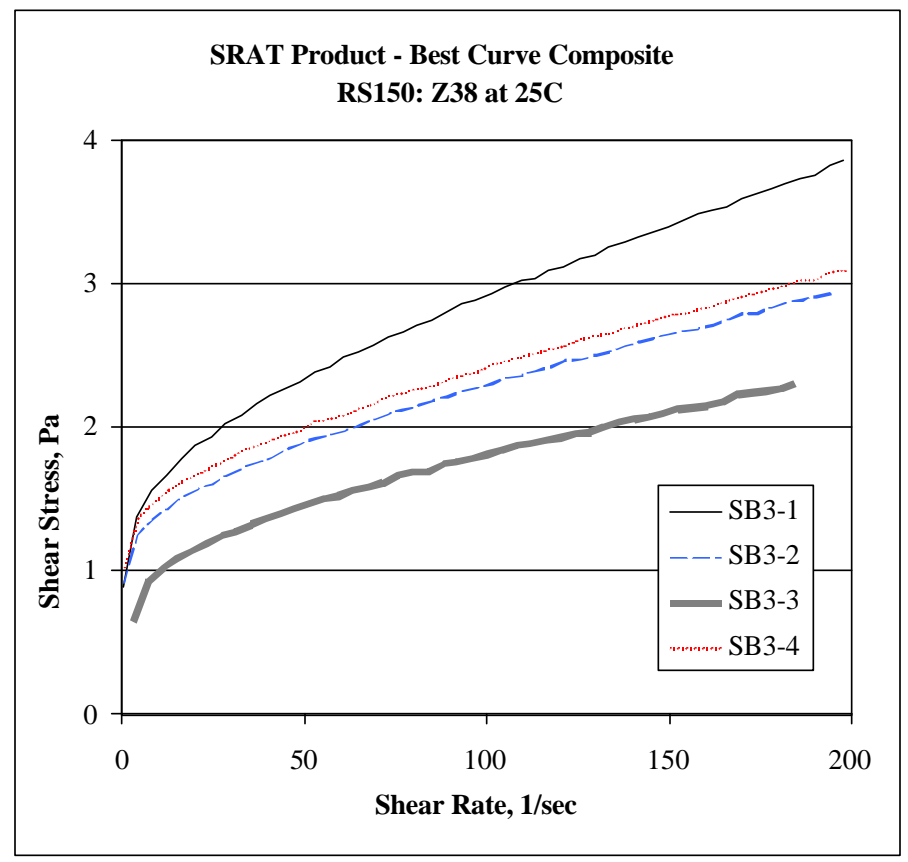

Table 5 - Bingham Plastic Model Fit Data for SB3-1 to SB3-4

\begin{tabular}{|c|c|c|c|c|c|}
\hline Run & $\begin{array}{c}\text { Yield Stress, } \\
\text { dynes/cm }\end{array}$ & $\begin{array}{c}\text { Plastic Viscosity, } \\
\text { cP }\end{array}$ & $\begin{array}{c}\text { Wt. \% } \\
\text { Total Solids }\end{array}$ & $\begin{array}{c}\text { Wt. \% Insoluble } \\
\text { Solids }\end{array}$ & pH \\
\hline SB3-1 & 18 & 10.6 & 18.5 & 13.7 & 7.81 \\
\hline SB3-2 & 15 & 7.6 & 18.7 & 13.9 & 7.70 \\
\hline SB3-3 & 12 & 6.6 & 20.0 & 14.2 & 5.79 \\
\hline SB3-4 & 16 & 7.7 & 18.9 & 14.1 & 7.52 \\
\hline
\end{tabular}

Visual observation of the SRAT samples during testing indicated that the SB3-3 samples had far fewer bubbles after shaking than the samples from the other three runs. Observations also indicated the presence of persistent bubbles in many of the samples. The difference in behavior can more likely be attributed to the absence of noble metals versus the presence of $\mathrm{Gd}$.

Based on the testing performed, the presence of Gd did not appear to impact the rheology of the SRAT process or product as evidenced mostly by the comparison of SB3-2 and SB3-4 observations and data. A general conclusion of the testing with respect to SB3 samples was that down ramp data generally agreed better for a given pair of equivalent SRAT product samples than up ramp data. With respect to the presence of sand and coal, an occasional observation was made of some particulates on the bottom of the beaker after a measurement. Settled solids were also noticed in the sample bottles, but were fairly readily redispersed by vigorous shaking and did not appear to be gelling or caking. 
$\underline{\text { SRAT Product Acceptability }}$

Nitrite destruction and mercury stripping efficiency were discussed above. The chemical composition and solids content of the SRAT products were also analyzed to determine the impacts of the Gd. Results of the analyses are shown in Table 6. Overall, no real differences in SRAT product compositions were seen from run to run. Run SB3-3 had the highest measured concentration of $\mathrm{Na}_{2} \mathrm{O}$ in the product, while Run SB3-2 had the highest measured $\mathrm{SiO}_{2}$ content. For $\mathrm{Na}_{2} \mathrm{O}$, Run SB3-3 most closely met the target calcined $\mathrm{Na}_{2} \mathrm{O}$ content of $\sim 9 \mathrm{wt} \%$. No explanation for the difference was found in the data. For $\mathrm{SiO}_{2}$, the elevated $\mathrm{SiO}_{2}$ may be the result of uneven distribution of the sand particles in the SRAT product. Runs SB3-3 and SB3-4 were actually $\sim 1 \mathrm{wt} \%$ lower than the target $\mathrm{SiO}_{2}$ level for the trimmed sludge, which was once again likely due to the problems with keeping the sand particles suspended in the slurry and obtaining representative samples of the slurry with the sand. When compared to the composition of the trimmed calcined sludge, $\mathrm{BaO}, \mathrm{CaO}$, and $\mathrm{ZrO}_{2}$ were also slightly lower than anticipated. Solids content of the SB3-3 product was slightly higher than the solids content of the products from the other runs; however, no difference in solids content was seen between Runs SB3-2 and SB3-4 that contained noble metals and the exact explanation for this difference is not known. The calcined solids content was consistent between the runs. Based on the results of the four tests, Gd is not believed to impact SRAT Product Acceptability. The preliminary results also do not suggest any impacts of product acceptability from the presence of sand and coal.

Table 6 - Runs SB3-1 to SB3-4 SRAT Product Results

\begin{tabular}{|c|c|c|c|c|}
\hline & SB3-1 & SB3-2 & SB3-3 & SB3-4 \\
\hline Oxide & Calcined wt\% & Calcined wt\% & Calcined wt\% & Calcined wt\% \\
\hline $\mathrm{Al}_{2} \mathrm{O}_{3}$ & 23.4 & 21.9 & 23.2 & 23.1 \\
\hline $\mathrm{BaO}$ & 0.358 & 0.346 & 0.355 & 0.354 \\
\hline $\mathrm{CaO}$ & 3.12 & 2.97 & 3.32 & 3.16 \\
\hline $\mathrm{CeO}_{2}$ & $<0.022$ & $<0.022$ & $<0.022$ & $<0.022$ \\
\hline $\mathrm{Cr}_{2} \mathrm{O}_{3}$ & 0.464 & 0.431 & 0.467 & 0.461 \\
\hline $\mathrm{CuO}$ & 0.214 & 0.179 & 0.220 & 0.191 \\
\hline $\mathrm{Fe}_{2} \mathrm{O}_{3}$ & 47.8 & 45.4 & 46.9 & 47.5 \\
\hline $\mathrm{Gd}_{2} \mathrm{O}_{3}$ & $<0.010$ & $<0.010$ & 0.086 & 0.086 \\
\hline $\mathrm{K}_{2} \mathrm{O}$ & $<0.220$ & $<0.220$ & $<0.220$ & $<0.220$ \\
\hline $\mathrm{La}_{2} \mathrm{O}_{3}$ & $<0.020$ & $<0.020$ & $<0.020$ & $<0.020$ \\
\hline $\mathrm{MgO}_{\mathrm{MnO}}$ & 0.208 & 0.291 & 0.216 & 0.237 \\
\hline $\mathrm{Na}_{2} \mathrm{O}$ & 4.64 & 4.35 & 4.17 & 4.49 \\
\hline $\mathrm{NiO}_{\mathrm{PbO}}$ & 7.97 & 7.84 & 9.41 & 7.55 \\
\hline $\mathrm{SiO}$ & 4.71 & 4.43 & 4.67 & 4.67 \\
\hline $\mathrm{ZnO}$ & 0.175 & 0.165 & 0.171 & 0.170 \\
\hline $\mathrm{ZrO} O_{2}$ & 2.57 & 4.94 & 2.63 & 2.97 \\
\hline $\mathrm{Total}$ & 0.331 & 0.300 & 0.334 & 0.326 \\
\hline & 0.622 & 0.760 & 0.771 & 0.736 \\
\hline Total Solids \% & 18.621 & 94.338 & 96.967 & 96.043 \\
\hline Insoluble Solids \% & 13.65 & & & \\
\hline Soluble Solids \% & 4.85 & 18.7 & 19.95 & 18.9 \\
\hline Calcined Solids & 14.2 & 14.2 & 14.2 & 14.1 \\
\hline & & & 5.79 & 4.825 \\
\hline
\end{tabular}




\subsection{Solubility Studies - Runs SB3-5 through SB3-8}

The main objective of the solubility studies was to monitor the solubility of $\mathrm{Fe}, \mathrm{Gd}, \mathrm{Sm}$, and oxalate during and after completion of SRAT processing. This information will help DWPF determine if criticality will be an issue, especially with regards to formation of tris-oxalato iron complexes. The main difference between Runs SB3-5 through SB3-8 compared to the Runs SB3-1 through SB3-4 was the presence of sodium oxalate. Two baseline levels of oxalate were studied; $50 \%$ and $75 \%$ sodium oxalate removed. Data from SB3-1 and SB3-4 were used to represent 0\% sodium oxalate cases. Since it is anticipated that washing to at least a $50 \%$ level will be performed, higher levels of sodium oxalate were not tested. During the runs, hydrogen generation, foaming, slurry $\mathrm{pH}$, and nitrite destruction were also monitored to help determine the impact of oxalate on the process.

Due to the relatively poor nitrite destruction seen in Run SB3-5, Runs SB3-7 and SB3-8 were run with higher acid to try to destroy the nitrites in the SRAT feed. SB3-8 also contained sand and coal since they were shown to have an impact on SRAT processing during the first set of runs.

\section{$\underline{\text { Solubility data }}$}

Samples were taken throughout the four runs for supernate cation and slurry anion analysis. Table E1 in Appendix E presents the results from the analyses of the supernate samples. SRAT product supernate results are also given in Appendix E as Table E2. Table E1 indicates the sample IDs, the time the samples were taken relative to the end of acid addition, and the pH of the SRAT slurry at the time of sampling. Samples were also taken during Runs SB3-7 and SB38 immediately after the SRAT vessels reached $93^{\circ} \mathrm{C}$ and are identified as "Initial" in the table. As reported in Table E2, iron was only detected in product supernate for Runs SB3-7 and SB3-8, and Gd was only detected in the product from Run SB3-3.

Table 7 contains the Fe and Gd supernate data from Runs SB3-5 through SB3-8. In this table, data is reported as the fraction of the total available $\mathrm{Fe}$ and $\mathrm{Gd}$ dissolved. The values were obtained as follows:

1. The grams of supernate in the sampled SRAT slurry were calculated based on the insoluble solids concentration and the mass of slurry available at the time of sampling.

2. The grams of supernate were multiplied by the Fe concentration in the supernate in ppm to give grams of Fe in the supernate.

3. The grams of Fe available for dissolving were calculated by multiplying the total mass of slurry available by the total solids, the ratio of the calcined to total solids, and the Fe concentration in the calcined solids.

4. The ratio of dissolved Fe was then calculated based on the grams of $\mathrm{Fe}$ in the supernate (step 2) divided by the total grams of Fe available (step 3).

The same method was followed for calculating the amount of Gd dissolved. Results were not available for SB3-5 and SB3-6 for the "Initial", "ICP-0", and "ICP-12" samples. The "Initial" and "ICP-12" samples were not taken in the SB35 and SB3-6 runs, and analytical problems were encountered with the "ICP-0" samples so no data was available. These calculations were not necessary for Sm since it was below the detection limit in all supernate samples. 
Table 7 - Fraction of Fe and Gd Dissolved during SRAT Processing

\begin{tabular}{|c|c|c|c|c|c|c|c|c|c|c|c|}
\hline Run & $\begin{array}{c}\text { Sample } \\
\text { ID }\end{array}$ & Initial & ICP-0 & ICP-1 & ICP-2 & ICP-4 & ICP-6 & ICP-8 & ICP-10 & ICP-12 & Product $^{3}$ \\
\hline \multirow{4}{*}{ SB3-5 } & $\begin{array}{l}\text { Time } \\
(\min )^{1}\end{array}$ & N/A & 20 & 201 & 320 & 425 & 553 & 673 & 743 & N/A & 744 \\
\hline & $\mathrm{pH}^{2}$ & N/A & 6.06 & 6.88 & 7.03 & 7.12 & 7.22 & 7.30 & 7.35 & N/A & 8.20 \\
\hline & $\begin{array}{c}\text { Fraction } \\
\text { Fe } \\
\text { Dissolved }\end{array}$ & N/A & N/A & $2.67 \mathrm{E}-4$ & $1.84 \mathrm{E}-4$ & $1.36 \mathrm{E}-4$ & $9.02 \mathrm{E}-5$ & $9.23 \mathrm{E}-5$ & $2.11 \mathrm{E}-4$ & N/A & $<9.11 \mathrm{E}-7$ \\
\hline & $\begin{array}{c}\text { Fraction } \\
\text { Gd } \\
\text { Dissolved }\end{array}$ & N/A & N/A & $3.25 \mathrm{E}-2$ & $3.36 \mathrm{E}-2$ & $2.65 \mathrm{E}-2$ & $2.26 \mathrm{E}-2$ & $1.94 \mathrm{E}-2$ & $2.06 \mathrm{E}-2$ & N/A & $<2.55 \mathrm{E}-3$ \\
\hline \multirow{4}{*}{ SB3-6 } & $\begin{array}{l}\text { Time } \\
(\text { min })^{1}\end{array}$ & N/A & 12 & 193 & 313 & 429 & 548 & 670 & 743 & N/A & 750 \\
\hline & $\mathbf{p H}^{2}$ & N/A & 4.84 & 6.35 & 6.56 & 6.79 & 6.99 & 7.21 & 7.39 & N/A & 8.31 \\
\hline & $\begin{array}{c}\text { Fraction } \\
\text { Fe } \\
\text { Dissolved }\end{array}$ & N/A & N/A & $<5.74 \mathrm{E}-7$ & $<5.74 \mathrm{E}-7$ & $<5.74 \mathrm{E}-7$ & $<5.74 \mathrm{E}-7$ & $<5.74 \mathrm{E}-7$ & $<5.74 \mathrm{E}-7$ & N/A & $<5.74 \mathrm{E}-7$ \\
\hline & $\begin{array}{c}\text { Fraction } \\
\text { Gd } \\
\text { Dissolved }\end{array}$ & N/A & N/A & $<2.57 \mathrm{E}-3$ & $<2.57 \mathrm{E}-3$ & $<2.57 \mathrm{E}-3$ & $<2.57 \mathrm{E}-3$ & $<2.57 \mathrm{E}-3$ & $<2.57 \mathrm{E}-3$ & N/A & $<2.57 \mathrm{E}-3$ \\
\hline \multirow{4}{*}{ SB3-7 } & $\begin{array}{l}\text { Time } \\
(\min )^{1}\end{array}$ & -215 & 11 & 107 & 190 & 318 & 431 & 731 & 671 & 751 & 755 \\
\hline & $\mathbf{p H}^{2}$ & 4.53 & 4.68 & 5.72 & 6.11 & 6.32 & 6.45 & 6.56 & 6.63 & 6.71 & 7.65 \\
\hline & $\begin{array}{c}\text { Fraction } \\
\text { Fe } \\
\text { Dissolved }\end{array}$ & $<7.59 \mathrm{E}-7$ & $5.59 \mathrm{E}-3$ & $1.05 \mathrm{E}-3$ & $5.13 \mathrm{E}-4$ & $3.74 \mathrm{E}-4$ & $2.60 \mathrm{E}-4$ & $2.21 \mathrm{E}-4$ & $1.50 \mathrm{E}-4$ & $1.87 \mathrm{E}-4$ & $5.61 \mathrm{E}-5$ \\
\hline & $\begin{array}{c}\text { Fraction } \\
\text { Gd } \\
\text { Dissolved }\end{array}$ & $<3.63 \mathrm{E}-3$ & $6.15 \mathrm{E}-3$ & $1.03 \mathrm{E}-2$ & $1.72 \mathrm{E}-2$ & $2.11 \mathrm{E}-2$ & $2.58 \mathrm{E}-2$ & $2.74 \mathrm{E}-2$ & $2.87 \mathrm{E}-2$ & $1.01 \mathrm{E}-2$ & $<3.63 \mathrm{E}-3$ \\
\hline \multirow{4}{*}{ SB3-8 } & $\begin{array}{l}\text { Time } \\
(\min )^{1}\end{array}$ & -201 & 8 & 102 & 185 & 307 & 410 & 532 & 652 & 726 & 735 \\
\hline & $\mathbf{p H}^{\prime 2}$ & 9.44 & 4.52 & 5.92 & 6.24 & 6.37 & 6.50 & 6.61 & 6.73 & 6.78 & 7.81 \\
\hline & $\begin{array}{c}\text { Fraction } \\
\text { Fe } \\
\text { Dissolved } \\
\end{array}$ & $<7.46 \mathrm{E}-7$ & $5.84 \mathrm{E}-3$ & 7.16E-4 & $3.93 \mathrm{E}-4$ & $3.41 \mathrm{E}-4$ & $1.93 \mathrm{E}-4$ & $1.40 \mathrm{E}-4$ & $1.02 \mathrm{E}-4$ & $1.99 \mathrm{E}-4$ & $1.12 \mathrm{E}-5$ \\
\hline & $\begin{array}{c}\text { Fraction } \\
\text { Gd } \\
\text { Dissolved }\end{array}$ & $<3.67 \mathrm{E}-3$ & $5.20 \mathrm{E}-3$ & $1.18 \mathrm{E}-2$ & $2.09 \mathrm{E}-2$ & $2.04 \mathrm{E}-2$ & $2.31 \mathrm{E}-2$ & $2.50 \mathrm{E}-2$ & $2.37 \mathrm{E}-2$ & $5.12 \mathrm{E}-3$ & $<3.67 \mathrm{E}-3$ \\
\hline
\end{tabular}

${ }^{1}$ Elapsed Time from End of Acid Addition

${ }^{2} \mathrm{pH}$ as measured during processing without temperature correction.

${ }^{3}$ Sample taken after product cooled to room temperature.

The solubility of Fe and Gd were both affected by the amount of oxalate present in the feed. For the $25 \%$ sodium oxalate remaining test, no $\mathrm{Fe}$ or $\mathrm{Gd}$ was dissolved within the detection limits. The fractions of $\mathrm{Fe}$ and $\mathrm{Gd}$ dissolved during SRAT processing are given in Figures 4 and 5. Corresponding pH plots for the runs are given in Appendix $\mathrm{C}$ as Figure C2. Figure 4 shows that the largest amount of Fe was dissolved when the SRAT process was at the minimum $\mathrm{pH}$ (i.e., the end of acid addition). After concentration was completed, the fraction of Fe dissolved remained relatively constant and at a low level. For Gd, the opposite response was seen after concentration. Gd continued to dissolve even as $\mathrm{pH}$ rose. The level of dissolved $\mathrm{Gd}$ after concentration was completed remained relatively high compared to the fraction of Fe dissolved. Overall, the amounts dissolved were negligible compared to the amount present in the sludge. In all cases, the "Product" samples, which were taken after the SRAT product cooled to room temperature, contained less soluble Fe and Gd than samples taken at the end of the SRAT process while the contents were at boiling. 
Figure 4 - Fraction of Fe Dissolved during SRAT Processing

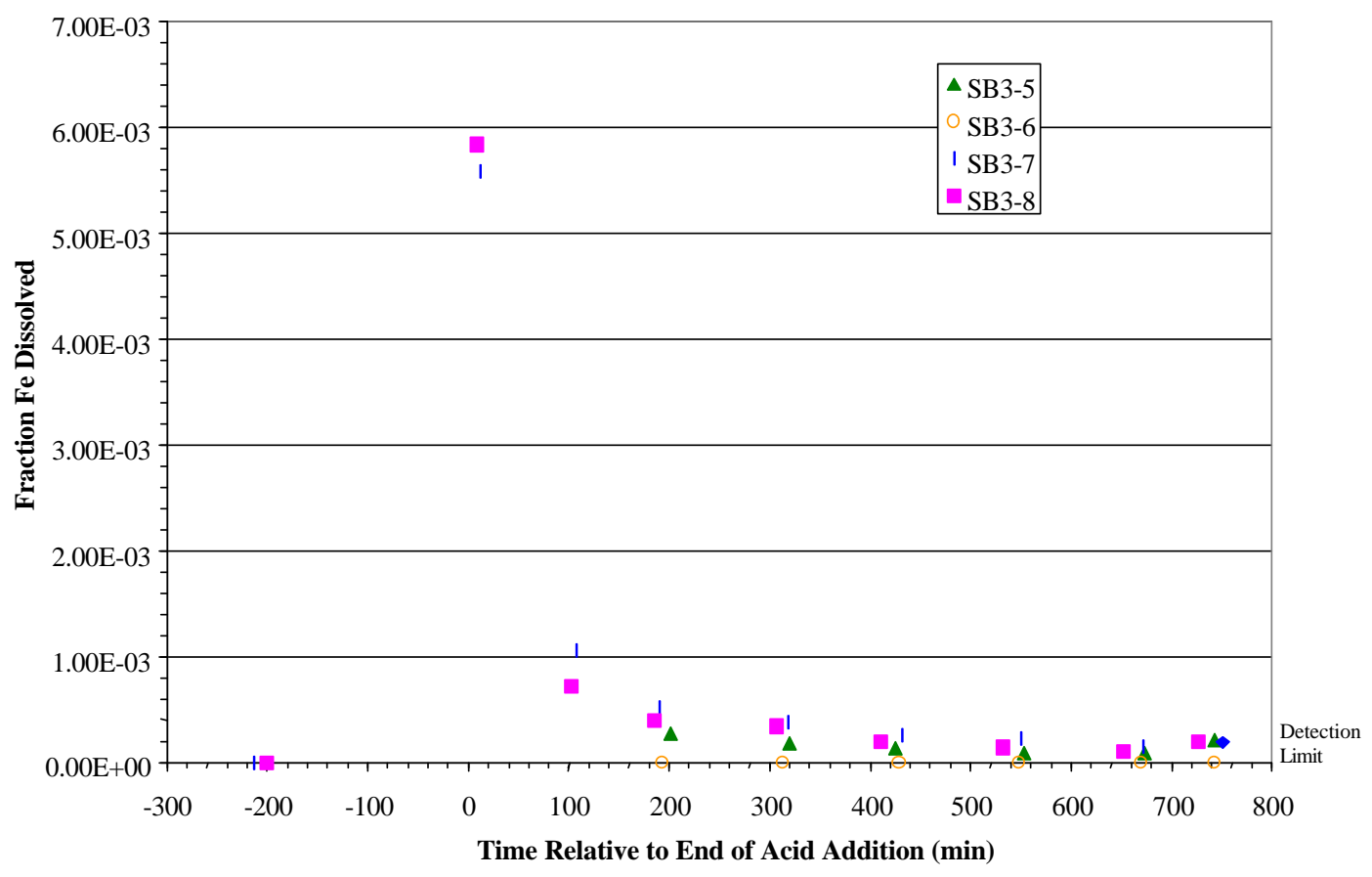

Figure 5 - Fraction of Gd Dissolved during SRAT Processing

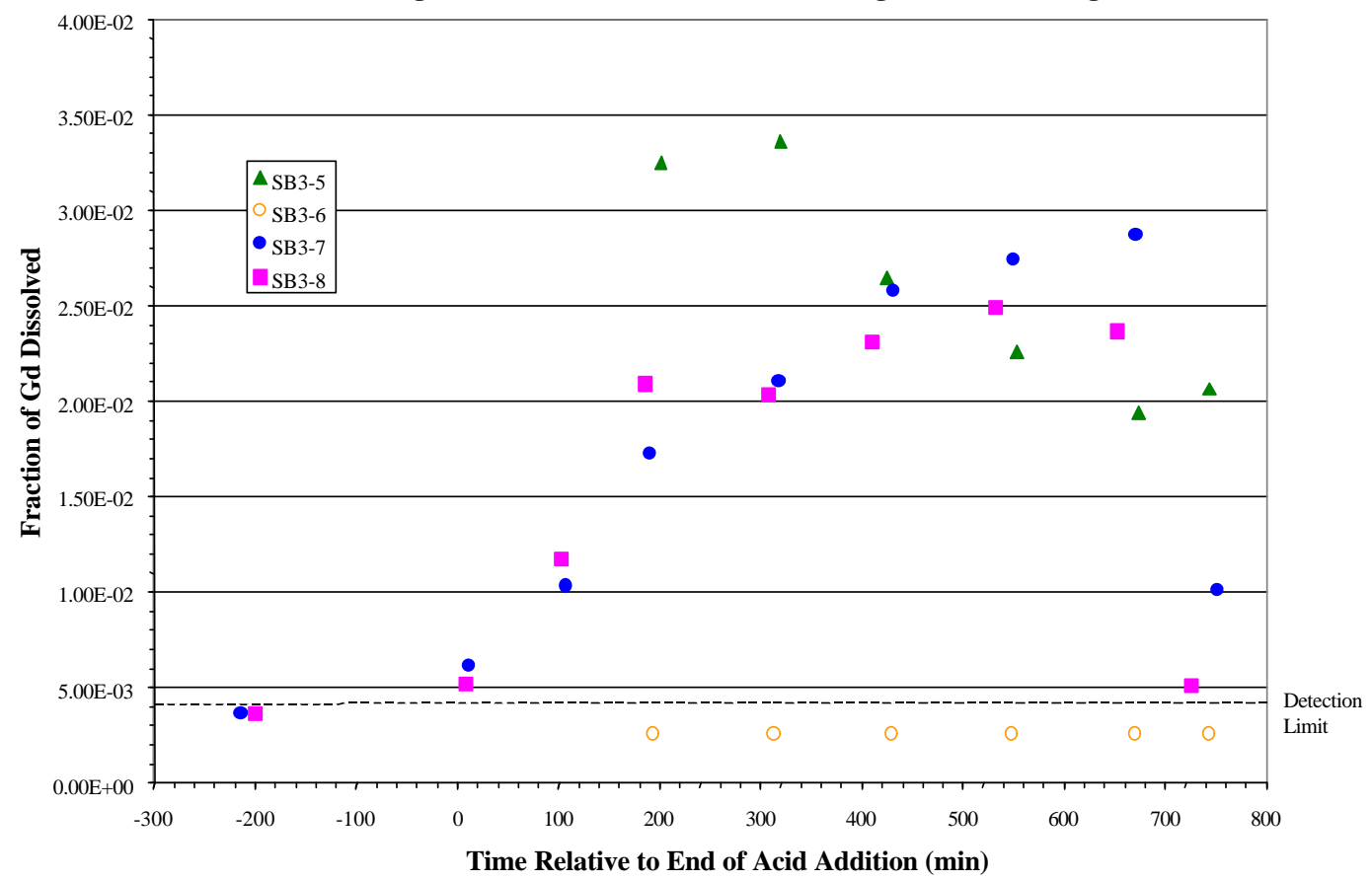


The products from Runs SB3-5 through SB3-8 were filtered and the supernate was analyzed for oxalate concentration. The concentrations of the products are given in Table 8. Only a fraction of the sodium oxalate added was found in the final supernate product. For the three tests at $50 \%$ oxalate, roughly 25 to $30 \%$ of the oxalate added was detected in the supernate. For the Run SB3-6 at 25\% oxalate, approximately $15 \%$ of the total oxalate was detected in the supernate.

\section{Table 8 - Oxalate Concentration in the Product Supernate}

\begin{tabular}{|c|c|}
\hline Run ID & Oxalate (mg/L) \\
\hline SB3-5 & 19900 \\
\hline SB3-6 & 2180 \\
\hline SB3-7 & 10500 \\
\hline SB3-8 & 10000 \\
\hline
\end{tabular}

XRD was performed on the solids remaining after centrifuging for Runs SB3-7 and SB3-8. Two distinct layers were found; the lower layer was light brown and the upper was dark brown. In the light brown layer, $\mathrm{ZrO}_{2}, \mathrm{SiO}_{2}, \mathrm{BaSO}_{4}$, and hydrated iron and calcium oxalate compounds were identified. The dark brown layer contained aluminum hydroxide and magnetite $\left(\mathrm{Fe}^{2+} \mathrm{Fe}^{3+}{ }_{2} \mathrm{O}_{4}\right)$.

\section{Oxalate Processing Effects}

As with the other four SRAT tests, the $\mathrm{pH}$ was monitored throughout the SRAT runs. Figure C2 in Appendix C contains the $\mathrm{pH}$ data for this set of four runs, while Figure $\mathrm{C} 3$ contains the $\mathrm{pH}$ data for all eight of the SRAT runs reported. These plots show the affect that sodium oxalate had on SRAT processing. During acid addition, the $\mathrm{pH}$ was higher for all runs containing oxalate than the runs made without oxalate. After the end of acid addition, the measured pH of Runs SB3-5 and SB3-6 were higher than any of the other runs. When higher acid amounts were added to try to destroy additional nitrite (SB3-7 \& SB3-8), pH measurements were similar to those seen in the runs with noble metals and without oxalate.

No appreciable amounts of hydrogen were generated during any of the runs with oxalate. Even Run SB3-8, which had equivalent levels of sand and coal to those tested in SB3-2 and SB3-4, did not have any appreciable amounts of hydrogen generated. The GC data from Runs SB3-5 through SB3-8 are plotted in Appendix D as Figures D5 through D8, respectively. For Run SB3-5, problems with obtaining oxygen and carbon dioxide data occurred during acid addition, so the data points were omitted from Figure D5. Problems were also encountered with the GC instrument during the beginning of Run SB3-6, so this data has been omitted from Figure D6. Run SB3-7 also had problems obtaining helium and hydrogen data for a $1 / 2$ hour near the end of the run, so the problematic data was omitted from Figure D7. No problems were encountered with GC data from Run SB3-8. Similar trends were seen in all of the runs. All plots showed a peak in carbon dioxide to complement a large drop in nitrogen concentration at the beginning of the runs. These peaks reflect the changeout from the nitric acid to the formic acid auto feeders. A significant peak of nitrous oxide occurred during concentration in all of the runs. Two very late surges in nitrous oxide were also seen towards the end of boiling in Runs SB3-6 and SB3-8. Run SB3-6 had the largest volume percent nitrous oxide generated, approximately twice as high as the other runs.

No appreciable foaming was seen in the runs during processing. However, the two runs with higher acid additions (SB3-7 and SB3-8) had significantly more bubbles generated during boiling. The SB3-8 slurry also had a significant volume expansion just after the completion of acid addition. During this expansion, a black material believed to be coal was seen wicking onto the agitator shaft. It then remained on the surface near the shaft for a few minutes before floating around the top of the surface near the vessel walls for the remainder of the run. The volume expansion lasted for about an hour after acid addition completion and equated to an increase in volume of approximately 20\%. No additional antifoam was deemed necessary.

The SRAT products were analyzed in duplicate and the results are presented in Table 9. Some difficulties were found when the products from Runs SB3-7 and SB3-8 were calcined to perform ICP-AES analyses. Three different calcination temperatures were used, which were 900,1000 , and $1100^{\circ} \mathrm{C}$, and the higher temperature gave the best recovery on a sum of oxides basis. Therefore, the data from Runs SB3-7 and SB3-8 are reported from the calcination at $1100^{\circ} \mathrm{C}$, while the data from Runs SB3-5 and SB3-6 are reported from calcinations performed at $900^{\circ} \mathrm{C}$. Compared to the target compositions for the slurry, the major sludge oxides were slightly higher. Analyses of $\mathrm{SiO}_{2}$ had the same problems as Runs SB3-1 to SB3-4. 
Table 9 - SRAT Product Results for SB3-5 through SB3-8

\begin{tabular}{|c|c|c|c|c|}
\hline & SB3-5 & SB3-6 & SB3-7 & SB3-8 \\
\hline Oxide & Calcined wt\% & Calcined wt\% & Calcined wt\% & Calcined wt\% \\
\hline $\mathrm{Al}_{2} \mathrm{O}_{3}$ & 18.5 & 19.7 & 19.3 & 19.3 \\
\hline $\mathrm{BaO}$ & 0.301 & 0.325 & 0.285 & 0.287 \\
\hline $\mathrm{CaO}$ & 3.18 & 3.49 & 3.41 & 3.33 \\
\hline $\mathrm{CeO}_{2}$ & $<0.022$ & $<0.022$ & $<0.022$ & $<0.022$ \\
\hline $\mathrm{Cr}_{2} \mathrm{O}_{3}$ & 0.342 & 0.366 & 0.339 & 0.355 \\
\hline $\mathrm{CuO}$ & 0.167 & 0.185 & 0.126 & 0.113 \\
\hline $\mathrm{Fe}_{2} \mathrm{O}_{3}$ & 37.4 & 40.4 & 40.0 & 40.1 \\
\hline $\mathrm{Gd}_{2} \mathrm{O}_{3}$ & 0.047 & 0.048 & 0.045 & 0.044 \\
\hline $\mathrm{K}_{2} \mathrm{O}$ & 0.045 & 0.054 & 0.054 & 0.049 \\
\hline $\mathrm{La}_{2} \mathrm{O}_{3}$ & $<0.014$ & $<0.014$ & $<0.014$ & $<0.014$ \\
\hline $\mathrm{MgO}$ & 0.185 & 0.211 & 0.200 & 0.191 \\
\hline $\mathrm{MnO}$ & 3.62 & 4.02 & 3.79 & 3.82 \\
\hline $\mathrm{Na}_{2} \mathrm{O}$ & 23.0 & 15.6 & 24.0 & 24.4 \\
\hline $\mathrm{NiO}$ & 3.63 & 3.92 & 3.85 & 3.87 \\
\hline $\mathrm{PbO}$ & 0.128 & 0.151 & 0.000 & 0.000 \\
\hline $\mathrm{Sm}_{2} \mathrm{O}_{3}$ & N/A & N/A & 0.051 & 0.049 \\
\hline $\mathrm{SiO}_{2}$ & 2.01 & 2.10 & 1.94 & 1.98 \\
\hline $\mathrm{ZnO}$ & 0.348 & 0.384 & 0.390 & 0.398 \\
\hline $\mathrm{ZrO}_{2}$ & 0.692 & 0.746 & 0.684 & 0.677 \\
\hline Totals & 93.70 & 92.18 & 99.30 & 99.27 \\
\hline Total Solids \% & 23.95 & 21.55 & 19.4 & 19.35 \\
\hline Insoluble Solids \% & 14.85 & 15.3 & 11.85 & 11.75 \\
\hline Soluble Solids \% & 9.085 & 6.275 & 7.54 & 7.69 \\
\hline Calcined Solids & 16.5 & 15.7 & 13 & 12.65 \\
\hline
\end{tabular}

Table 10 provides the anion analyses of the slurry, including oxalate results, throughout the SRAT processing. These samples were spiked with sodium hydroxide to quench the reactions after sampling. The reported results are weighted dilutions and not filtered supernate results. Small differences are seen between the product oxalate results reported in Tables 8 and 10. This difference is likely due to some of the insoluble portion of the oxalate being analyzed in the IC analyses of the slurry samples instead of only the filtered supernate. The weighted dilution may have dissolved a small fraction of the oxalate solids. 
Table 10 - Anion Results for SB3-5 through SB3-8 during SRAT Processing (mg/L)

\begin{tabular}{|c|c|c|c|c|c|c|c|c|}
\hline Run & $\begin{array}{l}\text { Sample } \\
\text { ID }\end{array}$ & Time & $\mathrm{NO}_{2}$ & $\mathrm{NO}_{3}$ & $\mathrm{SO}_{4}$ & $\mathrm{HCO}_{2}$ & Cl & $\mathrm{C}_{2} \mathrm{O}_{4}$ \\
\hline \multirow{8}{*}{ SB3-5 } & IC-0 & 18 & 4885 & 10573 & 981 & 25510 & 1259 & 15306 \\
\hline & IC-1 & 201 & 5087 & 12392 & 1034 & 27066 & 1478 & 17718 \\
\hline & IC-2 & 319 & 4397 & 12824 & 1002 & 26295 & 1487 & 18213 \\
\hline & IC-4 & 425 & 4423 & 12483 & 1184 & 22383 & 1614 & 16679 \\
\hline & IC-6 & 550 & 3756 & 12305 & 1101 & 26336 & 1511 & 18349 \\
\hline & IC-8 & 670 & 3370 & 13781 & 1077 & 27669 & 1529 & 17872 \\
\hline & IC-10 & 742 & 3033 & 12285 & 985 & 25657 & 1500 & 18482 \\
\hline & Product* & 745 & 2900 & 12300 & $<100$ & 24200 & 1390 & 15300 \\
\hline \multirow{8}{*}{ SB3-6 } & IC-0 & 10 & 4403 & 10568 & 495 & 19154 & 1288 & 2092 \\
\hline & IC-1 & 190 & 1981 & 12693 & 666 & 25714 & 1576 & 2954 \\
\hline & IC-2 & 310 & 1689 & 13467 & 679 & 26824 & 1534 & 3433 \\
\hline & IC-4 & 430 & 925 & 14529 & 1735 & 25264 & 1583 & 4012 \\
\hline & IC-6 & 550 & 633 & 15232 & 661 & 25820 & 1512 & 4429 \\
\hline & IC-8 & 672 & 335 & 13782 & 1572 & 22826 & 1507 & 3887 \\
\hline & IC-10 & 741 & 108 & 14468 & 740 & 23321 & 1490 & 4265 \\
\hline & Product* & 750 & $<100$ & 12700 & $<100$ & 23800 & 1430 & 3780 \\
\hline \multirow{9}{*}{ SB3-7 } & IC-0 & 10 & 3874 & 16619 & 589 & 16839 & 1026 & 10016 \\
\hline & IC-1 & 105 & 2478 & 20484 & 109 & 17180 & 1112 & 9967 \\
\hline & IC-2 & 188 & 2005 & 21247 & 109 & 18537 & 1192 & 11491 \\
\hline & IC-4 & 315 & 1516 & 22956 & 1571 & 18123 & 1197 & 12192 \\
\hline & IC-6 & 430 & 1217 & 22431 & 719 & 18937 & 1184 & 12512 \\
\hline & IC-8 & 550 & 956 & 22393 & 778 & 18242 & 1169 & 12016 \\
\hline & IC-10 & 670 & 862 & 23058 & 717 & 18976 & 1192 & 13901 \\
\hline & IC-12 & 750 & 479 & 22855 & 688 & 15455 & 1154 & 13931 \\
\hline & Product* & 755 & 481 & 22200 & 650 & 19000 & 1100 & 11000 \\
\hline \multirow{9}{*}{ SB3-8 } & IC-0 & 6 & 3542 & 17818 & 608 & 15289 & 1012 & 10152 \\
\hline & IC-1 & 100 & 1673 & 19132 & 672 & 17710 & 1115 & 10047 \\
\hline & IC-2 & 185 & 1331 & 21426 & 704 & 19586 & 1234 & 11795 \\
\hline & IC-4 & 305 & 949 & 23058 & 1650 & 17813 & 1333 & 12130 \\
\hline & IC-6 & 410 & 797 & 24344 & 1695 & 18693 & 1282 & 12063 \\
\hline & IC-8 & 531 & 479 & 24000 & 834 & 18461 & 1184 & 12163 \\
\hline & IC-10 & 651 & 113 & 23328 & 705 & 19275 & 1194 & 14128 \\
\hline & IC-12 & 725 & 109 & 23764 & 696 & 18881 & 1150 & 13455 \\
\hline & Product* & 735 & $<100$ & 22800 & 657 & 18600 & 1130 & 10300 \\
\hline
\end{tabular}

*Sample taken at room temperature and wasn't quenched with $\mathrm{NaOH}$.

Figure 6 contains the nitrite data plotted versus time to show the nitrite destruction rate. SB3-5 did not meet the required nitrite destruction level as mentioned earlier. Although Run SB3-7 had a nitrite concentration above $100 \mathrm{ppm}$, it met the DWPF processing limit of $<1000 \mathrm{ppm}$. After the initial nitrite destruction, Runs SB3-7 and SB3-8 had very similar destruction slopes. Run SB3-8, containing sand and coal, had the most efficient destruction of the four runs performed with oxalate. Run SB3-6 had a quicker destruction rate near the end of processing. This may have correlated with a late surge in nitrous oxide generation at the end of the run. The mechanisms for the nitrite destruction in the presence of oxalate and coal will continue to be evaluated as part of the SB3 qualification testing. 
Figure 6 - Nitrite Destruction for Runs SB3-5 to SB3-8

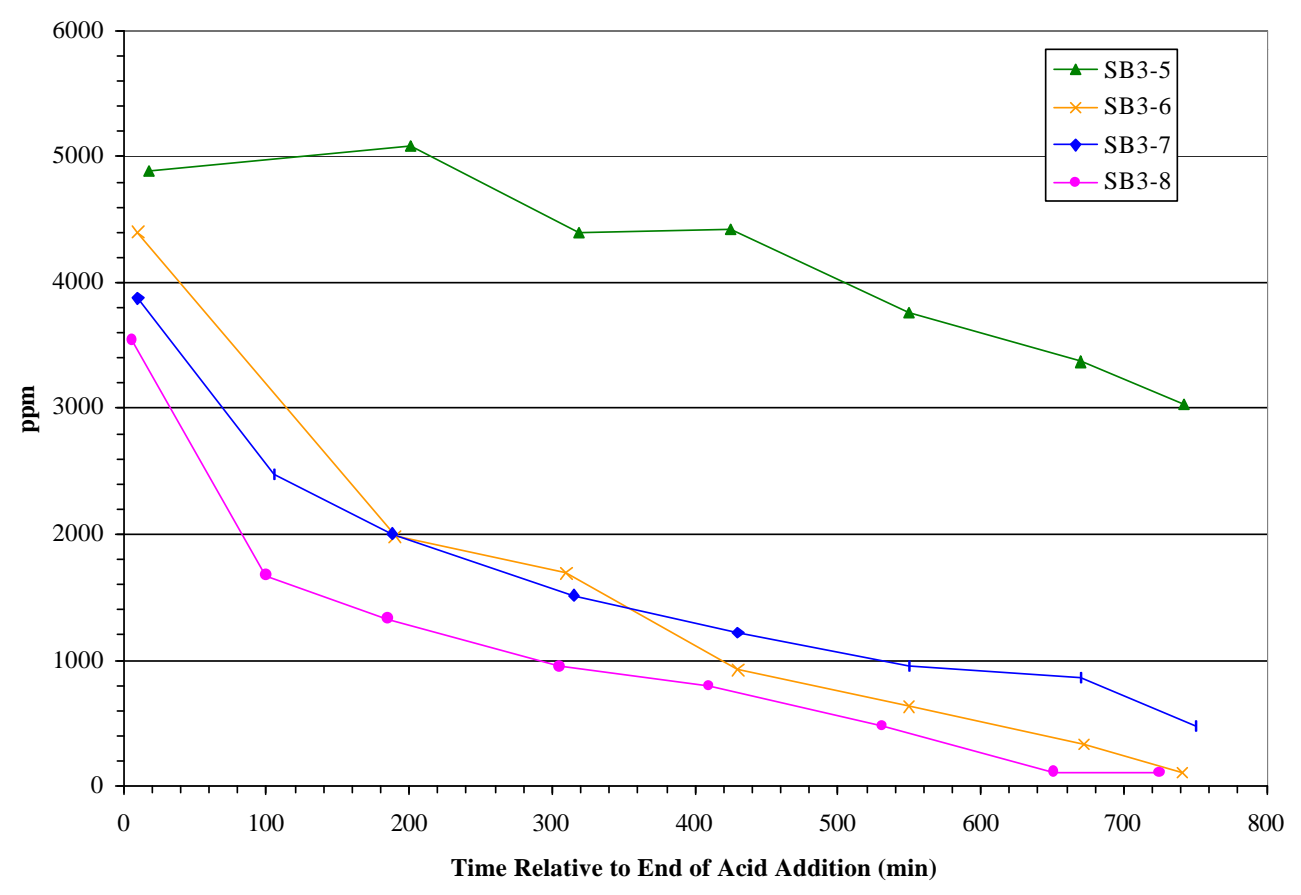

\subsection{Low pH Studies}

Two $\mathrm{pH}$ adjustment tests were performed to determine fractions of $\mathrm{Fe}$ and $\mathrm{Gd}$ dissolved at low $\mathrm{pH}$ values as might be experienced if some of the SRAT material were inadvertently transferred to the SMECT. One used SB3-4 SRAT product (no sodium oxalate test with sand and coal). The other used SB3-8 SRAT product (50\% sodium oxalate test with sand and coal). Iron in the Tank 8 simulant used for this work is probably in the form of a hydrous ferric oxide $\left(\mathrm{Fe}_{2} \mathrm{O}_{3} \cdot \mathrm{xH}_{2} \mathrm{O}\right)$. The exact form of iron in the actual radioactive $\mathrm{SB} 3$ waste is not known at this time.

As described in Section 3, the SRAT products from Runs SB3-4 and SB3-8 were heated to $85^{\circ} \mathrm{C}$ with a goal of adjusting the $\mathrm{pH}$ to a target of $\sim 2$ by adding additional nitric acid. However, since the $\mathrm{pH}$ reading was not adjusted for temperature, this goal was not met and a $\mathrm{pH}$ of $\sim 2.8$ was obtained. During the process, samples were taken at each $\mathrm{pH}$ level, along with additional samples at some of the $\mathrm{pH}$ levels to account for upward drift in the $\mathrm{pH}$. These samples were analyzed to determine the soluble species at the $\mathrm{pH}$ levels and throughout the testing. The amounts of soluble $\mathrm{Fe}$ and $\mathrm{Gd}$ for each sample were then used to determine the fraction of Fe and Gd soluble. Table 11 contains the fraction of Fe and $\mathrm{Gd}$ dissolved as the $\mathrm{pH}$ was lowered to $\sim 2.8$ and with respect to time. Supernate results for all elements analyzed are given as Tables E3 and E4 of Appendix E. The $\mathrm{pH}$ measurements could be uncertain by about $+0.1 /-0.3$ units due to a gradual drift away from calibration during each run and also due to the temperature corrections that were performed. Uncertainty in the values for fraction of $\mathrm{Fe}$ and $\mathrm{Gd}$ dissolved exist due to analytical uncertainty in the initial $\mathrm{Fe}$ and $\mathrm{Gd}$ mass combined with analytical uncertainty in the determination of supernate mass and supernate $\mathrm{Fe}$ and $\mathrm{Gd}$ concentration. More uncertainty exists in the values for fraction of total $\mathrm{Gd}$ dissolved than for $\mathrm{Fe}$, because the uncertainties in initial and supernate Gd masses are larger due to the lower Gd concentrations being measured. 
Table 11 - Percentage Fraction of Fe and Gd Dissolved in Low pH Testing at $85^{\circ} \mathrm{C}$

\begin{tabular}{|c|c|c|c|c|c|c|c|}
\hline \multicolumn{4}{|c|}{ SB3-4 (No Oxalate) } & \multicolumn{4}{|c|}{ SB3-8 (50\% Oxalate) } \\
\hline $\begin{array}{l}\text { Elapsed } \\
\text { Time } \\
(\text { min) }\end{array}$ & $\begin{array}{l}\text { pH @ } \\
85^{\circ} \mathrm{C}\end{array}$ & $\begin{array}{c}\text { \% Total } \\
\text { Fe } \\
\text { Dissolved }\end{array}$ & $\begin{array}{l}\text { \% Total } \\
\text { Gd } \\
\text { Dissolved }\end{array}$ & $\begin{array}{l}\text { Elapsed } \\
\text { Time } \\
(\mathbf{m i n})\end{array}$ & $\begin{array}{l}\mathrm{pH} @ \\
85^{\circ} \mathrm{C}\end{array}$ & $\begin{array}{c}\text { \% Total } \\
\text { Fe } \\
\text { Dissolved }\end{array}$ & $\begin{array}{l}\text { \% Total } \\
\text { Gd } \\
\text { Dissolved }\end{array}$ \\
\hline 0 & 6.18 & $<2 \mathrm{E}-04$ & 0.050 & 0 & 6.14 & 0.108 & 1.55 \\
\hline 22 & 5.34 & $<2 \mathrm{E}-04$ & 0.050 & 22 & 5.35 & 0.387 & 0.162 \\
\hline 59 & 4.50 & $<2 \mathrm{E}-04$ & 0.116 & 54 & 4.51 & 0.940 & 0.350 \\
\hline 92 & 4.60 & $<2 \mathrm{E}-04$ & 0.258 & 87 & 4.51 & 0.837 & 0.380 \\
\hline 97 & 4.08 & $2.11 \mathrm{E}-04$ & 0.878 & 93 & 4.10 & 1.31 & 0.748 \\
\hline 130 & 4.15 & 0.149 & 1.14 & 123 & 4.12 & 1.08 & 0.875 \\
\hline 140 & 3.66 & 0.344 & 2.13 & 128 & 3.67 & 1.69 & 1.72 \\
\hline 165 & 3.75 & No sample & No sample & 159 & 3.69 & 1.47 & 2.18 \\
\hline 178 & 3.25 & 0.806 & 3.89 & 166 & 3.25 & 2.15 & 4.50 \\
\hline 208 & 3.32 & 1.36 & 4.56 & 207 & 3.25 & 1.87 & 6.22 \\
\hline 286 & 3.21 & 2.47 & 5.22 & 267 & 3.26 & 1.77 & 7.15 \\
\hline 290 & 2.83 & 2.55 & 7.47 & 279 & 2.90 & 2.54 & 13.7 \\
\hline 348 & 2.90 & 3.38 & 8.90 & 342 & 2.78 & 2.36 & 17.9 \\
\hline 398 & 2.79 & 3.64 & 13.4 & 393 & 2.79 & 2.18 & 22.0 \\
\hline
\end{tabular}

The percent total Fe dissolved increased as $\mathrm{pH}$ decreased for both of the SB3-4 and SB3-8 products. The amount of Fe in solution at each $\mathrm{pH}$ level changed with time in both tests. The percent of dissolved Fe gradually decreased with time at a given $\mathrm{pH}$ in the test with SB3-8 SRAT product, whereas it slowly increased with time at a given $\mathrm{pH}$ in the test with the SB3-4 SRAT product. For Gd, the percent total Gd dissolved increased as $\mathrm{pH}$ decreased in the testing. The mass of dissolved $\mathrm{Gd}$ in solution at each $\mathrm{pH}$ increased with time in both tests. The changes with time at the $\mathrm{pH}$ levels may indicate that equilibrium was not completely achieved between the insoluble solids and the supernate. The rates of change of concentrations with time at each pH level were measurable, but relatively small over periods of 30-100 minutes.

Centrifuged solids from the final samples of the $\mathrm{pH}$ adjusted SB3-4 and SB3-8 products were also submitted for XRD analyses. Once again, two distinct layers were formed and analyzed. The lower layer was light brown in color, while the upper layer was dark brown in color. In both products, $\mathrm{ZrO}_{2}, \mathrm{SiO}_{2}, \mathrm{BaSO}_{4}$, and a hydrated iron oxalate were identified in the light brown layer. Although the XRD results were not quantitative, significantly more iron oxalate was present in the solids from SB3-8 than SB3-4. Since oxalate was not added to SB3-4, the oxalate detected may have resulted from oxidation of formic acid in the SRAT process. The dark brown layer was determined to contain aluminum hydroxide, $\mathrm{SiO}_{2}$, and magnetite $\left(\mathrm{Fe}^{2+} \mathrm{Fe}^{3+}{ }_{2} \mathrm{O}_{4}\right)$. A hydrated calcium oxalate compound was also found in the dark brown layer of the SB3-8 product.

Some other general observations concerning these tests can be made:

- Significantly more Ni (see Tables E3 and E4 in Appendix E) was dissolved in the SB3-4 test than in the SB3-8 test. There was more Ni than Fe in solution in SB3-4, while the opposite was true for SB3-8.

- Significantly more Al was in solution in SB3-8 than in SB3-4.

- Calcium was nearly all insoluble in SB3-8 initially and nearly all in solution in SB3-4 initially. By the end of the test, about half of the Ca in SB3-8 had redissolved. The calcium in SB3-4 remained in solution during the test.

In order to adjust the $\mathrm{pH}$ of the products to a $\mathrm{pH}$ level that might be expected in the SMECT $(\mathrm{pH} \sim 2)$, approximately 100 grams of the SB3-4 and SB3-8 pH adjusted products were lowered to $\mathrm{pH} 2$. The adjustments were performed in a flask that was heated to $85^{\circ} \mathrm{C}$ in a water bath on a hot plate. The product was stirred the entire time and samples were pulled after maintaining the $\mathrm{pH}$ level for $\sim 1 \mathrm{hr}$. Small amounts of acid were added throughout the $31 / 2$ hours of mixing to maintain a $\mathrm{pH}$ of 2. The results for $\mathrm{Fe}$ and $\mathrm{Gd}$ for this testing are included in Table 12. Supernate results for all elements analyzed are given in Table E5 of Appendix E. 
Table 12 - Fraction of Fe and Gd Dissolved at pH 2

\begin{tabular}{|c|c|c|c|c|c|c|c|}
\hline \multicolumn{3}{|c|}{ SB3-4 (No Oxalate) } & \multicolumn{4}{c|}{ SB3-8 (50\% Oxalate) } \\
\hline $\begin{array}{c}\text { Elapsed } \\
\text { Time } \\
\text { (min)* }\end{array}$ & pH & $\begin{array}{c}\text { \% Total } \\
\text { Fe } \\
\text { Dissolved }\end{array}$ & $\begin{array}{c}\text { \% Total } \\
\text { Gd } \\
\text { Dissolved }\end{array}$ & $\begin{array}{c}\text { Elapsed } \\
\text { Time } \\
\text { (min)* }\end{array}$ & pH & $\begin{array}{c}\text { \%otal } \\
\text { Fe } \\
\text { Dissolved }\end{array}$ & $\begin{array}{c}\text { \% Total } \\
\text { Gd } \\
\text { Dissolved }\end{array}$ \\
\hline 60 & 2.17 & 5.89 & 27.7 & 67 & 2.13 & 3.28 & 40.4 \\
\hline 124 & 2.14 & 6.02 & 30.6 & 127 & 2.08 & 3.51 & 47.4 \\
\hline 212 & 2.18 & 7.04 & 43.0 & 218 & 1.99 & 3.73 & 58.1 \\
\hline \multicolumn{3}{rl}{ *Elapsed time is from the acid adjustment to 2.00. } \\
\hline
\end{tabular}

The amounts of dissolved Fe remained relatively small even at this lower $\mathrm{pH}$ level. In the presence of oxalate, the amount of dissolved Fe did not change greatly throughout this test. The behavior of Fe in the SB3-8 product over time in this test was opposite of the behavior exhibited in the $>2 \mathrm{pH}$ tests. In the $>2 \mathrm{pH}$ test, dissolved Fe in SB3-8 decreased at a given $\mathrm{pH}$ over time. Gadolinium continued to dissolve during this test with the amount being greater in the slurry with oxalate. Overall, the total Fe dissolved in the oxalate containing feed was $\sim 4 \%$ and the total Gd was $\sim 58 \%$. For the product without oxalate, $\sim 7 \% \mathrm{Fe}$ dissolved and $\sim 43 \% \mathrm{Gd}$ dissolved. A larger amount of $\mathrm{Fe}$ or $\mathrm{Gd}$ might have been dissolved if the two systems were tested using a more dilute acid to lower the $\mathrm{pH}$. In this case, the volumes in the tests would be larger and thus more $\mathrm{Fe}$ or Gd might be dissolved. The solubility limits are not known in this system. Literature data indicates that $\mathrm{Fe}$ and $\mathrm{Pu}$ (IV) have similar solubilities in weak nitric acid solutions, and therefore $\mathrm{Fe}$ and $\mathrm{Pu}$ would not be separately dissolved over the $\mathrm{pH}$ range of 0 to 4 [12].

Figure 7 shows the percentage of $\mathrm{Fe}$ in the supernate phase as a function of $\mathrm{pH}$ and includes all of the samples taken at each $\mathrm{pH}$ value. Figure 8 shows the percent $\mathrm{Gd}$ in the supernate phase as a function of $\mathrm{pH}$ and also includes all of the samples taken at each $\mathrm{pH}$ value.

Figure 7 - Iron Dissolution with pH Adjustment

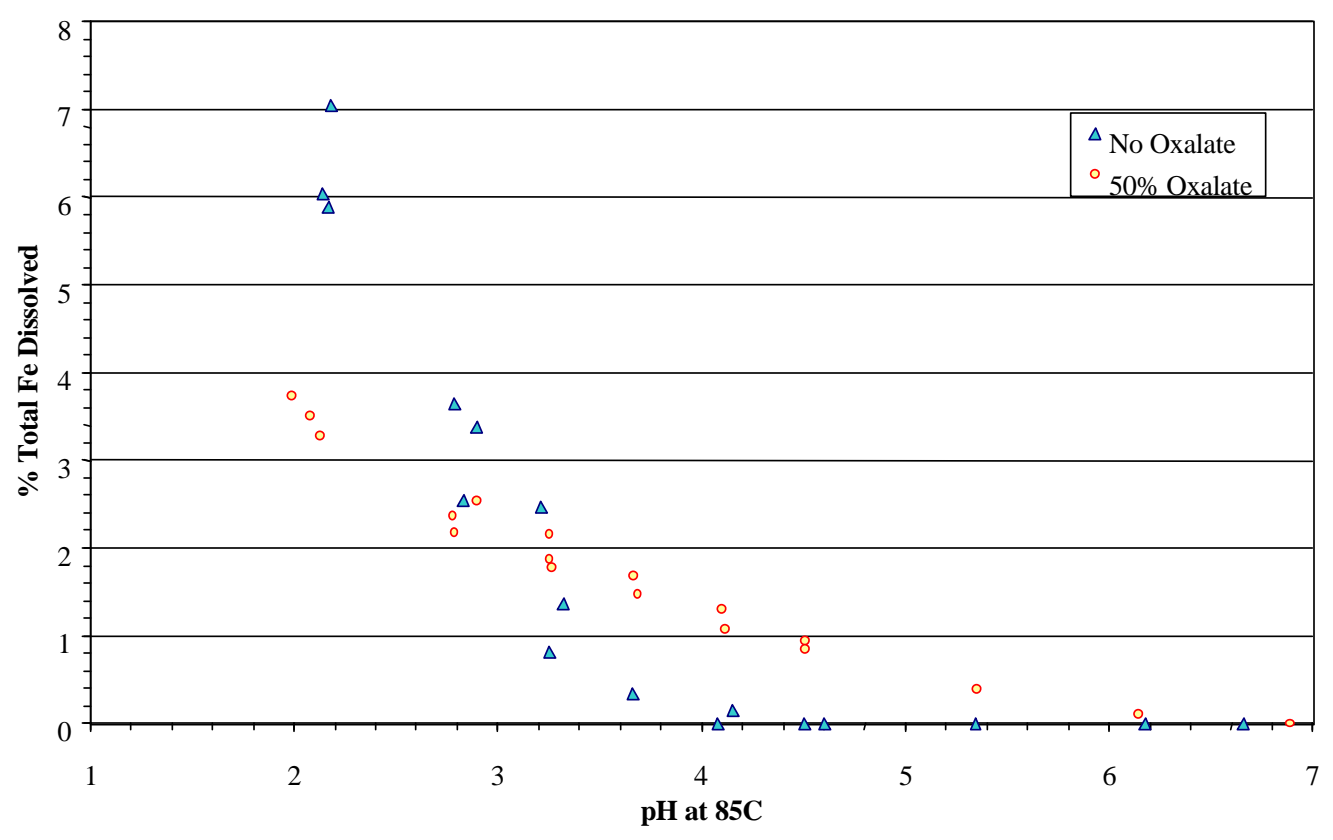


Figure 8 - Gadolinium Dissolution with pH Adjustment

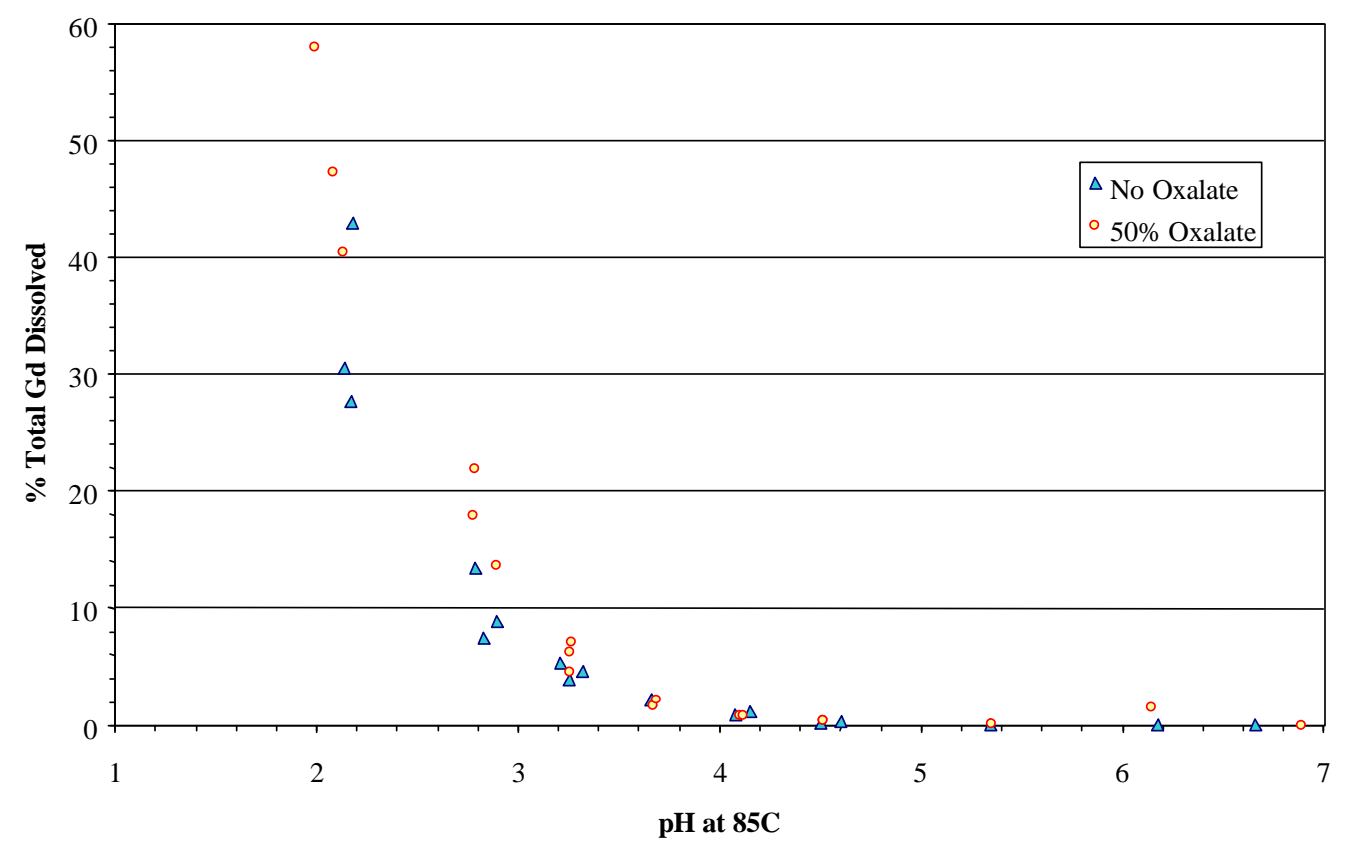

In the test using SB3-8 with oxalate present, $54 \mathrm{~mL}$ of $10 \mathrm{M}$ nitric acid were necessary to lower the $\mathrm{pH}$ from 6.89 to 2 for 447 grams of SRAT product. On a DWPF scale, 439 gallons of 10M nitric acid would be necessary for 4000 gallons of SRAT product presuming the compositions of the SRAT products were identical. This means that if this 4000 gallons (nominally half a SRAT batch) were inadvertently transferred to the SMECT, 439 gallons of 10M nitric acid would have to be added to the SMECT to reduce the $\mathrm{pH}$ to 2 . The results presented here indicate that if this were done at least $96 \%$ of the Fe would still be in the sludge as a neutron poison, while up to $60 \%$ of the Gd could be dissolved. For SB34 without oxalate present, $84 \mathrm{~mL}$ of $10 \mathrm{M}$ nitric acid were necessary to lower the $\mathrm{pH}$ from 6.66 to 2 for 599 grams of SRAT product. On a DWPF scale, 499 gallons of $10 \mathrm{M}$ nitric acid would be necessary for 4000 gallons of SRAT product presuming the compositions of the SRAT products were identical. This means that if this 4000 gallons (nominally half a SRAT batch) were inadvertently transferred to the SMECT, 499 gallons of 10M nitric acid would have to be added to the SMECT to reduce the $\mathrm{pH}$ to 2 . The results presented here indicate that if this were done at least $93 \%$ of the Fe would still be in the sludge as a neutron poison, while up to $43 \%$ of the Gd could be dissolved.

\subsection{CONCLUSIONS}

Based on the limited SRTC SRAT testing, no major impacts on SRAT processing were seen from the presence of the H-Canyon slurry. Specifically, in the Gd SRAT testing, no analytical, volatility, offgas, rheology, or hydrogen issues were identified. For the solubility testing, the amounts of iron and gadolinium solubilized were negligible and no samarium was solubilized. In the lower $\mathrm{pH}$ testing, increased amounts of iron, gadolinium, and samarium solubility were seen. Iron and samarium present in the supernate still represented a small portion of the total amount in the sludge, whereas gadolinium concentration was more significant. The highest Fe was dissolved with the SB3-4 or no oxalate product and was $\sim 7 \%$, whereas the highest Gd was dissolved with the SB3-8 or oxalate product and was $\sim 58 \%$.

In addition to the information gained for the processing of the H-Canyon slurry, initial insight into the affects of the non-typical components (i.e., sand, coal, and sodium oxalate) in Tank 7 was gained. The findings that will be studied 
further in the SB3 testing include the impact of coal on hydrogen generation, the effect of oxalate on nitrite destruction (and acid addition amount), and the impact of coal on nitrite destruction.

\subsection{REFERENCES}

[1] C.C. Herman, T.L. Fellinger, N.E. Bibler, and D.C. Koopman, "Scoping SRAT Runs with Simulated Sludge Batch 3", SRT-GPD-2002-00044, April 12, 2002.

[2] M.G. Bronikowski, M.C. Thompson, F.R. Graham, T.L. Fellinger, W.R. Wilmarth, and D.T. Hobbs, "Technical Task and Quality Assurance Plan for Assessing Downstream Effects of Plutonium/Gadolinium in Sludge Washing and SRAT', WSRC-RP-2002-00178, March 6, 2002.

[3] N.E. Bibler, D.K. Peeler, and T.B. Edwards, "An Assessment of the Impacts of Adding Am/Cm and Pu/Gd Waste Streams to Sludge Batch 3 (SB3) on DWPF Hz Generation Rates and Glass Properties", WSRCTR-2002-00145, March 22, 2002.

[4] H.H. Elder, 'Engineering Position Paper - Impact of Processing H-Canyon Stored Plutonium in Sludge Batch 3”, HLW-PRE-2002-00006, June 24, 2002.

[5] A.Q. Goslen, "Estimated Sodium Oxalate in the Tank Farm”, March 22, 1984.

[6] C.C. Herman, "Task Technical and QA Plan: Oxalate Studies for Sludge Batch 3 - SRAT Processing", WSRC-RP-2002-00320, June 3, 2002.

[7] K.G. Brown, C.M. Jantzen, and J.B. Pickett, "The Effects of Formate and Nitrate on Reduction/Oxidation (Redox) Process Control for the Defense Waste Processing Facility (DWPF)", WSRC-RP-97-34, February $5,1997$.

[8] L27 Manual, ITS/TNX Procedures Manual, 2002.

[9] C.C. Herman, "Analytical Study Plan: Oxalate Studies for Sludge Batch 3 - SRAT Processing", WSRCRP-2002-00342, June 19, 2002.

[10] T.L. Fellinger, D.T. Hobbs, M.G. Bronikowski, B.C. Hill, and J.H. Gray, "Demonstrations of the Tank Farm Washing Process and the DWPF SRAT Cycle with Sludge Batch 3 Simulant and Precipitated Pu/Gd Mixture from H-Canyon Tank 18.3", WSRC-TR-2002-00208, May 8, 2002.

[11] M.E. Smith, 'Impact Analysis - Impact of Adding H-Canyon Stored Plutonium in Sludge Batch 3', WSRC-TR-2002-00199, April 30, 2002.

[12] D.G. Karraker, "Solubility of Uranium, Plutonium, Iron, and Manganese in Weak Nitric Acid and Oxalic Acid Solutions: A Literature Survey", WSRC-RP-98-00091, March 5, 1998.

\subsection{ACKNOWLEDGEMENTS}

The authors would like to acknowledge the following personnel and groups for their assistance in performing the studies and analyzing the required samples:

- V.J. Williams, M.L. Moss, S.O. King, J.W. Duvall, and T.O. Burckhalter for performing the SRAT runs.

- I.A. Reamer for preparing the sand and coal for the experiments.

- R.J. Workman, P.A. Toole, D.J. Pittman, and S.T. Vissage for providing assistance with the demonstrations and analyses.

- W.G. Daniel and J.M. Pareizs for assistance with GC analyses.

- $\quad$ ADS for providing analytical support. 
Westinghouse Savannah River Company

Savannah River Technology Center
WSRC-TR-2002-00322

Page 25 of 46

Appendix A - SRAT Run Parameters 
Table A1 - Run Parameters

\begin{tabular}{|c|c|c|c|c|c|c|c|c|}
\hline Parameter & SB3-1 & SB3-2 & SB3-3 & SB3-4 & SB3-5 & SB3-6 & SB3-7 & SB3-8 \\
\hline Total Sludge $(\mathrm{g})$ & 2200.0 & 2200.0 & 2200.0 & 2200.0 & 2200.0 & 2200.0 & 1829.0 & 1829.3 \\
\hline Sludge Solids (air dried basis) & $18.0 \%$ & $18.0 \%$ & $18.0 \%$ & $18.0 \%$ & $18.0 \%$ & $18.0 \%$ & $17.3 \%$ & $17.3 \%$ \\
\hline Hg Content (wt\% air dried basis) & $0.076 \%$ & $0.076 \%$ & $0.076 \%$ & $0.076 \%$ & $0.076 \%$ & $0.076 \%$ & $0.076 \%$ & $0.076 \%$ \\
\hline 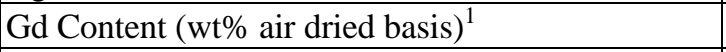 & N/A & N/A & $0.061 \%$ & $0.061 \%$ & $0.037 \%$ & $0.037 \%$ & $0.037 \%$ & $0.037 \%$ \\
\hline Sm Content (wt $\%$ air dried basis for $\mathrm{Pu}$ ) & N/A & N/A & N/A & N/A & $0.024 \%$ & $0.024 \%$ & $0.024 \%$ & $0.024 \%$ \\
\hline Sand Content (wt $\%$ air dried basis) & N/A & $1.11 \%$ & $1.11 \%$ & $1.11 \%$ & N/A & $\mathrm{N} / \mathrm{A}$ & N/A & $1.11 \%$ \\
\hline Coal (carbon) Content (wt\% air dried basis) & N/A & $0.71 \%$ & $0.71 \%$ & $0.71 \%$ & N/A & N/A & N/A & $0.71 \%$ \\
\hline Sodium Oxalate Added (g - equivalent washed \%) & N/A & N/A & N/A & N/A & $133.97(50 \%)$ & $66.98(75 \%)$ & $115.03(50 \%)$ & $115.03(50 \%)$ \\
\hline Rinse Water for Sludge and Trim Chemicals (g) & 330.3 & 330.3 & 330.3 & 330.3 & 330.3 & 330.3 & 272.7 & 312.7 \\
\hline Total SRAT Feed with Trim Chemicals (g) & 2207.04 & 2214.41 & 2208.37 & 2215.12 & 2341.72 & 2274.74 & 2408.54 & 2414.74 \\
\hline SRAT Feed Solids (air dried basis) & $18.00 \%$ & $18.32 \%$ & $18.26 \%$ & $18.32 \%$ & $22.73 \%$ & $20.46 \%$ & $18.05 \%$ & $18.26 \%$ \\
\hline Acid Stoichiometry $^{2}$ & $125 \%$ & $125 \%$ & $125 \%$ & $125 \%$ & $125 \%$ & $125 \%$ & $156 \%$ & $156 \%$ \\
\hline Nitric Acid Amount Added (ml) & 38.41 & 38.41 & 38.41 & 38.41 & 38.41 & 38.41 & 79.57 & 79.57 \\
\hline Nitric Acid Addition Rate (ml/min) & 0.69 & 0.69 & 0.69 & 0.69 & 0.69 & 0.69 & 0.75 & 0.75 \\
\hline Formic Acid Amount Added (ml) & 71.56 & 71.56 & 71.56 & 71.56 & 71.56 & 71.56 & 54.30 & 54.32 \\
\hline Formic Acid Addition Rate $(\mathrm{ml} / \mathrm{min})$ & 0.71 & 0.71 & 0.71 & 0.71 & 0.71 & 0.71 & 0.77 & 0.77 \\
\hline Dewater Amount $(\mathrm{g})$ - SMECT & 452.3 & 452.8 & 454.7 & 449.1 & 449.0 & 449.1 & 418.5 & 418.2 \\
\hline Condensing/Dewater Time (hrs) & 2.9 & 3.0 & 2.5 & 2.7 & 2.7 & 2.3 & 2.5 & 2.4 \\
\hline Time at Boiling (hrs) & 10.5 & 10.9 & 10.8 & 10.7 & 11.6 & 11.8 & 12.0 & 11.7 \\
\hline Target Boil-up Rate (g/min) & 3.3 & 3.3 & 3.3 & 3.3 & 3.3 & 3.3 & 3.6 & 3.6 \\
\hline Air Purge on System (slm) & 0.462 & 0.462 & 0.462 & 0.462 & 0.462 & 0.462 & 0.505 & 0.505 \\
\hline Helium Purge on System (sccm) & 2.32 & 2.32 & 2.32 & 2.32 & 2.32 & 2.32 & 2.54 & 2.54 \\
\hline DWPF Scale Factor ${ }^{3}$ & 11458 & 11458 & 11458 & 11458 & 10800 & 11120 & 10500 & 10500 \\
\hline Initial Sludge pH with Trim Chemicals & 9.86 & 9.77 & 10.05 & 9.81 & 9.43 & 9.34 & 9.90 & 9.89 \\
\hline Minimum $\mathrm{pH}$ during SRAT Run & 4.12 & 3.91 & 3.87 & 3.98 & 5.83 & 4.60 & 4.50 & 4.39 \\
\hline Final SRAT Product $\mathrm{pH}$ at Room Temperature & 7.81 & 7.70 & 5.79 & 7.52 & 8.20 & 8.31 & 7.65 & 7.81 \\
\hline Antifoam Addition Amounts (ppm) at $40 \mathrm{C}$ & 200 & 200 & 200 & 200 & 200 & 200 & 200 & 200 \\
\hline Antifoam Addition Amount (ppm) after Acid & 500 & 500 & 500 & 500 & 500 & 500 & 500 & 500 \\
\hline Peak Hydrogen Generation (lbs/hr) & 0.244 & 0.521 & 0.001 & 0.608 & $\mathrm{~N} / \mathrm{A}$ & $\mathrm{N} / \mathrm{A}$ & $\mathrm{N} / \mathrm{A}$ & N/A \\
\hline Notebook Number, WSRC-NB-2002-xxxxx & 00068 & 00068 & 00068 & 00068 & 00095 & 00095 & 00095 & 00095 \\
\hline Run Plan Number, SRT-GPD-2002-xxxx & 00045 & 00046 & 00047 & 00048 & 00062 & 00064 & 00065 & 00066 \\
\hline
\end{tabular}

Notes: 1. Gd was added for Pu and Gd in Runs SB3-3 and SB3-4.

2. Target for SB3-7 and SB3-8 was 275 , but acid addition was stopped when minimum $\mathrm{pH}$ of $\sim 4.5$ was reached.

3. DWPF Scale without oxalate would be 11458 for SB3-5 \& SB3-6 and 13780 for SB3-7 \& SB3-8. 
Westinghouse Savannah River Company

WSRC-TR-2002-00322

Savannah River Technology Center

Page 27 of 46

Appendix B - Rheology Measurements Performed on SRAT Products from Runs SB3-1 to SB3-4 


\section{Rheometer Configuration}

The relevant features of the ThermoHaake RS150 RheoStress rheometer are described here. The Z38 cylinder with the DZ43 cup was selected for the SRAT products, since three of the SRAT products contained sand and coal particles nearly $0.7-\mathrm{mm}$ in size. This approaches the width of the annular gap of the Z41/DZ43 cylinder/cup configuration of 0.99-mm. The effective geometry for the Z38/DZ43 configuration is an annulus with inner and outer radii of 19.010-mm and $21.700-\mathrm{mm}$ and a contact length of $55-\mathrm{mm}$. The Tank 8 sludge simulant and some of the SB3-1 SRAT product were analyzed using the Z41/DZ43 configuration, since neither had sand and coal. The effective geometry for the Z41/DZ43 configuration is an annulus with inner and outer radii of $20.710-\mathrm{mm}$ and $21.700-\mathrm{mm}$ and a contact length of 55-mm.

\section{Measurements on Tank 8 Simulant and SRAT Product Samples}

Raw rheogram data for the first four SRAT products (SB3-1 through SB3-4) are given as Figures B1 - B4. Quality and reproducibility of the data was limited by the presence of persistent bubbles in the slurry. The shear rate range in onedimensional laminar flow was limited by the formation of Taylor vortices (marked on the figures). These occurred at about $2 / 3$ of the anticipated shear rate than anticipated. This may relate to the relatively large gap between the Z38 sensor and the beaker wall. Down ramp data generally agreed better for a given pair of equivalent SRAT product samples than up ramp data. A notable exception was found with the SB3-3 pair of samples. All ramp data, both up and down, agreed well. These two samples had far fewer bubbles after shaking than the six samples from the other three runs. This could be related to noble metals, since this was the only identified consistent difference between SB3-3 and the other three runs.

Visual observations during the rheological measurements indicated little beyond the presence of persistent bubbles in many of the samples. Bubbles were not observed sticking to the cylindrical sensor following the measurement. This observation was also made with simulated SB2 SRAT product and SRAT acid addition samples from the Glass Feed Preparation System (GFPS). Conversely, SB2 simulant SME product bubbles seemed to migrate and stick to the cylindrical sensor surface. The present SRAT and sludge samples may not be viscous enough to hold the bubbles on the sensor during its removal from the beaker.

The sand and coal appeared to both be well-mixed into the simulant slurry prior to loading the rheometer beaker. Sand and coal did not appear to be sticking to either the stainless steel surface of the beaker or to the titanium surface of the cylindrical sensor. An occasional observation was made of some particulates on the bottom of the beaker after a measurement. They were definitely in the sand and coal size range, but there were rarely as many as ten particles. No other unusual visual observations were made. All samples were characterized as brown, thin slurries, which were slow to settle. The settled solids in the sample bottles were fairly readily redispersed by vigorous shaking. There didn't appear to be any long-lived clumps of solids in the sample bottles (no evidence of claying or caking).

The best eight rheograms for the four SRAT products are given in the main body of the text, along with a discussion of the data and the results of the Bingham plastic model fit. The rest of the raw data is included in this appendix as Figures B1 through B4.

Raw rheogram data for the SB3-1 SRAT product and the starting Tank 8 simulant are given as Figures B5 and B6. The impact of using Z38 versus Z41 is clearly shown. Z41 data is inherently closer to a corrected, or true, rheogram, because the inner to outer radii ratio is closer to unity. Conversely, it is desirable to have a gap that is five or more times wider than the size of the larger particles. The solid particles are supposed to be common enough for the sample to qualify as a fluid continuum. This implies that there is very little variation in properties as a function of spatial position on length scales comparable to those of the system (the rheometer annular gap). Simulant sludge particles are primarily less than $20-\mu \mathrm{m}$ in diameter, or $1 / 50^{\text {th }}$ of the annular gap of the Z41. Visually it is seen that using Z38 had little impact on the yield stress (about 15 dynes $/ \mathrm{cm}^{2}$ ). Conversely, the flow curve slope, or plastic viscosity, appears to be larger using Z38 than when using Z41.

The Tank 8 simulant was clearly more viscous than the SB3-1 SRAT product using the Z41 (see Figure B5). The onset of Taylor vortices was delayed with Z41 because of the smaller annular gap. There was negligible evidence for thixotropic behavior during the Z41 measurements, i.e. no variation in the flow curve related to time under shear. Tank 8 simulant rheological data has been taken before using undecanted simulant, WSRC-TR-2001-00051. A comparison of the past and present data is shown in Table B1. Tank 8 data were fit on the shear rate range of 0-350 $\mathrm{sec}^{-1}$ in both cases. Neither the Tank 8 as-made or as-used contained sand and coal, mercury, or noble metals. The dewashed Tank 8 
simulant, described later, does contain sand and coal. Results for modified Tank 51 Optima simulant trimmed to look more like Sludge Batch 1B are included for comparison.

Table B1 - Bingham Plastic Model Fits for Tank 8 Sludge at $25^{\circ} \mathrm{C}$

\begin{tabular}{|l|c|c|c|c|c|}
\hline \multicolumn{1}{|c|}{ Sludge } & $\begin{array}{c}\text { Yield Stress, } \\
\text { dynes/cm }\end{array}$ & $\begin{array}{c}\text { Plastic Viscosity, } \\
\text { cP }\end{array}$ & $\begin{array}{c}\text { Wt. \% Total } \\
\text { Solids }\end{array}$ & $\begin{array}{c}\text { Wt. \% Insoluble } \\
\text { Solids }\end{array}$ & pH \\
\hline 8, as-made & 7.4 & 4.8 & 14.9 & 12.5 & 9.8 \\
\hline 8, as-used & 23 & 7.6 & 18.0 & 15.7 & 10 \\
\hline 8, dewashed & 16 & 12 & 32.6 & 11.7 & $>13$ \\
\hline SB-1B & 15 & 5.6 & 17.0 & 13.9 & 12.8 \\
\hline
\end{tabular}

A sample of Tank 8 simulant was modified to resemble unwashed sludge by adding sodium salts to it. Sand and carbon were added to the unwashed sludge. This dewashed sample was used as a test fluid. Rheological data were obtained with both the Z41 and the Z38 cylindrical sensors. The agreement between up ramp and down ramp data was generally excellent with both sensors. The Z38 dewashed sludge data also showed the Taylor vortices at about $200 \mathrm{sec}^{-1}$ that were seen in the SRAT product data. Results of a Bingham plastic model fit to the low shear rate region before Taylor vortices are given in Table B1. The higher consistency compared to the other three samples is likely due to the Z38 gap combined with the higher dissolved solids content. The other data is from $\mathrm{Z} 41$ type configurations. The high $\mathrm{pH}$ may be helping to produce the comparatively low yield stress. There is no way to tell from this data whether the rheological changes were due to the sand and coal, or to $\mathrm{pH}$, or to other changes in the supernate concentration.

The Z41 data from the dewashed Tank 8 simulant recorded many episodes where particles temporarily bridged the annular gap. This produced spikes in the motor torque as the instrument worked to maintain the programmed rotational speed (shows in the raw data as a shear stress spike, see Figure B6). As the fluid sped up, the large particles gradually tended to disperse and align with the velocity streamlines, giving a smoother flow curve at higher shear rates. Nevertheless, the presence of large particles produces a distortion in the flow curve that becomes more significant as the annular gap width decreases. This particle streamlining effect appears to be causing a higher effective consistency in the Z41 data than would be expected (based, e.g. on the SB3-1 Z38 and Z41 data). This data is given here to support the decision to use the Z38 cylinder for the SRAT product samples from this study. 
Figure B1 - SB3-1 SRAT Product Raw Rheogram Data (Noble Metals; No Sand, Carbon, or Gd)

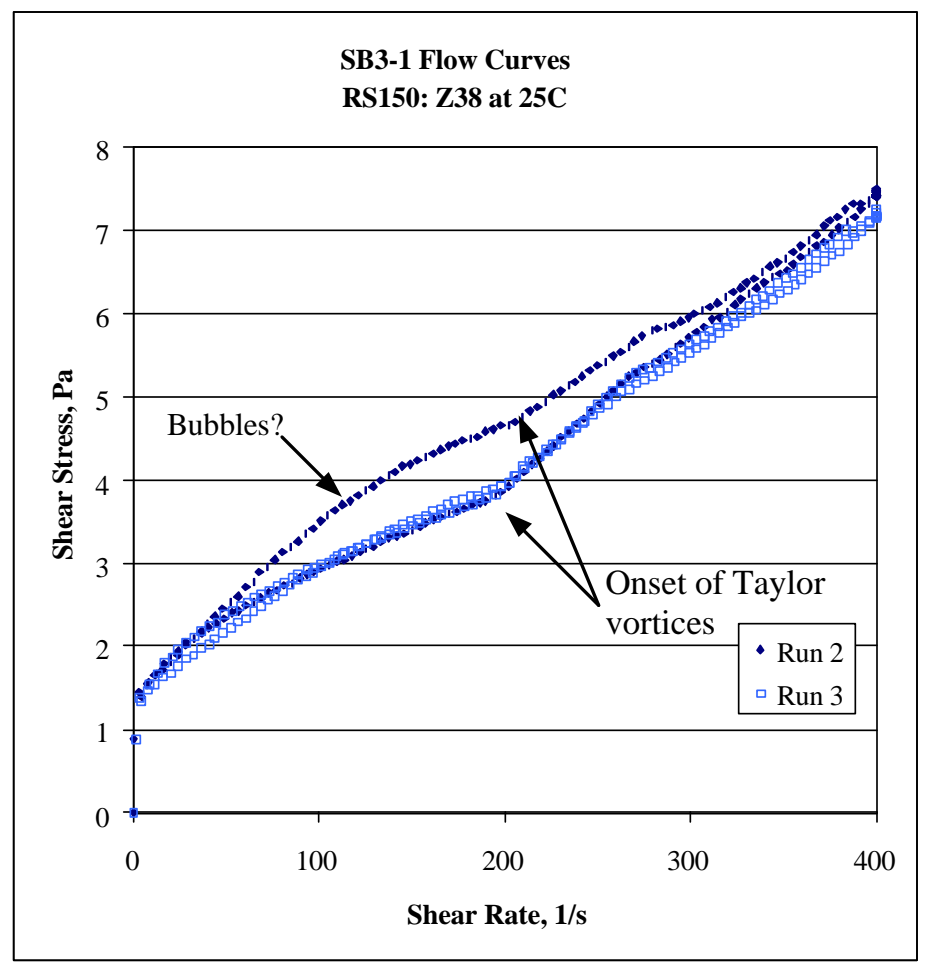

Figure B2 - SB3-2 SRAT Product Raw Rheogram Data (Noble Metals, Sand and Carbon; No Gd)

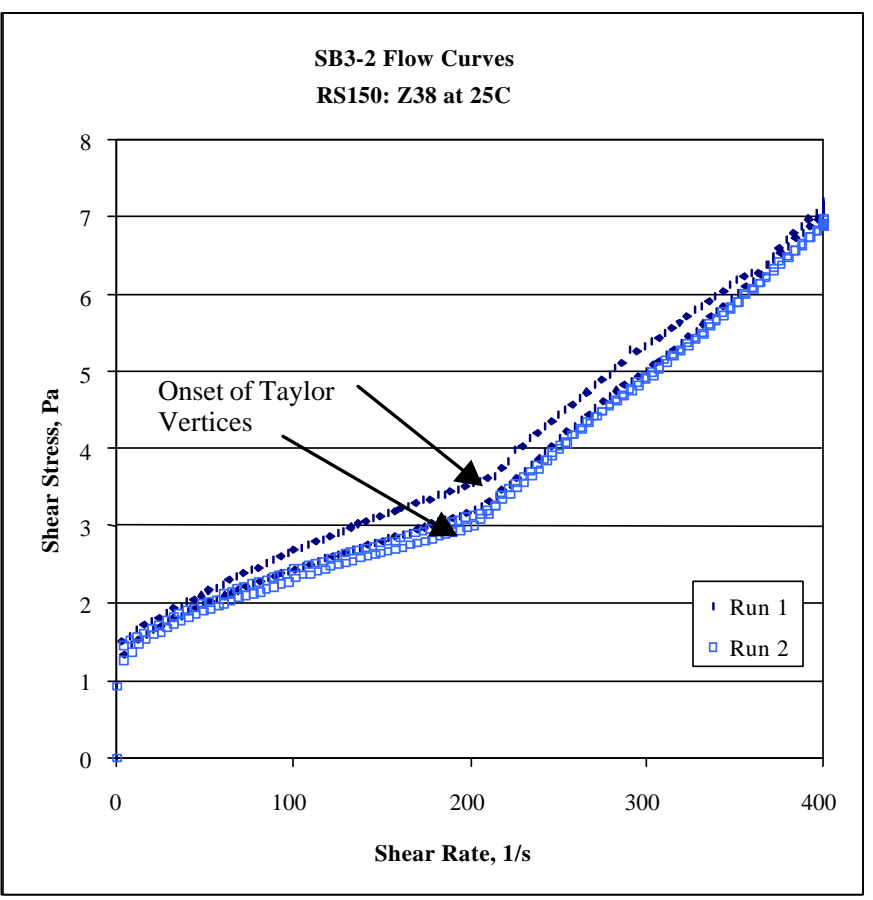


Figure B3 - SB3-3 SRAT Product Raw Rheogram Data (Sand, Carbon, and Gd; No Noble Metals)

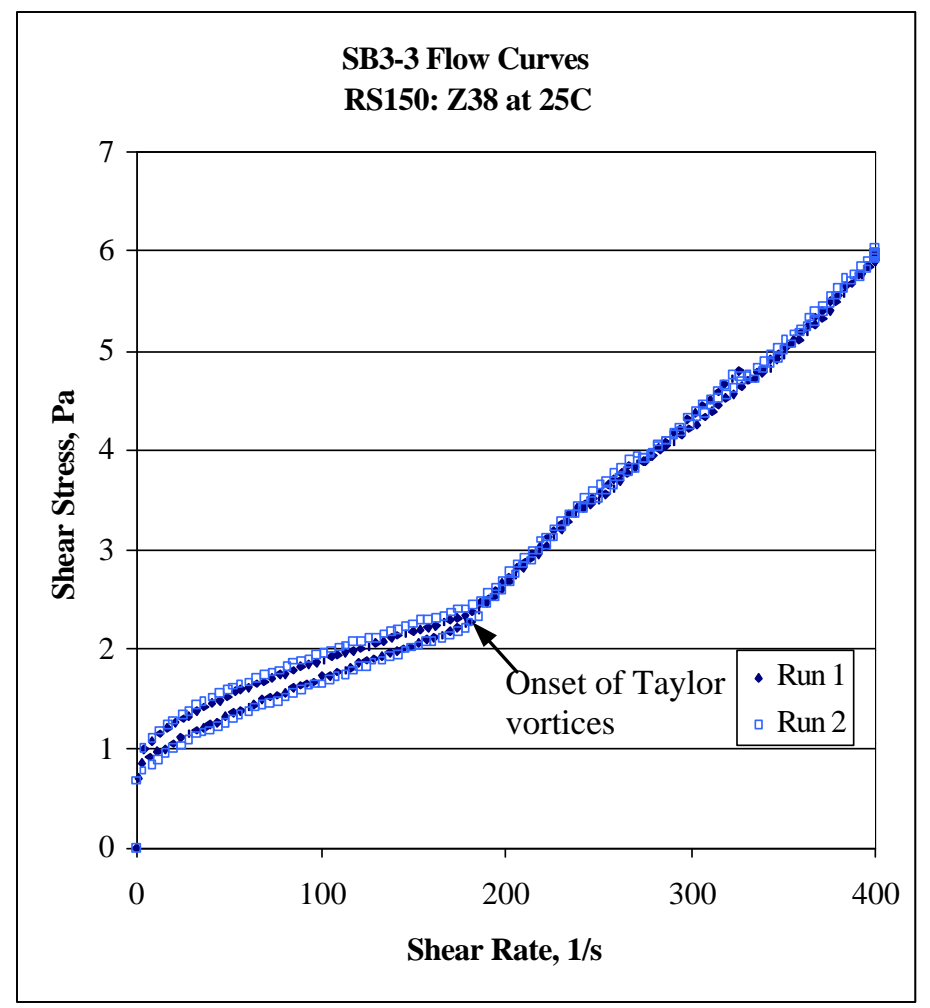

Figure B4 - SB3-4 SRAT Product Raw Rheogram Data (Noble Metals, Sand, Carbon, and Gd)

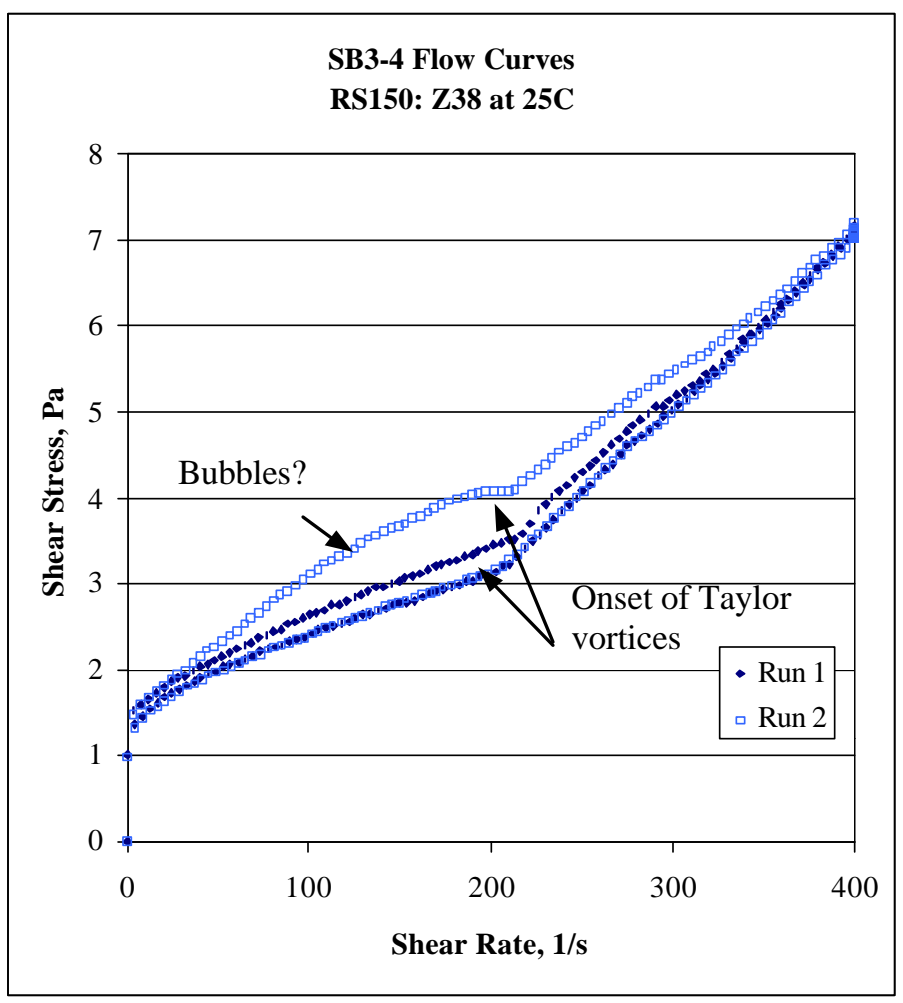


Figure B5 - SB3-1 SRAT Product and Tank 8 Sludge Simulant (No Sand, Carbon, or Gd)

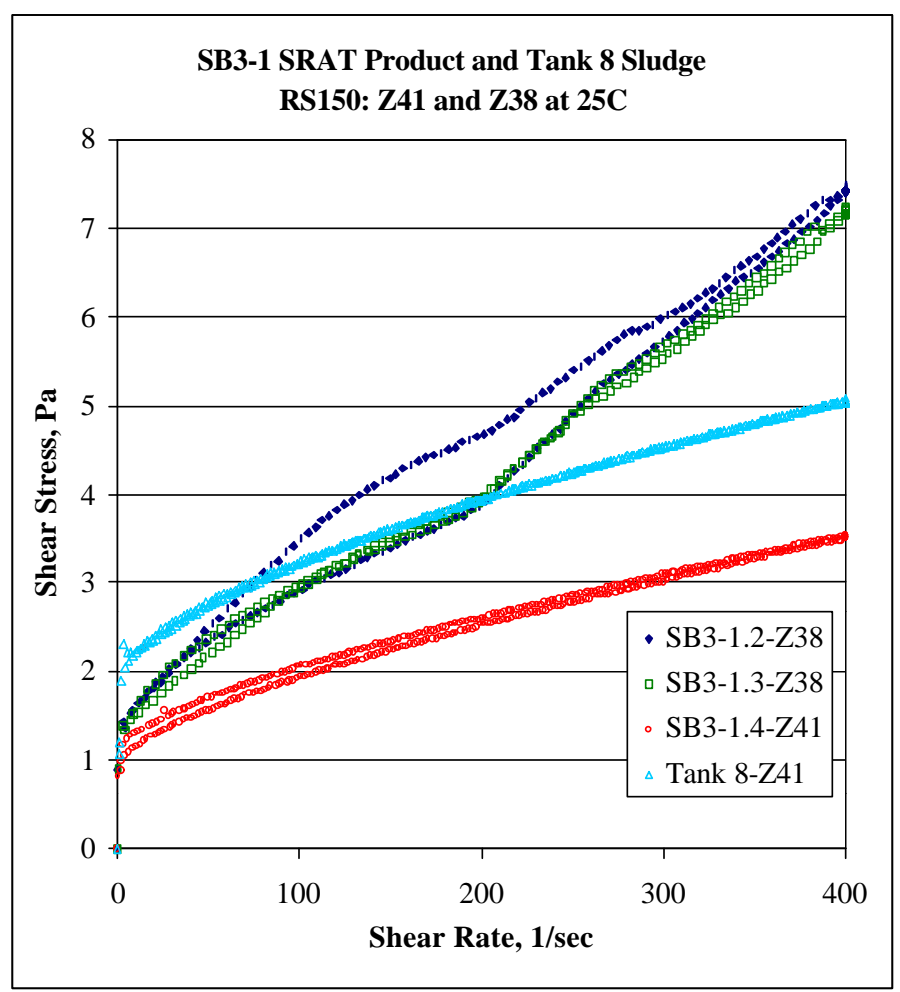

Figure B6 - Tank 8 Simulant Dewashed with Sodium Salts (Containing Sand and Carbon)

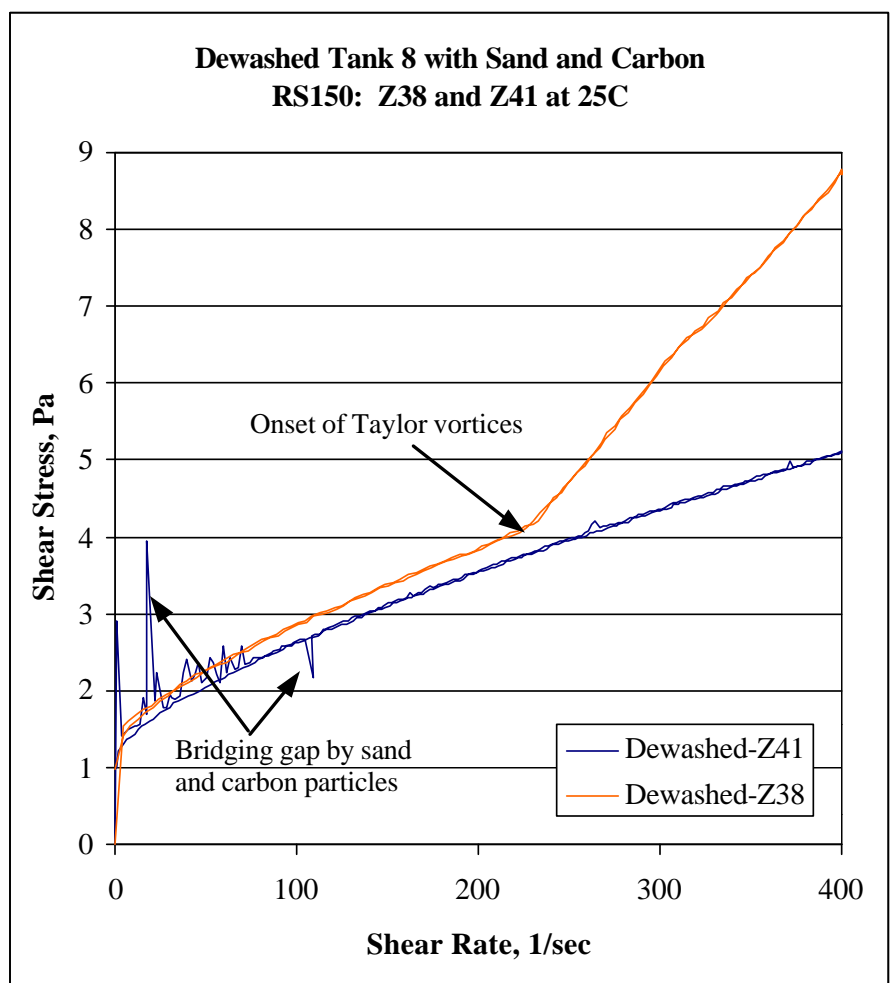


Westinghouse Savannah River Company

WSRC-TR-2002-00322

Savannah River Technology Center

Page 33 of 46

Appendix C - pH Plots for SRAT Processing 
Figure C1 - pH during SRAT Processing for SB3-1 through SB3-4

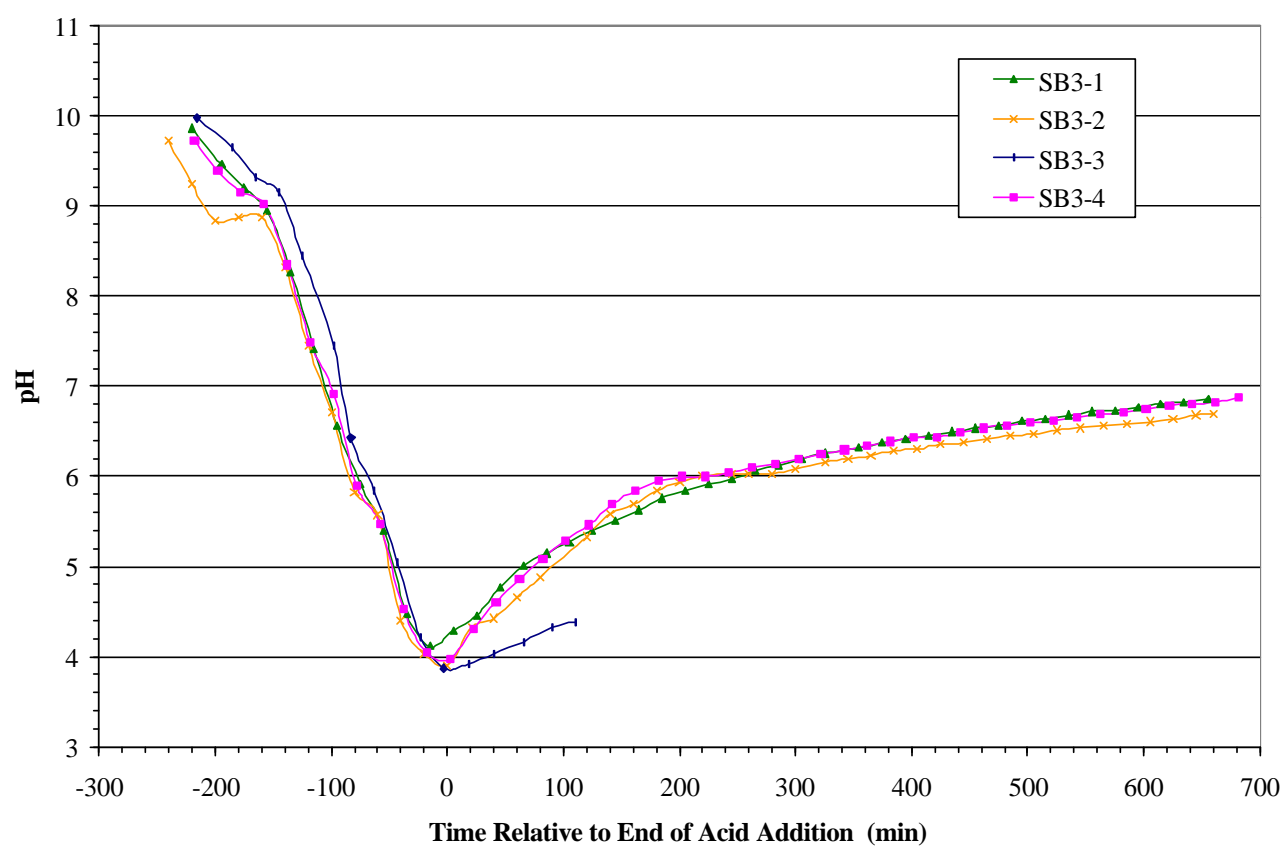

Figure C2 - pH during SRAT Processing for SB3-5 through SB3-8

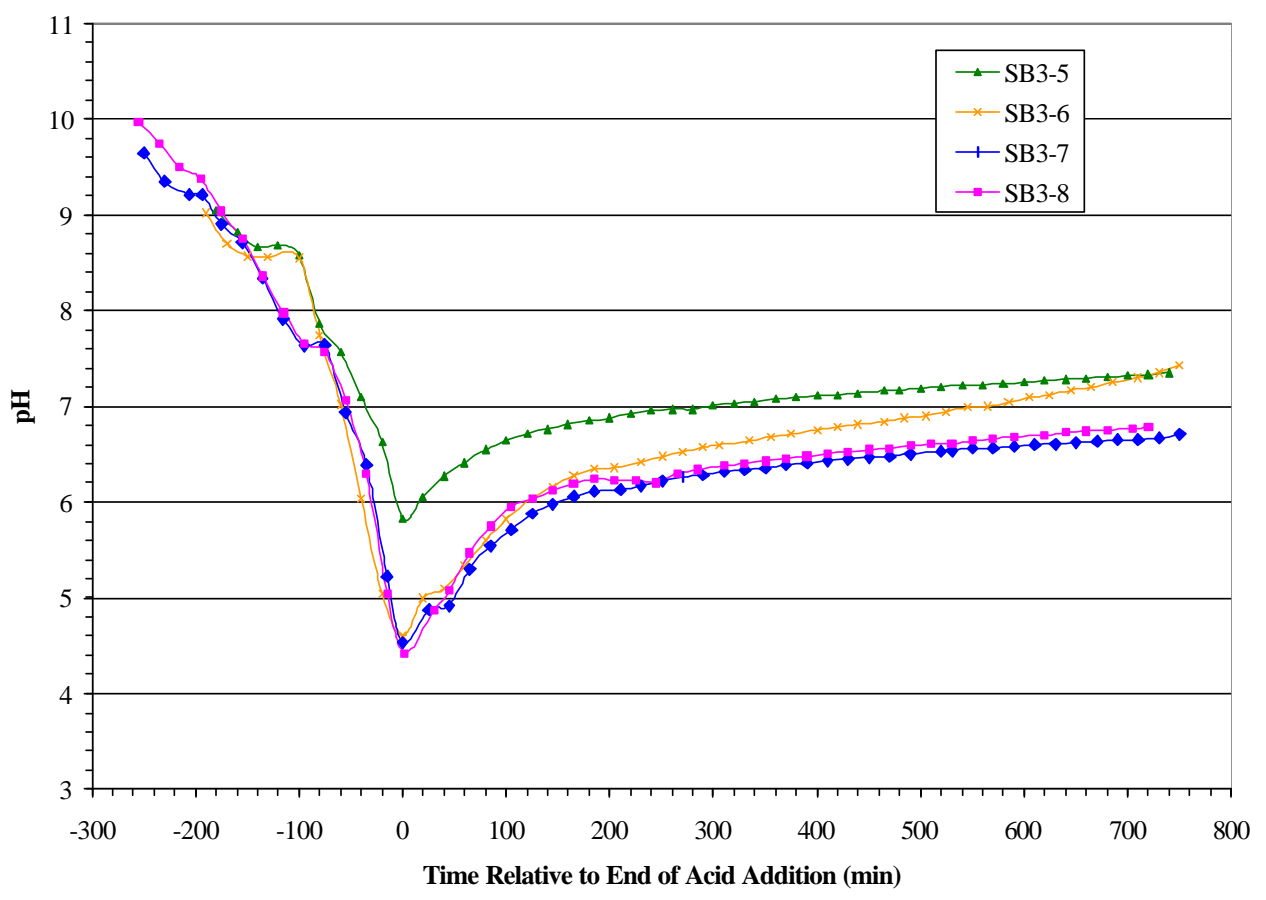


Figure C3 - pH Plots for Runs SB3-1 through SB3-8

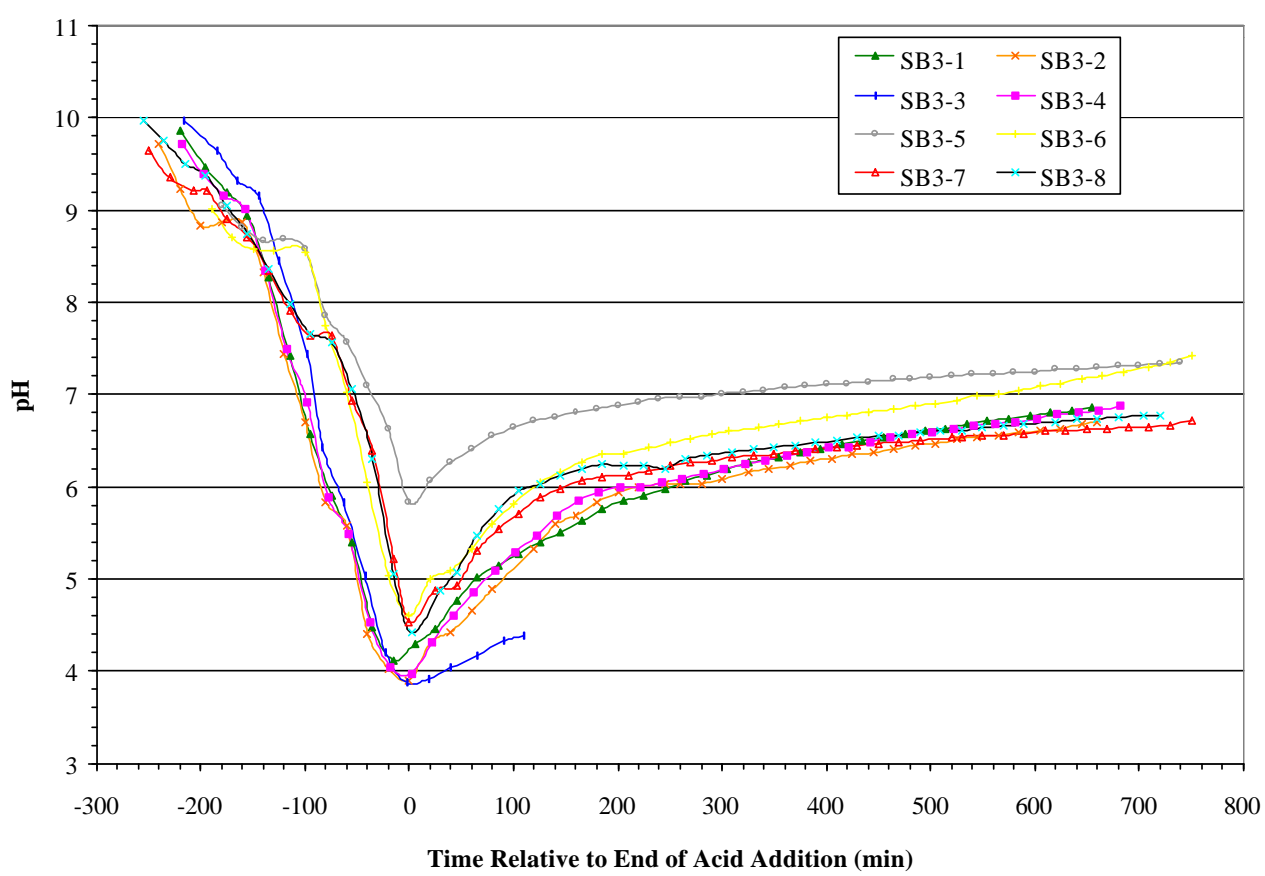


Westinghouse Savannah River Company

WSRC-TR-2002-00322

Savannah River Technology Center

Page 36 of 46

Appendix D - GC Results from SRAT Runs SB3-1 to SB3-8 
Figure D1 - Run SB3-1 GC Data

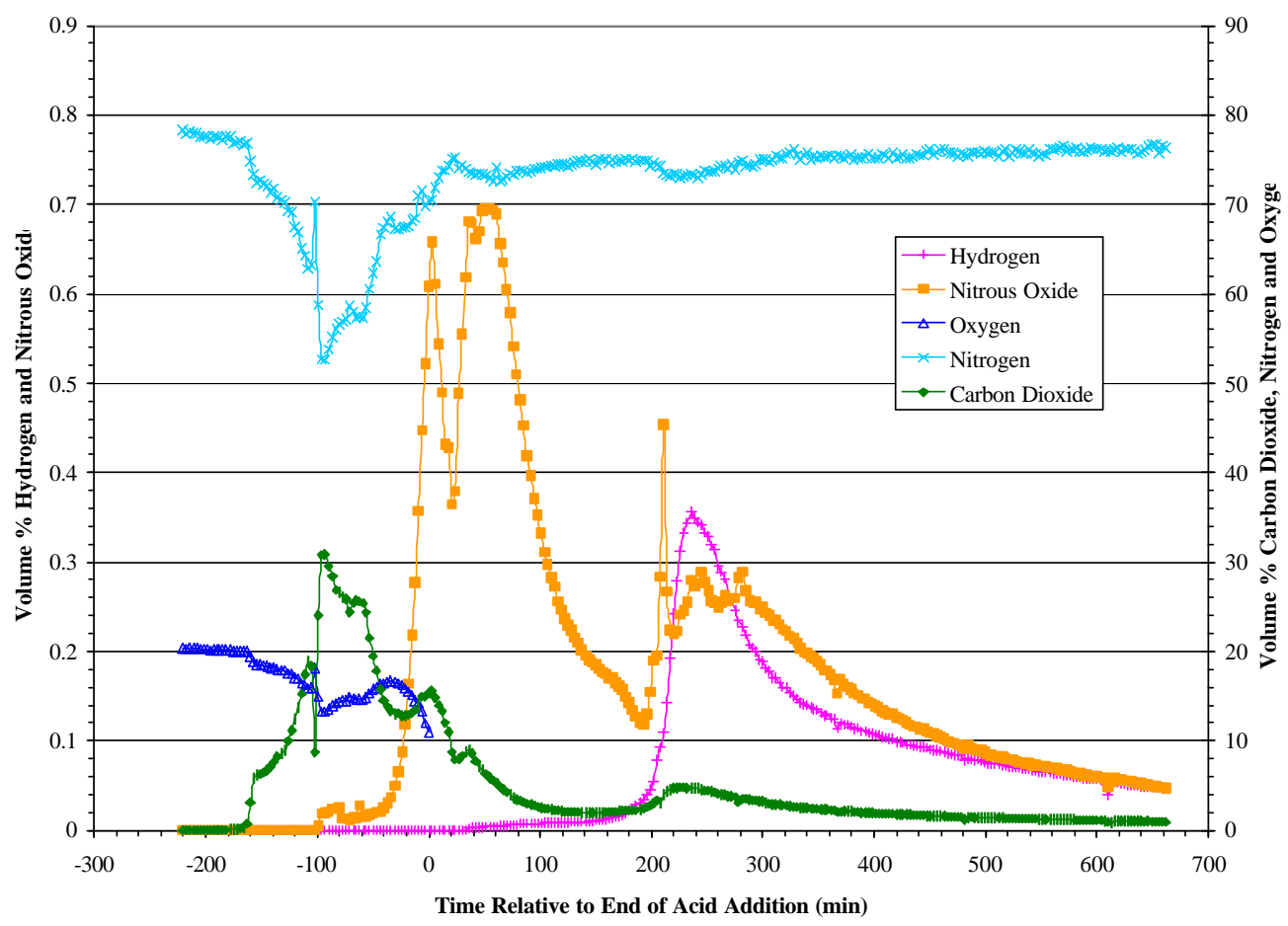

Figure D2 - Run SB3-2 GC Data

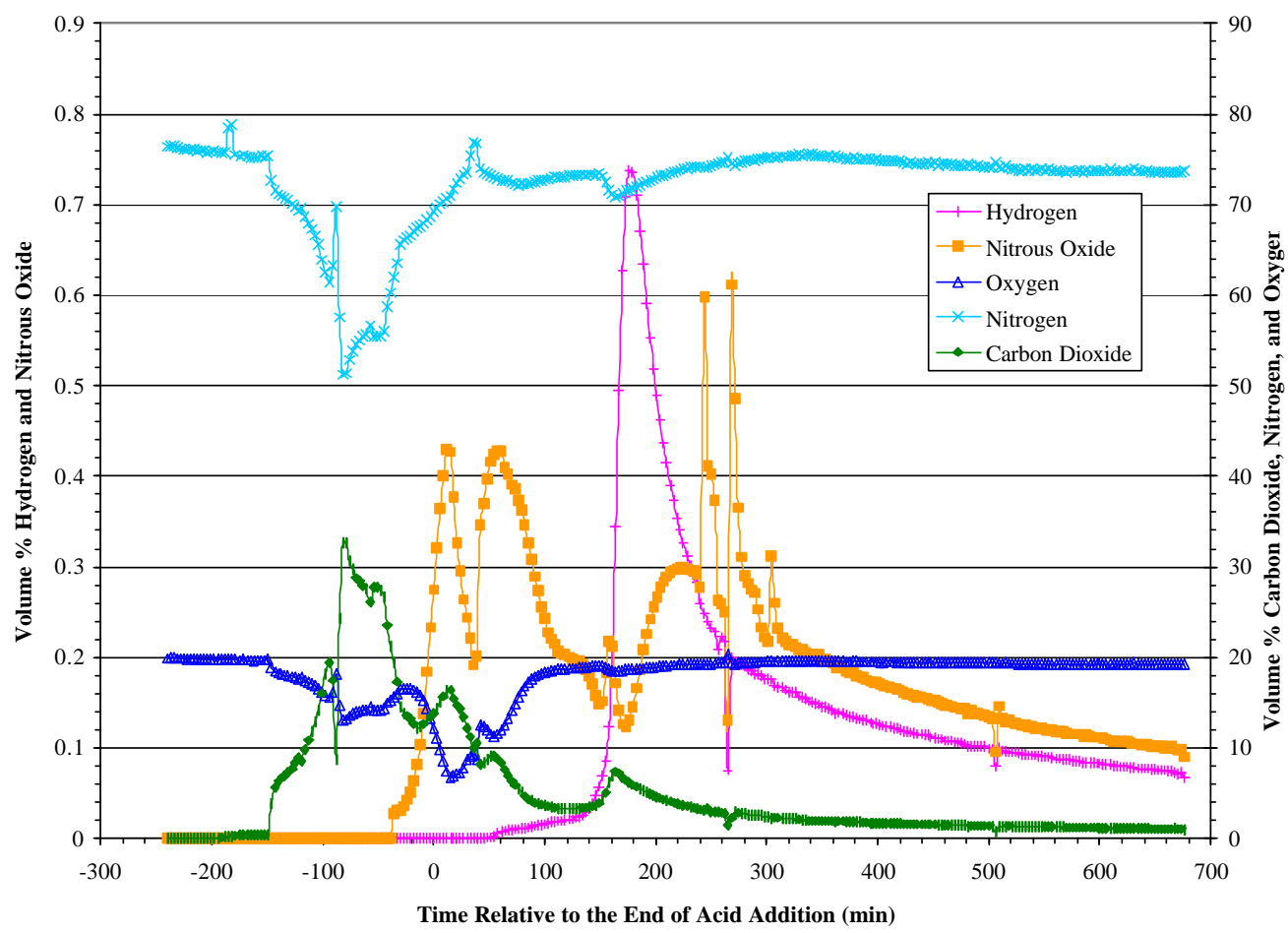


Figure D3 - Run SB3-3 GC Data

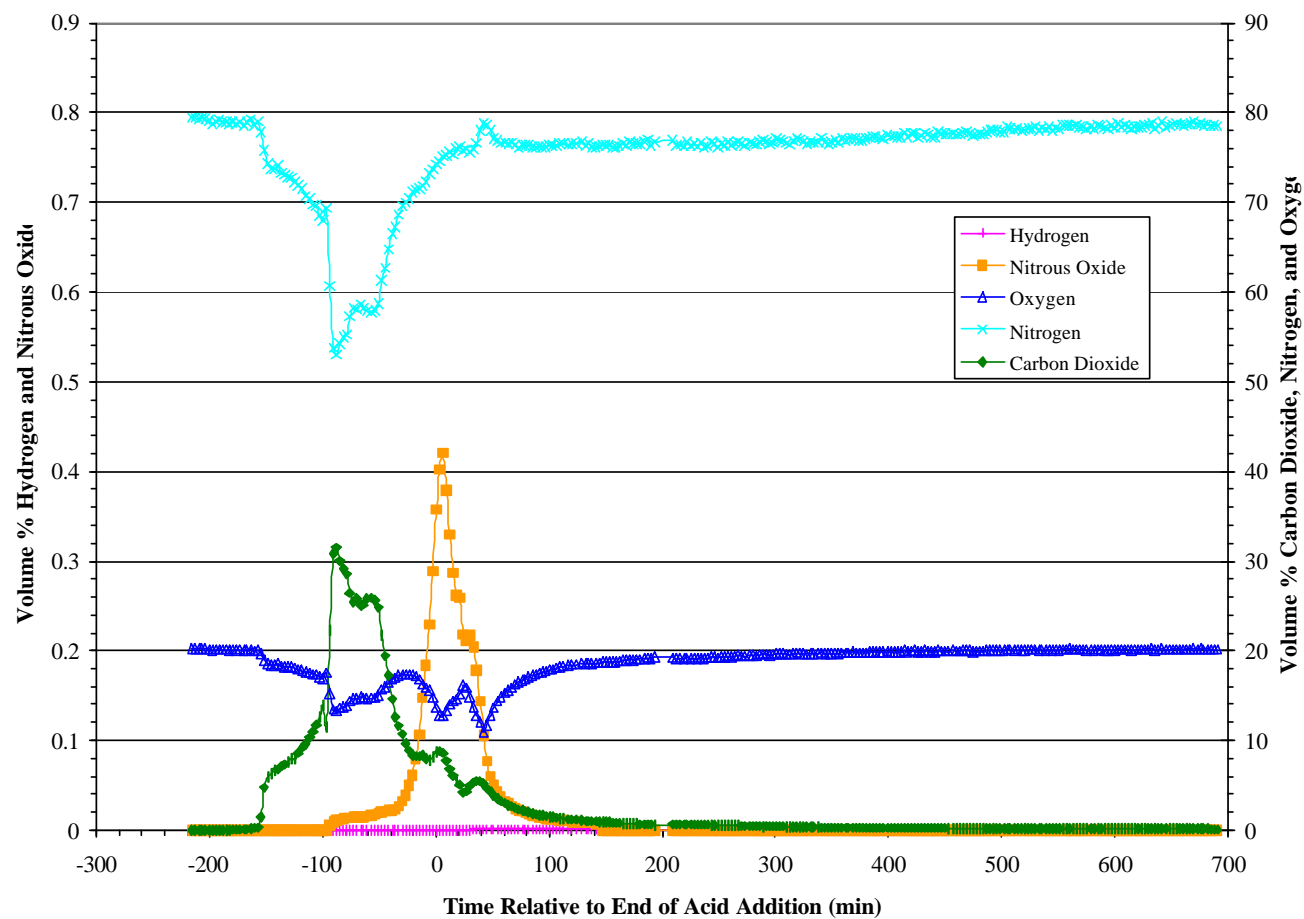

Figure D4 - Run SB3-4 GC Data

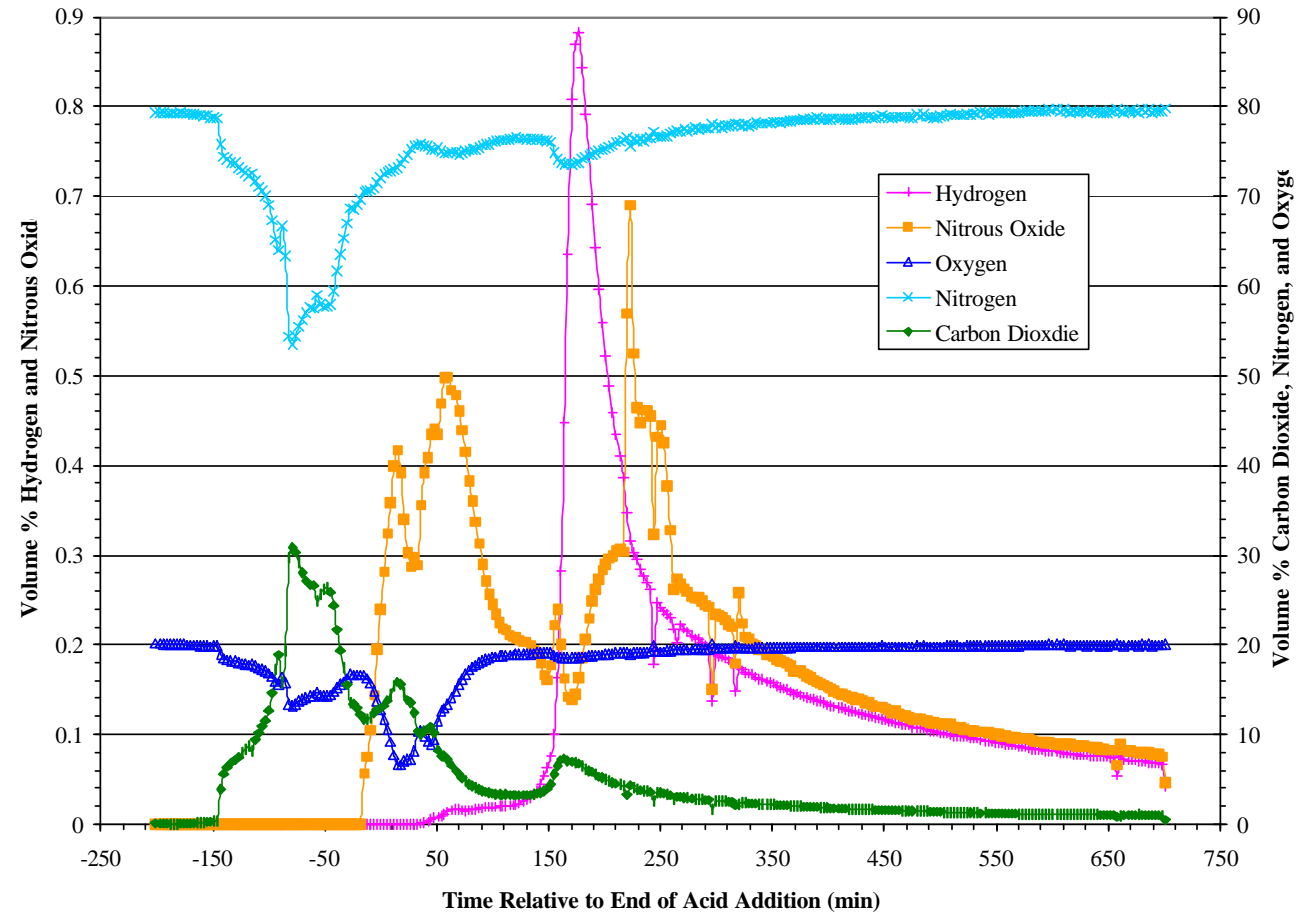


Figure D5 - Run SB3-5 GC Data

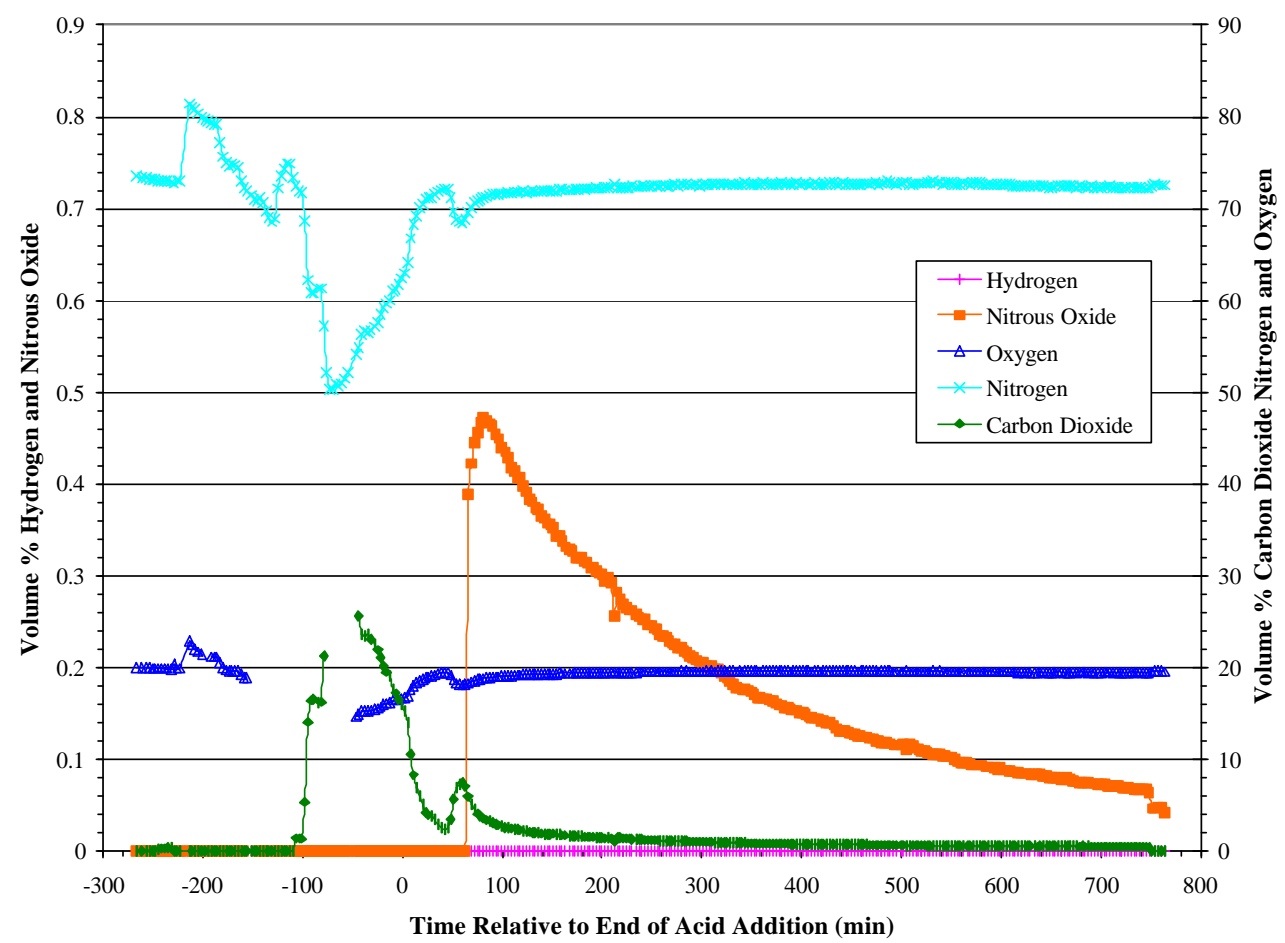

Figure D6 - Run SB3-6 GC Data

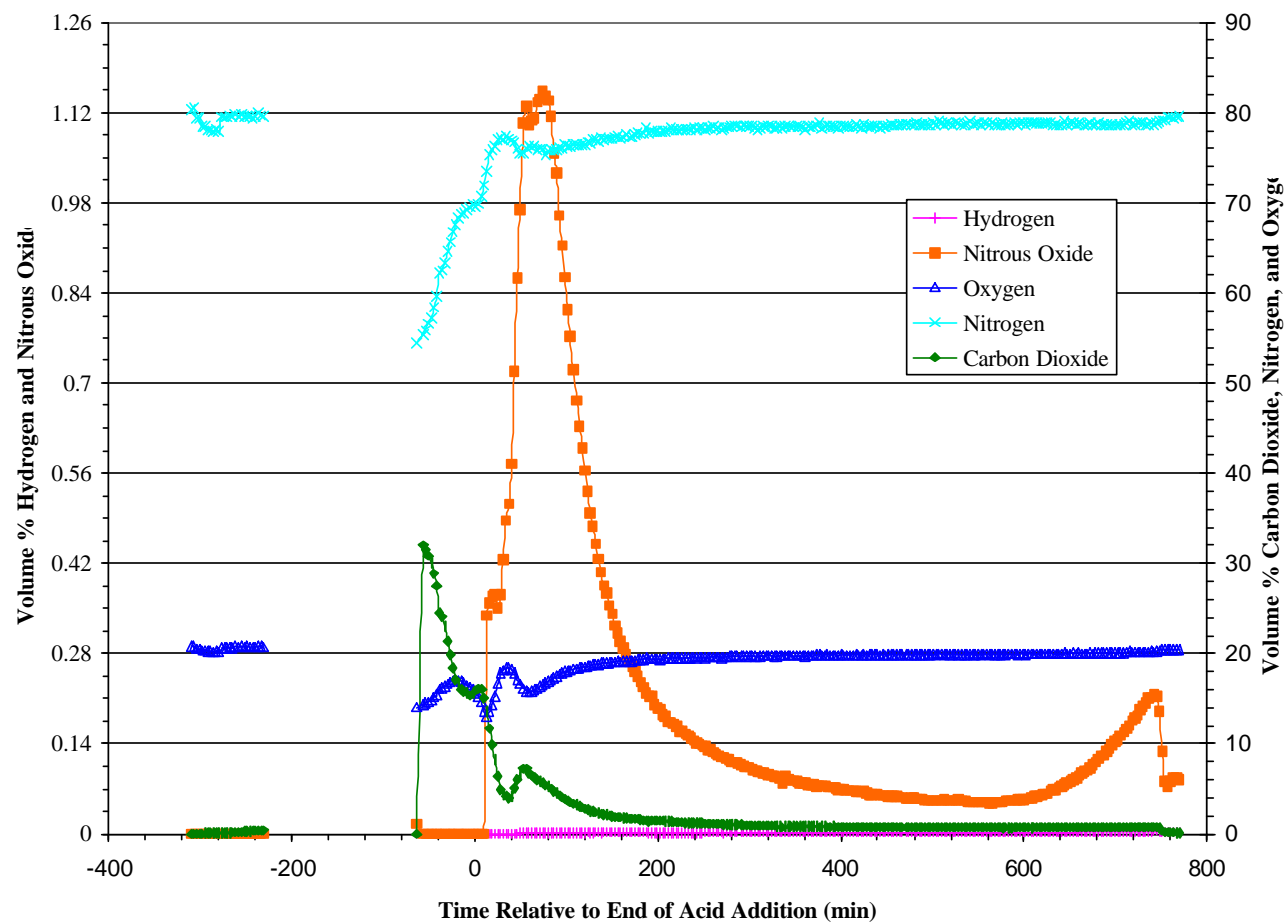


Westinghouse Savannah River Company

WSRC-TR-2002-00322

Savannah River Technology Center

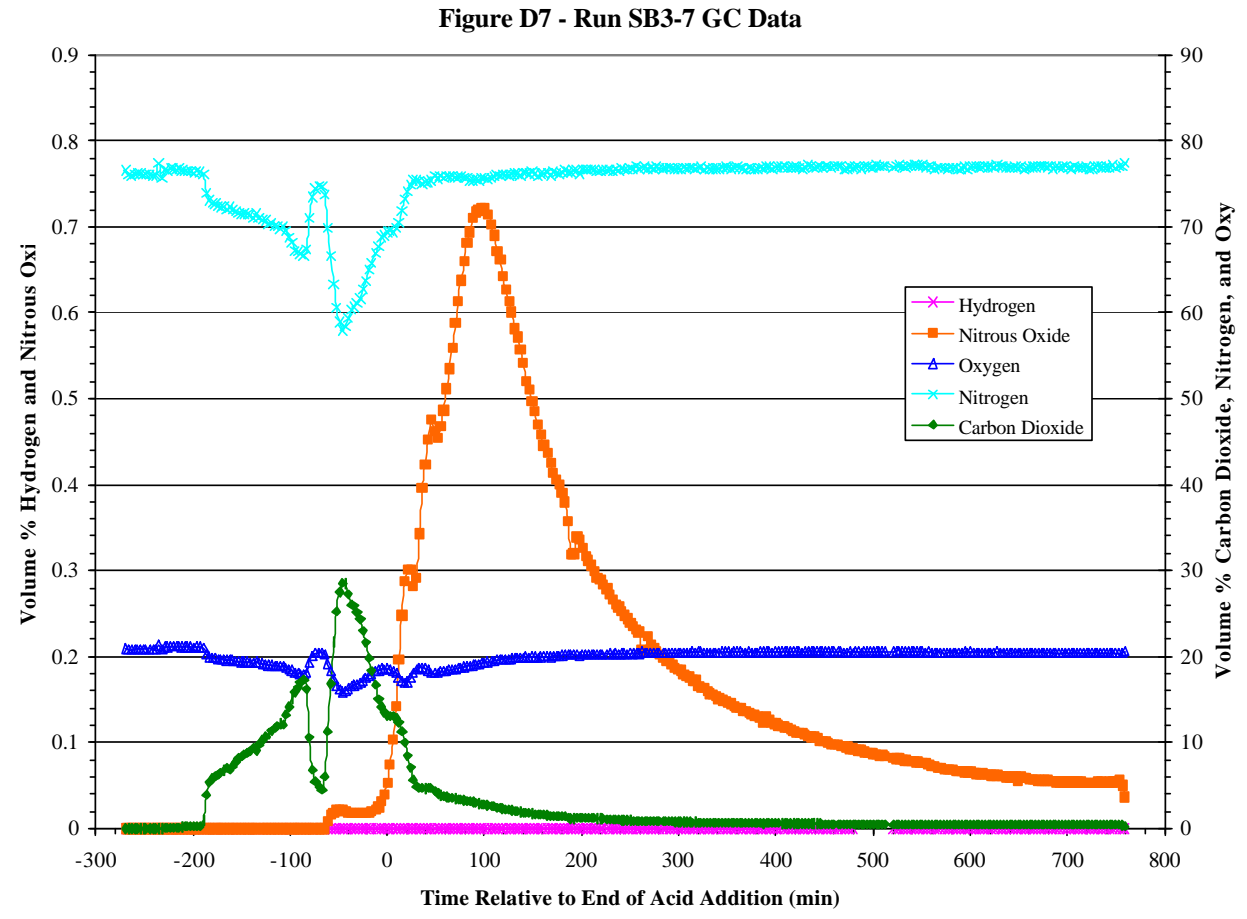

Figure D8 - Run SB3-8 GC Data

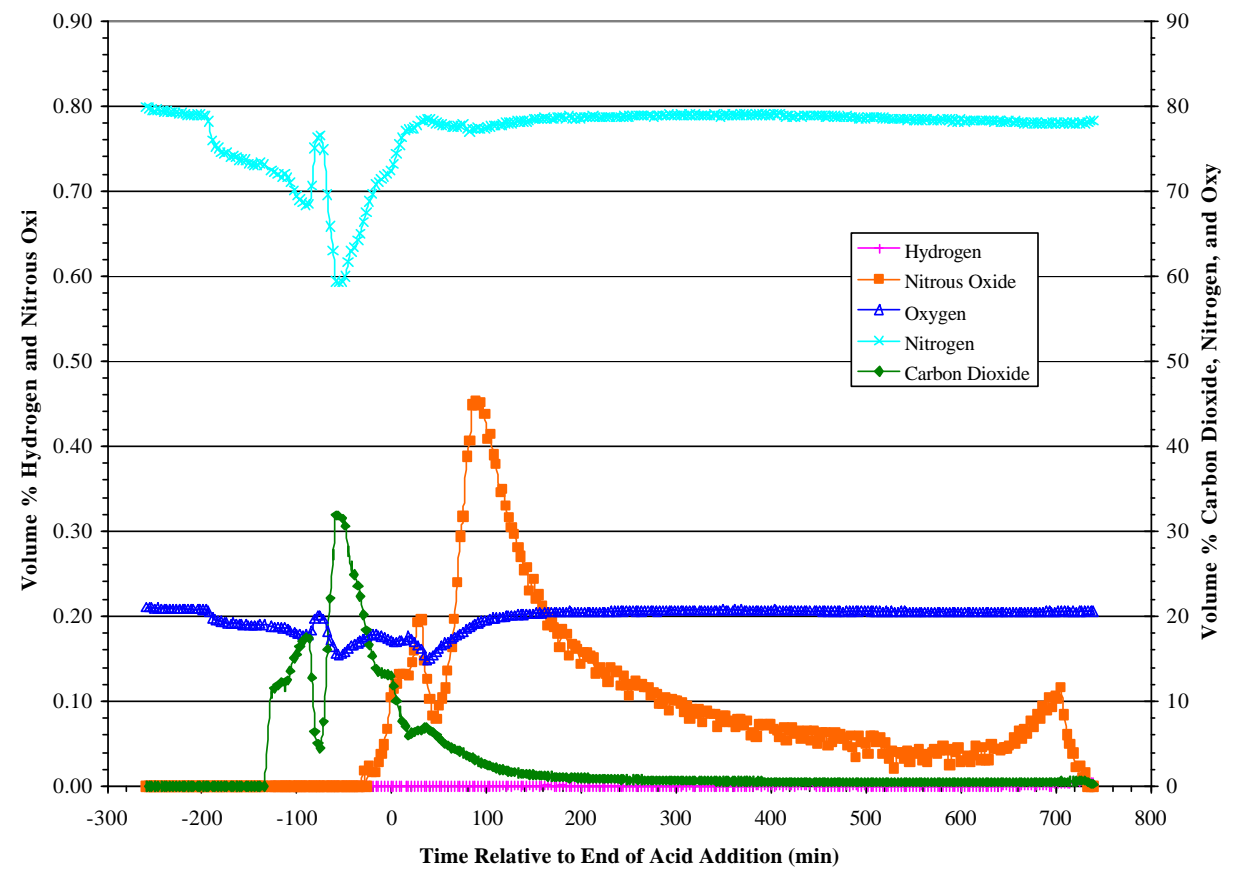


Westinghouse Savannah River Company

WSRC-TR-2002-00322

Savannah River Technology Center

Page 41 of 46

Appendix E - Supernate Analyses from SRAT Runs SB3-1 to SB3-8 
Table E1 - Supernate Results during Processing for Runs SB3-5 through SB3-8 (mg/L)

\begin{tabular}{|c|c|c|c|c|c|c|c|c|c|c|c|c|c|c|c|c|c|c|c|c|c|}
\hline Run & $\begin{array}{c}\text { Sample } \\
\text { ID }\end{array}$ & $\begin{array}{c}\text { Time Relative to End } \\
\text { of Acid Addition (min) }\end{array}$ & $\mathbf{p H}^{*}$ & Al & $\mathbf{B a}$ & Ca & $\mathrm{Cr}$ & $\mathrm{Cu}$ & $\mathbf{F e}$ & Gd & $\mathbf{K}$ & Mg & Mn & $\mathbf{N a}$ & $\mathbf{N i}$ & $\mathbf{R h}$ & $\mathbf{R u}$ & $\mathbf{S i}$ & Sm & $\mathbf{Z n}$ & $\mathbf{Z r}$ \\
\hline \multirow{6}{*}{ SB3-5 } & ICP-1 & 201 & 6.88 & 221 & 3.38 & 5.67 & $<1.00$ & 97.5 & 8.78 & 2.55 & 162 & 57.6 & 1330 & 34600 & 472 & 33 & 2.80 & 248 & $<2.00$ & 24.4 & $<0.100$ \\
\hline & ICP-2 & 320 & 7.03 & 179 & 3.63 & 6.49 & $<1.00$ & 101 & 6.06 & 2.64 & 171 & 69.8 & 1570 & 36500 & 593 & 29 & 1.95 & 48.1 & $<2.00$ & 23.1 & $<0.100$ \\
\hline & ICP-4 & 425 & 7.12 & 75 & 3.10 & 6.54 & $<1.00$ & 78.7 & 4.49 & 2.08 & 175 & 80.9 & 1650 & 36100 & 723 & 18 & 0.862 & 60.3 & $<2.00$ & 18.3 & $<0.100$ \\
\hline & ICP-6 & 553 & 7.22 & 45.3 & 2.58 & 5.99 & $<1.00$ & 67.5 & 2.97 & 1.77 & 174 & 83.7 & 1610 & 34900 & 740 & 16 & 0.575 & 61.9 & $<2.00$ & 16.5 & $<0.100$ \\
\hline & ICP-8 & 673 & 7.30 & 23.8 & 2.64 & 6.59 & $<1.00$ & 55.8 & 3.04 & 1.52 & 178 & 101 & 1680 & 35500 & 879 & 10 & $<0.300$ & 52.7 & $<2.00$ & 13.6 & $<0.100$ \\
\hline & ICP-10 & 743 & 7.35 & 25.4 & 3.12 & 7.75 & $<1.00$ & 57.8 & 6.96 & 1.62 & 183 & 109 & 1700 & 36900 & 916 & 8.3 & $<0.300$ & 74.5 & $<2.00$ & 12.3 & $<0.100$ \\
\hline \multirow{6}{*}{ SB3-6 } & ICP-1 & 193 & 6.35 & 1.04 & 0.47 & 11.6 & $<1.00$ & 3.24 & $<0.030$ & $<0.200$ & 171 & 92.3 & 745 & 24900 & 33.5 & 6.1 & $<0.300$ & 49.7 & $<2.00$ & $<0.100$ & $<0.100$ \\
\hline & ICP-2 & 313 & 6.56 & 0.732 & 0.502 & 10.0 & $<1.00$ & 3.18 & $<0.030$ & $<0.200$ & 172 & 84.8 & 570 & 25000 & 28.1 & 2.6 & $<0.300$ & 35.7 & $<2.00$ & $<0.100$ & $<0.100$ \\
\hline & ICP-4 & 429 & 6.79 & 0.747 & 0.366 & 8.34 & $<1.00$ & 2.81 & $<0.030$ & $<0.200$ & 174 & 78.4 & 540 & 25300 & 25.9 & 2.0 & $<0.300$ & 38.4 & $<2.00$ & $<0.100$ & $<0.100$ \\
\hline & ICP-6 & 548 & 6.99 & 0.737 & 0.125 & 5.32 & $<1.00$ & 2.26 & $<0.030$ & $<0.200$ & 176 & 73.2 & 492 & 25800 & 30 & 1.2 & $<0.300$ & 51.8 & $<2.00$ & $<0.100$ & $<0.100$ \\
\hline & ICP-8 & 670 & 7.21 & 0.776 & 0.087 & 4.51 & $<1.00$ & 1.53 & $<0.030$ & $<0.200$ & 179 & 55.2 & 366 & 26000 & 19.9 & 0.9 & $<0.300$ & 41.7 & $<2.00$ & $<0.100$ & $<0.100$ \\
\hline & ICP-10 & 743 & 7.39 & 0.735 & 0.443 & 5.85 & $<1.00$ & 1.86 & $<0.030$ & $<0.200$ & 181 & 53.4 & 299 & 26500 & 19.7 & 0.8 & $<0.300$ & 126 & $<2.00$ & $<0.100$ & $<0.100$ \\
\hline \multirow{10}{*}{ SB3-7 } & Initial - A & -215 & 4.53 & 10.3 & $<0.010$ & $<0.200$ & 1.94 & 0.457 & $<0.030$ & $<0.200$ & 125 & $<0.010$ & $<0.010$ & 16200 & 8.22 & 1.6 & $<0.300$ & 79.1 & $<0.500$ & $<0.100$ & $<0.100$ \\
\hline & Initial - B & -215 & 4.52 & 10.3 & $<0.010$ & $<0.200$ & 1.94 & 0.457 & $<0.030$ & $<0.200$ & 125 & $<0.010$ & $<0.010$ & 16200 & 8.27 & 1.6 & $<0.300$ & 81.5 & $<0.500$ & $<0.100$ & $<0.100$ \\
\hline & ICP-0 & 11 & 4.68 & 1120 & 3.74 & 29.2 & 1.79 & 48.6 & 221 & 0.339 & 107 & 61 & 959 & 23800 & 82.1 & 65 & 15.9 & 29.0 & $<2.00$ & 4.20 & $<0.100$ \\
\hline & ICP-1 & 107 & 5.72 & 790 & 1.38 & 8.62 & 1.27 & 56.4 & 41.5 & 0.569 & 121 & 42.9 & 519 & 25600 & 57.3 & 46 & 18.8 & 77.0 & $<2.00$ & 4.06 & $<0.100$ \\
\hline & ICP-2 & 190 & 6.11 & 641 & 0.796 & 4.87 & 1.08 & 65.4 & 20.3 & 0.95 & 129 & 33.8 & 544 & 28400 & 77.4 & 29 & 8.86 & 43.9 & $<2.00$ & 6.98 & $<0.100$ \\
\hline & ICP-4 & 318 & 6.32 & 514 & 0.768 & 4.23 & $<1.00$ & 79.1 & 14.8 & 1.16 & 133 & 23.4 & 700 & 28900 & 85.8 & 21 & 2.99 & 43.0 & $<2.00$ & 11.2 & $<0.100$ \\
\hline & ICP-6 & 431 & 6.45 & 431 & 0.939 & 5.00 & $<1.00$ & 88.6 & 10.3 & 1.42 & 135 & 23.4 & 850 & 29700 & 115 & 16 & 1.29 & 78.5 & $<2.00$ & 13.2 & $<0.100$ \\
\hline & ICP-8 & 551 & 6.56 & 360 & 0.967 & 5.07 & $<1.00$ & 89.2 & 8.74 & 1.51 & 135 & 24.2 & 931 & 30000 & 145 & 13 & 0.596 & 90.4 & $<2.00$ & 13.5 & $<0.100$ \\
\hline & ICP-10 & 671 & 6.63 & 357 & 1.040 & 5.33 & $<1.00$ & 89.7 & 5.95 & 1.58 & 136 & 26.6 & 1040 & 29400 & 172 & 9.7 & $<0.300$ & \begin{tabular}{|l|}
73.8 \\
\end{tabular} & $<2.00$ & 13.9 & $<0.100$ \\
\hline & ICP-12 & 751 & 6.71 & 270 & $<0.020$ & 6.06 & 0.208 & 93.2 & 7.39 & 0.558 & 138 & 26.5 & 1100 & 30200 & 187 & 8.85 & 0.241 & 95.3 & 0.671 & 15.1 & $<0.010$ \\
\hline \multirow{10}{*}{ SB3-8 } & Initial-A & -201 & 9.44 & 19.5 & $<0.010$ & $<0.200$ & 1.91 & 0.464 & $<0.030$ & $<0.200$ & 123 & $<0.010$ & $<0.010$ & 15600 & 5.15 & 1.6 & $<0.300$ & 125 & $<2.00$ & $<0.100$ & $<0.100$ \\
\hline & Initial-B & -201 & 9.43 & 19.5 & $<0.010$ & $<0.200$ & 1.89 & 0.467 & $<0.030$ & $<0.200$ & 124 & $<0.010$ & $<0.010$ & 15700 & 5.1 & 1.6 & $<0.300$ & 123 & $<2.00$ & $<0.100$ & $<0.100$ \\
\hline & ICP-0 & 8 & 4.52 & 1140 & 3.69 & 35.7 & 1.71 & 54.7 & 235 & 0.283 & 110 & 45.7 & 804 & 24100 & 50.5 & 65 & 15.2 & 34.4 & $<2.00$ & 5.20 & $<0.100$ \\
\hline & ICP-1 & 102 & 5.92 & 695 & 1.15 & 6.42 & 1.15 & 58.0 & 28.8 & 0.642 & 119 & 38 & 504 & 25600 & 61.2 & 38 & 10.2 & 34.6 & $<2.00$ & 3.89 & $<0.100$ \\
\hline & ICP-2 & 185 & 6.24 & 572 & 0.956 & 4.96 & 1.00 & 68.0 & 15.8 & 1.14 & 136 & 36.6 & 640 & 29000 & 91.2 & 24 & 3.65 & 42.0 & $<2.00$ & 6.87 & $<0.100$ \\
\hline & ICP-4 & 307 & 6.37 & 517 & 0.911 & 4.45 & $<1.00$ & 68.0 & 13.7 & 1.11 & 136 & 33.6 & 690 & 28600 & 96.9 & 19 & 1.95 & 225 & $<2.00$ & 7.30 & $<0.100$ \\
\hline & ICP-6 & 410 & 6.50 & 360 & 0.970 & 4.72 & $<1.00$ & 70.0 & 7.77 & 1.26 & 137 & 31.9 & 800 & 29200 & 129 & 13 & 0.548 & 57.0 & $<2.00$ & 8.57 & $<0.100$ \\
\hline & ICP-8 & 532 & 6.61 & 277 & 1.08 & 5.14 & $<1.00$ & 71.6 & 5.64 & 1.36 & 140 & 33.9 & 954 & 28500 & 174 & 9.0 & $<0.300$ & 36.2 & $<2.00$ & 9.90 & $<0.100$ \\
\hline & ICP-10 & 652 & 6.73 & 212 & 0.983 & 4.92 & $<1.00$ & 69.4 & 4.10 & 1.29 & 140 & 34.5 & 970 & 29500 & 200 & 7.1 & $<0.300$ & 48.5 & $<2.00$ & 10.5 & $<0.100$ \\
\hline & ICP-12 & 726 & 6.78 & 175 & $<0.020$ & 4.33 & 0.09 & 65.2 & 7.99 & 0.279 & 146 & 34.5 & 1050 & 28200 & 231 & 5.35 & $<0.200$ & 55.5 & 0.596 & 11.9 & $<0.010$ \\
\hline
\end{tabular}

$* \mathrm{pH}$ is not adjusted for temperature in these results since these are from SRAT processing. 
Table E2 - Supernate Results for SRAT Product Samples (mg/L)

\begin{tabular}{|c|c|c|c|c|c|c|c|c|c|c|c|c|c|c|c|c|c|c|c|}
\hline Run & $\mathbf{p H}^{1}$ & Al & $\mathbf{B a}$ & $\mathbf{C a}$ & $\mathrm{Cr}$ & $\mathrm{Cu}$ & $\mathrm{Fe}$ & Gd & $\mathbf{K}$ & $\mathrm{Mg}$ & Mn & $\mathbf{N a}$ & $\mathbf{N i}$ & $\mathbf{R h}$ & $\mathbf{R u}$ & $\mathbf{S i}$ & $\mathbf{S m}^{2}$ & $\mathbf{Z n}$ & $\mathbf{Z r}$ \\
\hline \multirow{2}{*}{ SB3-1 } & \multirow{2}{*}{7.81} & 0.631 & 1.84 & 3690 & $<1.00$ & 0.211 & $<0.030$ & $<0.200$ & 158 & 143 & 640 & 13600 & 0.28 & 0.9 & $<0.300$ & 233 & N/A & $<0.100$ & $<0.100$ \\
\hline & & \begin{tabular}{|l|}
0.621 \\
\end{tabular} & 1.85 & 3680 & $<1.00$ & 0.209 & $<0.030$ & $<0.200$ & 157 & 141 & 625 & 13800 & 0.28 & 0.9 & $<0.300$ & 227 & N/A & $<0.100$ & $<0.100$ \\
\hline \multirow{2}{*}{ SB3-2 } & \multirow{2}{*}{7.7} & 0.627 & 1.75 & 3780 & $<1.00$ & 0.206 & $<0.030$ & $<0.200$ & 158 & 159 & 801 & 13600 & 0.46 & 0.8 & $<0.300$ & 167 & N/A & $<0.100$ & $<0.100$ \\
\hline & & 0.629 & 1.76 & 3770 & $<1.00$ & 0.206 & $<0.030$ & $<0.200$ & 158 & 159 & 794 & 13300 & 0.44 & 0.8 & $<0.300$ & 167 & N/A & $<0.100$ & $<0.100$ \\
\hline \multirow{2}{*}{ SB3-3 } & \multirow{2}{*}{5.79} & 0.662 & 1.59 & 4730 & $<1.00$ & 2.08 & $<0.030$ & 0.225 & 157 & 236 & 3690 & 13600 & 525 & 0.5 & $<0.300$ & 120 & N/A & 10.9 & 14.3 \\
\hline & & 0.633 & 1.58 & 4700 & $<1.00$ & 2.08 & $<0.030$ & 0.208 & 156 & 238 & 3660 & 13500 & 526 & 0.6 & $<0.300$ & 120 & N/A & 10.9 & 14.3 \\
\hline \multirow{2}{*}{ SB3-4 } & \multirow{2}{*}{7.52} & 0.629 & 1.68 & 3800 & $<1.00$ & 0.216 & $<0.030$ & $<0.200$ & 163 & 155 & 570 & 14100 & 0.47 & 0.9 & $<0.300$ & 174 & N/A & $<0.100$ & $<0.100$ \\
\hline & & 0.610 & 1.68 & 3790 & $<1.00$ & 0.216 & $<0.030$ & $<0.200$ & 164 & 155 & 572 & 14200 & 0.45 & 0.9 & $<0.300$ & 177 & N/A & $<0.100$ & $<0.100$ \\
\hline \multirow{2}{*}{ SB3-5 } & \multirow{2}{*}{8.20} & 12.0 & 1.45 & 3.32 & $<0.020$ & 44.4 & $<0.030$ & $<0.200$ & 198 & 102 & 1570 & 38900 & 927 & 9.0 & $<0.300$ & 21.3 & $<0.500$ & 17.2 & $<0.100$ \\
\hline & & 12.1 & 1.48 & 3.63 & $<0.020$ & 44.5 & $<0.030$ & $<0.200$ & 202 & 103 & 1560 & 40700 & 937 & 9.0 & $<0.300$ & 21.4 & $<0.500$ & 17.5 & $<0.100$ \\
\hline \multirow{2}{*}{ SB3-6 } & \multirow{2}{*}{8.31} & 1.08 & 0.113 & 1.68 & $<0.020$ & 1.19 & $<0.030$ & $<0.200$ & 200 & 96.7 & 283 & 26800 & 28.3 & 0.6 & $<0.300$ & 68.0 & $<0.500$ & $<0.100$ & $<0.100$ \\
\hline & & 0.796 & 0.141 & 1.19 & $<0.020$ & 1.19 & $<0.030$ & $<0.200$ & 195 & 98.8 & 277 & 27600 & 28.9 & 0.6 & $<0.300$ & 69.9 & $<0.500$ & $<0.100$ & $<0.100$ \\
\hline \multirow{2}{*}{ SB3-7 } & \multirow{2}{*}{7.65} & 156 & $<0.010$ & 1.62 & 0.054 & 81.8 & 2.22 & $<0.200$ & 152 & 19.6 & 740 & 30500 & 82.1 & 8.8 & $<0.300$ & 44.0 & $<0.500$ & 13.6 & $<0.100$ \\
\hline & & 156 & $<0.010$ & 1.46 & $<0.020$ & 76.9 & 2.03 & $<0.200$ & 151 & 18.3 & 742 & 31500 & 77.3 & 8.3 & $<0.300$ & 41.2 & $<0.500$ & 12.7 & $<0.100$ \\
\hline \multirow{2}{*}{ SB3-8 } & \multirow{2}{*}{7.81} & 75.8 & $<0.010$ & 1.21 & $<0.020$ & 58.0 & 0.468 & $<0.200$ & 162 & 23.5 & 739 & 30600 & 92.3 & 4.8 & $<0.300$ & 37.6 & $<0.500$ & 8.45 & $<0.100$ \\
\hline & & 73.4 & $<0.010$ & 1.12 & $<0.020$ & 56.0 & 0.438 & $<0.200$ & 162 & 22.6 & 738 & 31800 & 89.6 & 4.7 & $<0.300$ & 36.4 & $<0.500$ & 8.17 & $<0.100$ \\
\hline
\end{tabular}

1. $\mathrm{pH}$ is not adjusted for temperature in these results since these are from SRAT processing.

2. Samarium was not added to Runs SB3-1 through SB3-4. 
Table E3 - Supernate Results for Low pH Test with Oxalate in SRAT Product Samples (mg/L)

\begin{tabular}{|c|c|c|c|c|c|c|c|c|c|c|c|c|c|c|}
\hline $\begin{array}{c}\text { Measured } \\
\text { pH }\end{array}$ & 5.97 & 5.02 & 4.01 & 4.01 & 3.52 & 3.54 & 3.00 & 3.02 & 2.50 & 2.50 & 2.51 & 2.07 & 1.93 & 1.94 \\
\hline $\begin{array}{c}\text { Corrected } \\
\text { pH }\end{array}$ & 6.14 & 5.35 & 4.51 & 4.51 & 4.10 & 4.12 & 3.67 & 3.69 & 3.25 & 3.25 & 3.26 & 2.90 & 2.78 & 2.79 \\
\hline Al & 536 & 887 & 1040 & 1180 & 1290 & 1380 & 1570 & 1600 & 1920 & 2270 & 2480 & 2670 & 3390 & 3100 \\
\hline $\mathbf{B a}$ & 1.67 & 9.33 & 6.53 & 6.75 & 4.81 & 4.49 & 4.79 & 4.81 & 5.54 & 6.30 & 6.98 & 10.4 & 12.6 & 13.9 \\
\hline Ca & 1.17 & 17.6 & 78.2 & 103 & 121 & 142 & 258 & 306 & 478 & 635 & 726 & 1045 & 1740 & 1920 \\
\hline $\mathrm{Cr}$ & 0.123 & 2.04 & 1.69 & 2.01 & 1.29 & 1.38 & 1.31 & 1.39 & 1.46 & 1.54 & 1.52 & 1.58 & 1.69 & 1.38 \\
\hline $\mathbf{C u}$ & 29.0 & 142 & 142 & 166 & 114 & 110 & 106 & 103 & 105 & 93.1 & 81.7 & 81.4 & 74.4 & 60.9 \\
\hline $\mathrm{Fe}$ & 44.6 & 159 & 383 & 340 & 523 & 432 & 664 & 576 & 832 & 720 & 683 & 962 & 889 & 706 \\
\hline Gd & 0.870 & 0.090 & 0.193 & 0.209 & 0.405 & 0.474 & 0.912 & 1.16 & 2.36 & 3.25 & 3.73 & 7.01 & 9.14 & 9.66 \\
\hline $\mathbf{K}$ & 151 & 156 & 155 & 156 & 157 & 161 & 161 & 162 & 163 & 165 & 167 & 166 & 177 & 142 \\
\hline Mg & 17.4 & 35.3 & 22.9 & 25.8 & 17.6 & 19.9 & 19.6 & 23.0 & 24.6 & 33.6 & 42.8 & 47.6 & 56.9 & 52.7 \\
\hline Mn & 738 & 636 & 926 & 942 & 1040 & 1050 & 1090 & 1020 & 1170 & 1470 & 1750 & 1940 & 2210 & 1930 \\
\hline $\mathbf{N a}$ & 30600 & 31100 & 30100 & 30800 & 29600 & 29300 & 29600 & 29800 & 28500 & 29100 & 28700 & 28200 & 28200 & 23400 \\
\hline $\mathbf{N i}$ & 71.7 & 43.2 & 36.1 & 41.8 & 45.2 & 44.0 & 56.3 & 66.5 & 87.9 & 93.6 & 78.9 & 153 & 164 & 160 \\
\hline $\mathbf{P b}$ & 0.166 & 0.188 & 0.111 & $<0.010$ & 0.086 & 0.173 & 0.609 & 0.882 & 2.40 & 2.90 & 3.46 & 8.08 & 8.86 & 8.54 \\
\hline Rh & 5.32 & 16.8 & 13.8 & 17.1 & 11.9 & 12.9 & 12.5 & 13.3 & 13.6 & 14.5 & 15.3 & 15.6 & 16.5 & 13.8 \\
\hline Ru & 0.032 & 1.98 & 2.82 & 5.62 & 4.18 & 6.22 & 6.58 & 9.24 & 10.2 & 14.2 & 16.8 & 17.7 & 21.8 & 18.6 \\
\hline $\mathrm{Si}$ & 72.2 & 83.7 & 110 & 70.4 & 104 & 106 & 115 & 98.8 & 87.3 & 67.4 & 46.8 & 41.8 & 39.8 & 25.3 \\
\hline Sm & 0.374 & 0.217 & 0.190 & 0.195 & 0.279 & 0.320 & 0.553 & 0.741 & 1.49 & 1.98 & 1.98 & 4.53 & 5.62 & 6.06 \\
\hline Zn & 10.3 & 14.8 & 20.3 & 23.7 & 27.9 & 26.2 & 32.6 & 34.9 & 41.0 & 44.3 & 42.5 & 50.9 & 59.1 & 57.5 \\
\hline $\mathbf{Z r}$ & $<0.100$ & $<0.100$ & $<0.100$ & $<0.100$ & $<0.100$ & $<0.100$ & $<0.100$ & $<0.100$ & $<0.100$ & $<0.100$ & $<0.100$ & $<0.100$ & $<0.100$ & $<0.100$ \\
\hline
\end{tabular}


Table E4 - Supernate Results for Low pH Test without Oxalate in SRAT Product Samples (mg/L)

\begin{tabular}{|c|c|c|c|c|c|c|c|c|c|c|c|c|c|}
\hline $\begin{array}{c}\text { Measured } \\
\text { pH }^{1}\end{array}$ & 6.01 & 5.01 & 4.00 & 4.12 & 3.49 & 3.58 & 2.99 & 2.50 & 2.58 & 2.45 & 1.99 & 2.07 & 1.94 \\
\hline $\begin{array}{c}\text { Corrected } \\
\text { pH }^{2}\end{array}$ & 6.18 & 5.34 & 4.50 & 4.60 & 4.08 & 4.15 & 3.66 & 3.25 & 3.32 & 3.21 & 2.83 & 2.90 & 2.79 \\
\hline Al & 0.287 & 0.171 & 1.17 & 1.60 & 43.4 & 27.4 & 135 & 322 & 294 & 342 & 569 & 1020 & 1440 \\
\hline $\mathbf{B a}$ & 3.41 & 5.22 & 7.26 & 7.80 & 8.04 & 9.29 & 11.8 & 18.3 & 19.9 & 21.8 & 31.7 & 27.0 & 44.4 \\
\hline $\mathbf{C a}$ & 3980 & 4380 & 4590 & 4640 & 4660 & 4720 & 4720 & 4570 & 4750 & 4780 & 4680 & 4690 & 4720 \\
\hline $\mathrm{Cr}$ & $<0.100$ & $<0.100$ & $<0.100$ & $<0.100$ & $<0.100$ & $<0.100$ & $<0.100$ & $<0.100$ & $<0.100$ & $<0.100$ & $<0.100$ & $<0.100$ & $<0.100$ \\
\hline $\mathbf{C u}$ & $<0.050$ & 0.290 & 5.35 & 7.54 & 30.4 & 51.2 & 96.6 & 135 & 142 & 160 & 177 & 187 & 198 \\
\hline $\mathbf{F e}$ & $<0.050$ & $<0.050$ & $<0.050$ & $<0.050$ & 1.14 & 80.2 & 180 & 414 & 697 & 1260 & 1280 & 1680 & 1860 \\
\hline Gd & $<0.200$ & $<0.200$ & 0.142 & 0.316 & 1.07 & 1.38 & 2.52 & 4.52 & 5.28 & 6.03 & 8.48 & 10.0 & 15.5 \\
\hline $\mathbf{K}$ & 168 & 165 & 165 & 165 & 165 & 164 & 166 & 164 & 162 & 172 & 163 & 174 & 165 \\
\hline Mg & 176 & 196 & 208 & 213 & 214 & 215 & 215 & 222 & 223 & 227 & 224 & 228 & 226 \\
\hline Mn & 1300 & 2980 & 4680 & 5160 & 5400 & 5560 & 5660 & 5530 & 5700 & 5660 & 5580 & 5620 & 5620 \\
\hline $\mathrm{Na}$ & 14400 & 14000 & 14100 & 13500 & 13300 & 13800 & 13500 & 14200 & 13700 & 13200 & 13700 & 13800 & 13300 \\
\hline $\mathbf{N i}$ & 4.58 & 50.4 & 392 & 564 & 924 & 1240 & 1530 & 2000 & 2270 & 2480 & 2540 & 2740 & 2860 \\
\hline $\mathbf{P b}$ & $<0.200$ & $<0.200$ & $<0.200$ & $<0.200$ & 0.509 & 0.623 & 1.86 & 4.84 & 5.50 & 6.87 & 12.0 & 12.8 & 20.4 \\
\hline Rh & 0.889 & 1.36 & 2.55 & 2.88 & 4.15 & 3.75 & 4.90 & 5.51 & 5.15 & 4.20 & 4.33 & 4.76 & 5.21 \\
\hline Ru & $<0.300$ & $<0.300$ & $<0.300$ & 0.642 & 1.86 & 2.81 & 5.26 & 9.51 & 11.5 & 12.4 & 13.7 & 16.9 & 18.5 \\
\hline $\mathbf{S i}$ & 92.7 & 92.7 & 81.3 & 90.9 & 92.7 & 92.3 & 73.8 & 70.4 & 62.9 & 50.0 & 46.4 & 43.4 & 39.1 \\
\hline $\mathbf{Z n}$ & $<0.100$ & $<0.100$ & 10.5 & 17.1 & 45.7 & 67.3 & 99.4 & 146 & 162 & 190 & 200 & 229 & 242 \\
\hline $\mathbf{Z r}$ & $<0.100$ & $<0.100$ & $<0.100$ & $<0.100$ & $<0.100$ & $<0.100$ & $<0.100$ & $<0.100$ & $<0.100$ & $<0.100$ & $<0.100$ & $<0.100$ & $<0.100$ \\
\hline
\end{tabular}

1. Measured $\mathrm{pH}$ represents the reading taken during the test which was not adjusted for temperature.

2. Corrected $\mathrm{pH}$ is the measured $\mathrm{pH}$ corrected for the $85^{\circ} \mathrm{C}$ process temperature.

3. Samarium was not added to this sludge slurry. 
Table E5 - Supernate Results for pH 2 Test in SRAT Product Samples (mg/L)

\begin{tabular}{|c|c|c|c|c|c|c|}
\hline & \multicolumn{2}{|c|}{ SB3-8 (50\% Oxalate) } & \multicolumn{3}{c|}{ SB3-4 (No Oxalate) } \\
\hline $\mathbf{p H}$ & $\mathbf{2 . 1 3}$ & $\mathbf{2 . 0 8}$ & $\mathbf{1 . 9 9}$ & $\mathbf{2 . 1 7}$ & $\mathbf{2 . 1 4}$ & $\mathbf{2 . 1 8}$ \\
\hline $\mathbf{A l}$ & 5050 & 6140 & 7900 & 4060 & 4900 & 6840 \\
\hline $\mathbf{B a}$ & 24.0 & 27.5 & 32.2 & 90.9 & 82.4 & 100 \\
\hline $\mathbf{C a}$ & 3310 & 3710 & 4220 & 5120 & 5270 & 5940 \\
\hline $\mathbf{C r}$ & 1.70 & 1.88 & 2.24 & 0.932 & 0.952 & 1.26 \\
\hline $\mathbf{C u}$ & 56.8 & 63.1 & 74.9 & 236 & 247 & 280 \\
\hline $\mathbf{F e}$ & 1060 & 1120 & 1190 & 2950 & 3000 & 3450 \\
\hline $\mathbf{G d}$ & 17.7 & 20.5 & 25.1 & 31.4 & 34.4 & 47.6 \\
\hline $\mathbf{K}$ & 174 & 200 & 237 & 190 & 197 & 228 \\
\hline $\mathbf{M g}$ & 75.3 & 84.9 & 108 & 264 & 271 & 312 \\
\hline $\mathbf{M n}$ & 2650 & 3010 & 3560 & 6380 & 6440 & 7240 \\
\hline $\mathbf{N a}$ & 24300 & 27500 & 31900 & 13100 & 14900 & 14600 \\
\hline $\mathbf{N i}$ & 310 & 355 & 396 & 3530 & 3590 & 4270 \\
\hline $\mathbf{P b}$ & 16.7 & 21.0 & 27.0 & 32.1 & 33.9 & 44.3 \\
\hline $\mathbf{P d}$ & $<0.100$ & $<0.100$ & $<0.100$ & $<0.100$ & $<0.100$ & $<0.100$ \\
\hline $\mathbf{R h}$ & 17.4 & 19.4 & 23.6 & 9.24 & 8.28 & 10.2 \\
\hline $\mathbf{R u}$ & 22.4 & 24.5 & 28.9 & 23.9 & 22.4 & 25.8 \\
\hline $\mathbf{S i}$ & 26.7 & 27.8 & 32.2 & 35.9 & 29.1 & 32.9 \\
\hline $\mathbf{S m}$ & 7.45 & 8.98 & 11.4 & $<0.100$ & $<0.100$ & $<0.100$ \\
\hline $\mathbf{Z n}$ & 90.1 & 103 & 117 & 326 & 340 & 403 \\
\hline $\mathbf{Z r}$ & $<0.010$ & $<0.010$ & $<0.010$ & $<0.010$ & $<0.010$ & $<0.010$ \\
\hline
\end{tabular}

